Article

\title{
Experimental Study on Concrete under Combined FRP-Steel Confinement
}

\author{
Stefan Kaeseberg *(D), Dennis Messerer ${ }^{\mathbb{D}}$ and Klaus Holschemacher $\mathbb{D}$
}

Structural Concrete Institute (IfB), Leipzig University of Applied Sciences, Karl-Liebknecht-Str. 132, 04277 Leipzig, Germany; dennis.messerer@htwk-leipzig.de (D.M.); klaus.holschemacher@htwk-leipzig.de (K.H.)

* Correspondence: stefan.kaeseberg@htwk-leipzig.de

Received: 7 September 2020; Accepted: 3 October 2020; Published: 9 October 2020

\begin{abstract}
The confinement of reinforced concrete (RC) compression members by fiber-reinforced polymers (FRPs) is an effective measure for the strengthening and retrofitting of existing structures. Thus far, extensive research on the stress-strain behavior and ultimate limit state design of FRP-confined concrete has been conducted, leading to various design models. However, these models are significantly different when compared to one another. In particular, the use of certain empirical efficiency and reduction factors results in various predictions of load-bearing behavior. Furthermore, most experimental programs solely focus on plain concrete specimens or demonstrate insufficient variation in the material properties. Therefore, this paper presents a comprehensive experimental study on plain and reinforced FRP-confined concrete, limited to circular cross sections. The program included 63 carbon FRP (CFRP)-confined plain and 60 CFRP-confined RC specimens with a variation in the geometries and in the applied materials. The analysis showed a significant influence of the compressive strength of the confined concrete on the confinement efficiency in the design methodology, as well as the importance of the proper determination of individual reduction values for different FRP composites. Finally, applicable experimental test results from the literature were included, enabling the development of a modified stress-strain and ultimate condition design model.
\end{abstract}

Keywords: reinforced concrete; columns; confinement; CFRP; load-bearing capacity; strengthening

\section{Introduction}

The confinement of axially loaded concrete members is an effective measure for improving load-bearing capacity and ductility. Apart from conventional transverse tie reinforcing steel in combination with shotcrete, fiber-reinforced polymers (FRPs) are becoming increasingly considered for the strengthening and rehabilitation of reinforced concrete $(\mathrm{RC})$ structures. The composite material most commonly combines synthetic fibers (e.g., carbon fibers) and an epoxy-based resin matrix. In the application of confinement, the linear elastic FRP jacket resists the concrete's lateral expansion, leading to a steadily increasing transverse pressure, $\sigma_{\mathrm{r}}$. Regarding circular cross sections, the transverse pressure distributes evenly along the FRP jacket, as shown in Figure 1. The resulting confining pressure is carried by the mostly unidirectionally arranged FRP through tensile stresses $\sigma_{\mathrm{j}}$ in the hoop direction. Exceeding the initial compressive strength, an effective confinement leads to a multidimensional stress state of the concrete. Thereby, it is possible to increase its maximum bearing capacity and its ultimate strains without significantly affecting the dead loads.

The load-bearing behavior of short, plain concrete members confined with FRP composites has been extensively researched in the last two decades, leading to various experimental programs and design models, see, e.g., in [1-23]. To date, these models have already been included in national standards, codes, and guidelines by several countries and institutions, providing frameworks for the design of the FRP confinement of RC columns for strengthening purposes, see, e.g., in [24-30]. 


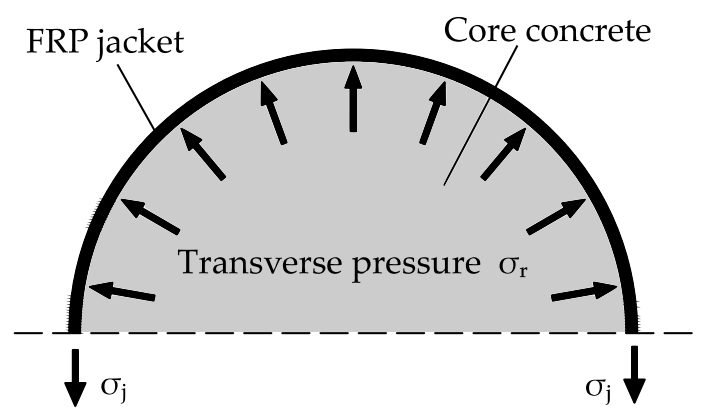

Figure 1. Confining action of a fiber-reinforced polymer (FRP) jacket.

In general, the ultimate confined concrete strength $f_{\mathrm{cc}}$ and the accompanying axial strain $\varepsilon_{\mathrm{ccu}}$ are derived by Equations (1) and (2):

$$
\begin{gathered}
f_{\mathrm{cc}}=f_{\mathrm{c} 0}+k_{1} \cdot f_{\mathrm{lj}}, \\
\varepsilon_{\mathrm{ccu}}=\varepsilon_{\mathrm{c} 0} \cdot k_{2}+\varepsilon_{\mathrm{c} 0} \cdot k_{3} \cdot \frac{f_{\mathrm{lj}}}{f_{\mathrm{c} 0}} \cdot\left(\frac{\varepsilon_{\mathrm{ju}}}{\varepsilon_{\mathrm{c} 0}}\right)^{k_{4}},
\end{gathered}
$$

where $f_{\mathrm{c} 0}$ is the mean value of the unconfined concrete strength, $\varepsilon_{\mathrm{c} 0}$ is the peak strain of the unconfined concrete, $f_{\mathrm{lj}}$ is the confinement pressure provided by the FRP jacket, $\varepsilon_{\mathrm{ju}}$ is the rupture strain of the FRP jacket in the application of confinement, and $k_{1}-k_{4}$ are factors affecting the impact of $f_{\mathrm{lj}}$ on $f_{\mathrm{cc}}$ and $\varepsilon_{\mathrm{ccu}}$.

The prediction of the ultimate condition of the confined concrete is directly dependent on the confining pressure $f_{\mathrm{lj}}$ provided by the FRP jacket. The commonly used form for the calculation of the confining pressure is given by Equation (3):

$$
f_{\mathrm{lj}}=\frac{1}{2} \cdot \rho_{\mathrm{j}} \cdot E_{\mathrm{j}} \cdot \varepsilon_{\mathrm{ju}}=E_{\mathrm{jl}} \cdot \varepsilon_{\mathrm{ju}}=\frac{2 \cdot t_{\mathrm{j}} \cdot E_{\mathrm{j}}}{D} \cdot \varepsilon_{\mathrm{ju}},
$$

where $\rho_{\mathrm{j}}$ is the confinement ratio, $E_{\mathrm{jl}}$ is the confinement modulus, $E_{\mathrm{j}}$ is the modulus of the composite material, $t_{j}$ is the FRP thickness, and $D$ is the diameter of the circular cross section.

The rupture strain of the carbon FRP (CFRP) jacket in the application of confinement, $\varepsilon_{\text {ju }}$, has a significant impact on the confinement pressure, $f_{\mathrm{lj}}$. According to the current state-of-the-art, $\varepsilon_{\mathrm{ju}}$ is defined as the actual hoop rupture strain measured in the FRP jacket, as, in most cases, it is considerably smaller than the ultimate tensile strain found from flat coupon tensile tests $\varepsilon_{\text {FRP }}$. Therefore, Lam and Teng [6] established an FRP efficiency factor $k_{\varepsilon}$, defined by

$$
\varepsilon_{\mathrm{ju}}=\varepsilon_{\mathrm{FRP}} \cdot k_{\varepsilon} .
$$

Although most approaches are derived by the same basic functions, the design models show significant differences. Table 1 provides an overview of the selected, renowned models for the design of confined concrete. 
Table 1. Different approaches to predict $f_{\mathrm{cc}}$ and $\varepsilon_{\mathrm{ccu}}$ of confined concrete columns.

\begin{tabular}{|c|c|c|}
\hline Authors & $\begin{array}{l}\text { Confined Concrete Compressive Strength } \\
\qquad f_{\mathrm{cc}}\end{array}$ & $\begin{array}{l}\text { Ultimate Axial Compressive Strain } \\
\qquad \varepsilon_{\mathrm{ccu}}\end{array}$ \\
\hline Richart et al. (1928) [31] & $\begin{array}{c}f_{\mathrm{cc}}=f_{\mathrm{c} 0}+k_{1} \cdot f_{\mathrm{lj}} \\
\quad k_{1}=4.1\end{array}$ & - \\
\hline Samaan et al. (1998) [32] & $\begin{array}{l}f_{\mathrm{cc}}=f_{\mathrm{c} 0}+k_{1} \cdot f_{\mathrm{lj}} \\
k_{1}=6.0 \cdot f_{\mathrm{lj}}^{-0.3}\end{array}$ & $\begin{array}{c}\varepsilon_{\mathrm{ccu}}=\frac{f_{\mathrm{cc}}+f_{0}}{E_{2}} \\
E_{2}=245.61 \cdot f_{\mathrm{c} 0}^{0.2}+1.3456 \cdot \frac{E_{\mathrm{j}}+t_{\mathrm{j}}}{D} \\
f_{0}=0.872 \cdot f_{\mathrm{c} 0}+0.371 \cdot f_{\mathrm{lj}}+6.258\end{array}$ \\
\hline Xiao and Wu (2003) [13] & $\begin{array}{c}f_{\mathrm{cc}}=\alpha \cdot f_{\mathrm{c} 0}+k_{1} \cdot f_{\mathrm{lj}} \\
k_{1}=4.1-0.45 \cdot\left(\frac{f_{\mathrm{c} 0}^{2}}{E_{\mathrm{jl}}}\right)^{1.4} \text { with } \alpha \approx 1.1\end{array}$ & $\varepsilon_{\mathrm{ccu}}=\frac{\varepsilon_{\mathrm{ju}}}{v_{2}}=\frac{\varepsilon_{\mathrm{ju}}}{10 \cdot\left(f_{\mathrm{c} 0} / E_{\mathrm{j}}\right)^{0.9}}$ \\
\hline Lam and Teng (2003) [6] & $\begin{array}{c}f_{\mathrm{cc}}=f_{\mathrm{c} 0}+k_{1} \cdot f_{\mathrm{lj}} \\
k_{1}=3.3\end{array}$ & $\varepsilon_{\mathrm{ccu}}=\varepsilon_{\mathrm{c} 0} \cdot 1.75+\varepsilon_{\mathrm{c} 0} \cdot 12 \cdot \frac{f_{\mathrm{lj}}}{f_{\mathrm{c} 0}} \cdot\left(\frac{\varepsilon_{\mathrm{ju}}}{\varepsilon_{\mathrm{c} 0}}\right)^{0.45}$ \\
\hline Teng et al. (2009) [11] & $\left\{\begin{array}{cl}f_{\mathrm{cc}}= & \\
f_{\mathrm{c} 0}+f_{\mathrm{c} 0} \cdot 3.5 \cdot\left(\rho_{\mathrm{k}}-0.01\right) \cdot \rho_{\varepsilon} & \text { if } \rho_{\mathrm{k}} \geq 0.01 \\
f_{\mathrm{c} 0} & \text { if } \rho_{\mathrm{k}}<0.01 \\
\rho_{\mathrm{k}}=\frac{2 \cdot E_{\mathrm{j}} \cdot t_{\mathrm{j}}}{\left(f_{\mathrm{c} 0} / \varepsilon_{\mathrm{c} 0}\right) \cdot D} \text { and } \rho_{\varepsilon}=\frac{\varepsilon_{\mathrm{ju}}}{\varepsilon_{\mathrm{c} 0}}\end{array}\right.$ & $\varepsilon_{\mathrm{ccu}}=\varepsilon_{\mathrm{c} 0} \cdot 1.75+\varepsilon_{\mathrm{c} 0} \cdot 6.5 \cdot \rho_{\mathrm{k}}^{0.8} \cdot \rho_{\varepsilon}^{1.45}$ \\
\hline Niedermeier (2009) [33] & $\begin{array}{c}f_{\mathrm{cc}}=f_{\mathrm{c} 0}+k_{1} \cdot f_{\mathrm{lj}} \\
k_{1}=3.66\end{array}$ & $\varepsilon_{\mathrm{ccu}}=\varepsilon_{\mathrm{c} 0} \cdot 1.75+\varepsilon_{\mathrm{c} 0} \cdot 19 \cdot \frac{f_{\mathrm{lij}}}{f_{\mathrm{c} 0}}$ \\
\hline
\end{tabular}

Most design models are used to determine the ultimate stress and strain conditions of a column under concentric compression or with comparatively small eccentricities. However, proper confinement can also provide significant strength enhancement for members subjected to combined compression and flexure. For the design of eccentrically loaded, FRP-confined columns, proper material models are essential. In general, these models use stress $\left(\sigma_{\mathrm{c}}\right)$-strain $\left(\varepsilon_{\mathrm{c}}\right)$ curves with a parabolic first portion and a straight line second portion (second modulus). An example is given by the stress-strain model of Lam and Teng [6]:

$$
\sigma_{\mathrm{c}}=\left\{\begin{array}{cl}
E_{\mathrm{c}} \cdot \varepsilon_{\mathrm{c} 0}-\frac{\left(E_{\mathrm{c}}-E_{2}\right)^{2}}{4 \cdot f_{\mathrm{c} 0}} \cdot \varepsilon_{\mathrm{c} 0}{ }^{2} & \text { if } 0 \leq \varepsilon_{\mathrm{c} 0} \leq \varepsilon_{\mathrm{t}} \\
f_{\mathrm{c} 0}+E_{2} \cdot \varepsilon_{\mathrm{c} 0} & \text { if } \varepsilon_{\mathrm{t}} \leq \varepsilon_{\mathrm{c} 0} \leq \varepsilon_{\mathrm{ccu}}
\end{array},\right.
$$

where $E_{2}$ is the second modulus, $E_{\mathrm{c}}$ is the modulus of elasticity, and $\varepsilon_{\mathrm{t}}$ is the strain value at the transition between the parabolic curve and the straight-line second portion. A graphical representation of Lam and Teng's stress-strain model is given in Figure 2.

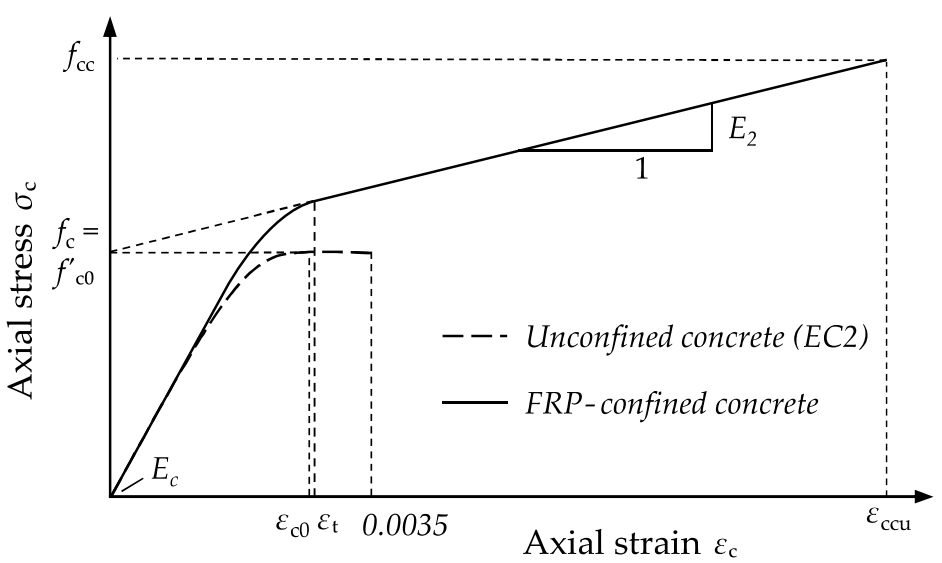

Figure 2. Stress-strain model for FRP-confined concrete according to Lam and Teng [6].

The empirical approaches for the development of design-oriented models (Table 1) mostly follow the concept of Richart et al. [31], introducing empirical confinement effectiveness coefficients $k_{1}$ (ultimate stress) and $k_{2}-k_{4}$ (ultimate strain). In the majority of cases, $k_{1}$ and $k_{2}-k_{4}$ are defined as 
constant values or are solely dependent on the maximum confining pressure $f_{\mathrm{lj}}$. These concepts lead to considerable discrepancies regarding the prediction of confined columns with different initial concrete strengths, $f_{\mathrm{c} 0}$. Figure 3 shows a graphical comparison of stress-strain curves, predicted by the models listed in Table 1, for two specimens-one with a normal (30 MPa) and one with a high (60 MPa) unconfined concrete strength. Particularly for a high initial concrete strength, remarkable differences between the calculated stress-strain curves and the ultimate condition values of $f_{\mathrm{cc}}$ and $\varepsilon_{\mathrm{ccu}}$ can be seen. The discrepancies between the predicted results tend to increase significantly alongside the unconfined concrete strength.

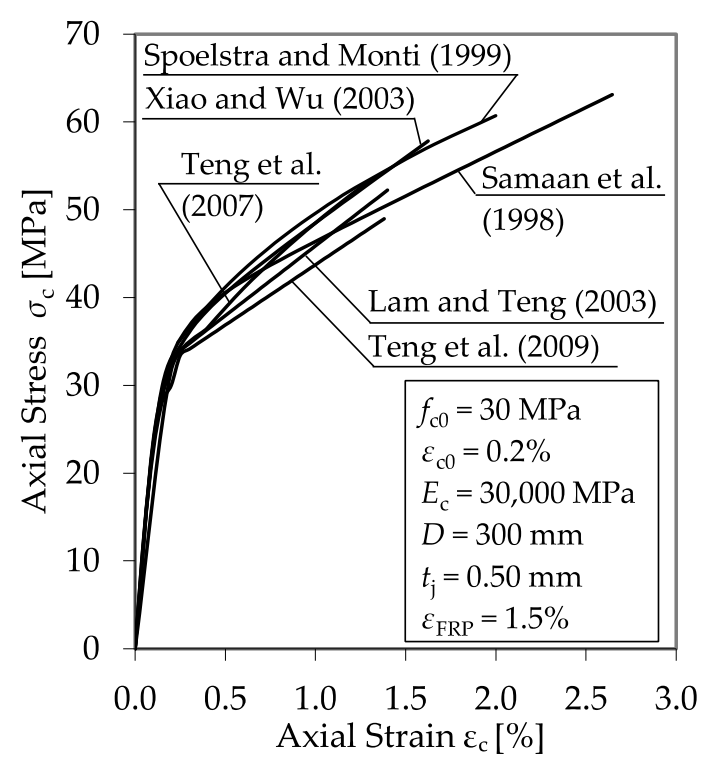

(a)

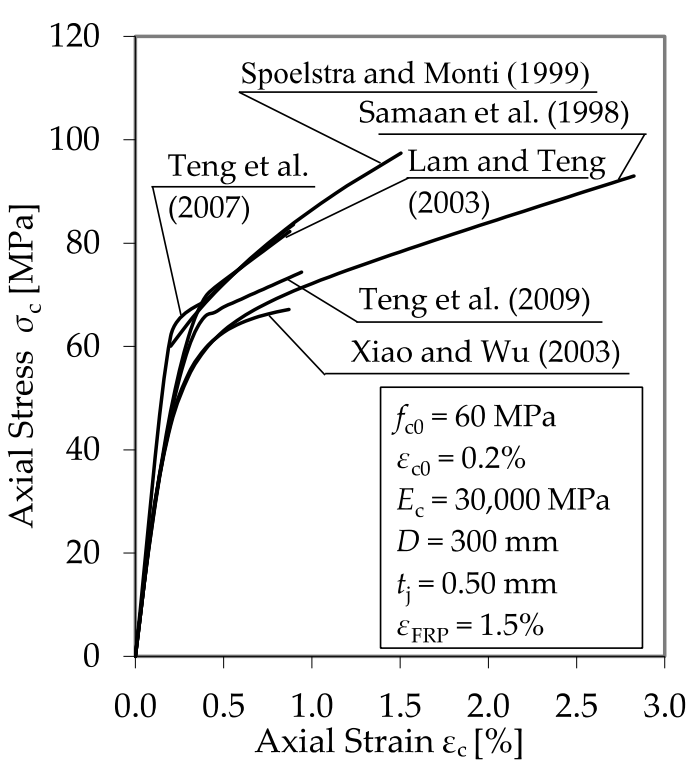

(b)

Figure 3. Theoretical material behavior of carbon FRP (CFRP)-confined normal strength (a) and high strength $(\mathbf{b})$ concrete columns according to different models and proposals collected from the literature $[6,11,13,19,32,34]$.

The relatively good correlations of the exemplary calculations with $f_{\mathrm{c} 0}=30 \mathrm{MPa}$ may be due to the fact that most empirical design models use experimental investigations on normal-strength concrete for the derivation of the confinement effectiveness, $k_{1}$ and $k_{2}-k_{4}$ (Figure 4 ).

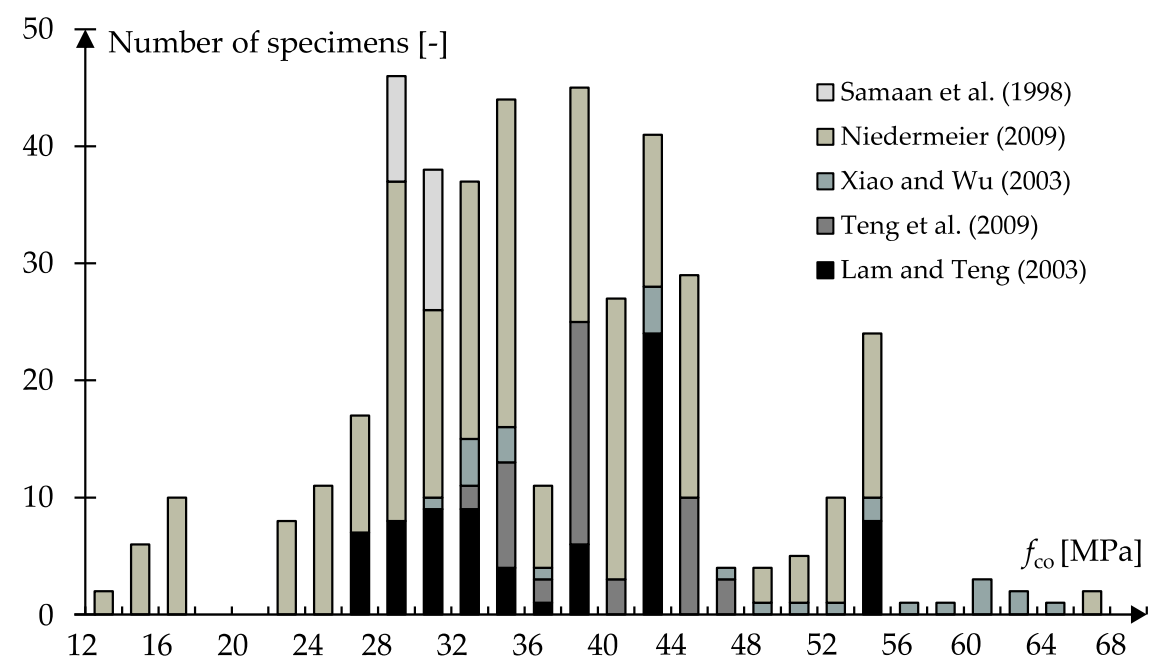

Figure 4. Number of specimens as a function of the initial concrete strength, $f_{\mathrm{c} 0}$, used for the derivation of empirical design models for FRP-confined concrete by the authors of $[6,11,13,32,33]$. 
Furthermore, the presented models and equations only concern the confinement effect of the CFRP jacket. The contribution of the internal transverse steel reinforcement and other effects, such as the buckling of the longitudinal steel reinforcement, are not taken into account. Only a few confinement models, e.g., Hu et al. [5], Eid and Paultre [3], Rousakis and Karabinis [35], Pellegrino and Modena [8], Teng et al. [12], or Niedermeier [33], consider the interaction between the internal lateral steel reinforcement and the external FRP jacket. The most common proposals are shown in Table 2. These models are mostly based on the basic function of Richart et al. [31] where the increase in strength and strain is not dependent on the unconfined concrete strength, $f_{\mathrm{c} 0}$.

Table 2. Different approaches to predict $f_{\mathrm{cc}}$ and $\varepsilon_{\mathrm{ccu}}$ of CFRP-confined reinforced concrete (RC) columns.

\begin{tabular}{|c|c|c|}
\hline Authors & $\begin{array}{l}\text { Confined Concrete Compressive Strength } \\
\qquad f_{\mathrm{cc}}\end{array}$ & $\begin{array}{l}\text { Ultimate Axial Compressive Strain } \\
\qquad \varepsilon_{\text {ccu }}\end{array}$ \\
\hline Eid and Paultre (2008) [3] & $\begin{array}{c}f_{\mathrm{cc}}=f_{\mathrm{c} 0}+k_{1} \cdot\left(f_{\mathrm{lj}}+f_{1, \mathrm{wy}}\right) \\
k_{1}=3.3\end{array}$ & $\varepsilon_{\mathrm{ccu}}=\varepsilon_{\mathrm{c} 0} \cdot 1.56+\varepsilon_{\mathrm{c} 0} \cdot 12 \cdot\left(\frac{f_{\mathrm{ji}}}{f_{\mathrm{c} 0}}+\frac{f_{\mathrm{i}, \mathrm{wy}}}{f_{\mathrm{co} 0}}\right) \cdot\left(\frac{\varepsilon_{\mathrm{ju}}}{\varepsilon_{\mathrm{c} 0}}\right)^{0.45}$ \\
\hline Pellegrino and Modena (2010) [8] & $\begin{array}{r}f_{\mathrm{cc}}=f_{\mathrm{c} 0}+k_{1} \cdot\left(f_{\mathrm{lj}}+f_{1, \mathrm{wy}} \cdot \frac{A_{\mathrm{cc}}}{A_{\mathrm{c}}}\right) \\
k_{1}=A \cdot\left[\frac{\left(\frac{\left(f_{\mathrm{j}}+f_{\mathrm{l}, \mathrm{wy}} \cdot \frac{A_{\mathrm{cc}}}{A_{\mathrm{c}}}\right)}{f_{\mathrm{c} 0}}\right]^{-\alpha}}{}\right.\end{array}$ & $\varepsilon_{\mathrm{ccu}}=\varepsilon_{\mathrm{c} 0} \cdot 2+\varepsilon_{\mathrm{c} 0} \cdot B \cdot \frac{\left(f_{\mathrm{j} j}+f_{\mathrm{l}, \mathrm{wy}} \cdot \frac{A_{\mathrm{cc}}}{A_{\mathrm{c}}}\right)}{f_{\mathrm{c} 0}}$ \\
\hline Niedermeier (2009) [33] & 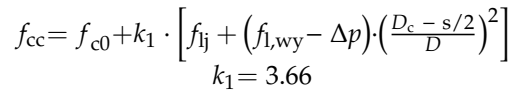 & $\varepsilon_{\mathrm{ccu}}=\varepsilon_{\mathrm{c} 0} \cdot 1.75+\varepsilon_{\mathrm{c} 0} \cdot 19 \cdot\left(\frac{f_{\mathrm{li}}}{f_{\mathrm{c} 0}}+\frac{f_{\mathrm{i}, \mathrm{wy}}}{f_{\mathrm{c} 0}}-\frac{\Delta p}{f_{\mathrm{c} 0}}\right)$ \\
\hline
\end{tabular}

Abbreviations: $f_{1, \mathrm{wy}}=$ confining pressure provided by transverse reinforcement; $A_{\mathrm{cc}}=$ area of core of section enclosed by the center lines of the perimeter spiral or tie; $A_{\mathrm{c}}=$ column cross section; $A, B$, and $\alpha=$ empirical parameters; $D_{\mathrm{c}}=$ horizontal center distance of the spiral or tie reinforcement; $\Delta p=$ reduction of confinement pressure between the core section and the concrete cover; $s=$ vertical spacing between spiral or tie bars.

Despite the extensive research efforts carried out in the field of FRP confinement of RC columns, there is still a substantial need for research. Particularly research regarding the determination of the confinement effectiveness coefficients as well as the interaction between the FRP-confining jacket and the internal steel reinforcement, which has thus far been considered contradictory by different design models. Furthermore, the literature lacks experimental investigations of FRP-confined RC specimens with adequate variation in different material parameters and sufficient documentation.

\section{Experimental Investigations}

\subsection{Experimental Program}

The main objective of this research program was to resolve the pending issues and knowledge gaps regarding the modeling of FRP-confined concrete revealed during the literature review. Primarily, the interaction between the FRP jacket and the transverse steel reinforcement formed part of the investigations. As described in Section 1, the existing design-oriented approaches for dual FRP-steel confinement (see, e.g., in $[3,7,8,36]$ ) show significant discrepancies. Furthermore, most experimental programs lack adequate variation in the material properties used.

Therefore, a test program of CFRP-confined plain and RC cylinders, including the following variation parameters, was conceived:

- Diameter of the concrete cylinders

- Concrete mixture/mechanical properties of the core concrete

- Shape of the transverse steel reinforcement (i.e., tie/spiral)

- Diameter and volumetric ratio of the transverse steel reinforcement

- Mechanical properties of the transverse steel reinforcement

- Surface texture of the transverse steel reinforcement

- Volumetric ratio of the longitudinal steel reinforcement

- CFRP material

- Volumetric ratio of the CFRP jacket 
In total, the program included 63 CFRP-confined plain concrete specimens and 60 CFRP-confined RC specimens with circular cross sections.

\subsection{Materials}

The following materials were used for the production of the test specimens.

\subsubsection{Concrete}

The concrete specimens were produced using different concrete mixtures. Each series was made of concrete from the same batch. All series used CEM II 32.5 cement according to EN 197-1:2011 [37], natural aggregates with a maximum grain size of $16 \mathrm{~mm}$ and fly ash. The concrete mixtures were mainly designed to meet the requirements of a standard concrete with a compressive strength $f_{\mathrm{c} 0}$ between 25 and $40 \mathrm{MPa}$. The properties of the hardened concrete were determined on cylinders with a diameter of $150 \mathrm{~mm}$ according to EN 12390-3:2009 [38].

\subsubsection{Steel Reinforcement}

Table 3 shows the experimentally determined properties of the applied internal steel reinforcement. In most cases, steel reinforcement B500 in accordance with the German standard DIN 488-1:2009-08 [39] was used (i.e., $\mathrm{T} 4, \mathrm{~T} 6, \mathrm{~T} 8, \mathrm{~T} 10$, and $\mathrm{T} 12$ ).

Table 3. Properties of the used steel reinforcement (mean values).

\begin{tabular}{ccccccc}
\hline Type & $\begin{array}{c}\text { Nominal } \\
\text { Diameter } \\
{[\mathbf{m m}]}\end{array}$ & $\begin{array}{c}\text { Ribbing } \\
{[-]}\end{array}$ & $\begin{array}{c}\text { Yield Strength } \\
f_{\mathbf{y m}} \\
{[\mathbf{M P a}]}\end{array}$ & $\begin{array}{c}\text { Tensile } \\
\text { Strength } f_{\text {tm }} \\
{[\mathbf{M P a}]}\end{array}$ & $\begin{array}{c}\text { Modulus of } \\
\text { Elasticity } \\
{[\mathrm{GPa}]}\end{array}$ & $\begin{array}{c}\text { Rupture } \\
\text { Strain } \\
{[\%]}\end{array}$ \\
\hline T4 & 4 & & & & & \\
T6 & 6 & & 550 & 610 & 196 & 8 \\
T8 & 8 & yes & & & & \\
T10 & 10 & & 500 & 608 & 194 & 14 \\
T12 & 12 & & 670 & 725 & 205 & - \\
T5 & 5 & & 730 & 760 & - & 12 \\
T6NR & 6 & no & & & & \\
\hline
\end{tabular}

The variation in the mechanical properties of the transverse steel reinforcement was realized using bars with differing yield strengths (i.e., T5 and T6NR) and without ribbing (i.e., T6NR).

\subsubsection{Carbon Fiber-Reinforced Polymer}

The confining jackets consisted of unidirectional carbon fiber (CF) sheets and a two-component, thixotropic impregnating epoxy adhesive. To ensure the variation of the material properties, three different sheets from two different manufacturers were used.

CF sheets M1 and M2 showed approximately the same material characteristics, as they originated from one manufacturer, but had a different arrangement of the carbon fibers. CF sheet M3 had a considerably higher tensile strength and rupture strain. The exact material properties, as provided by the manufacturer, are shown in Table 4, while the arrangement of the fibers of the different sheets can be seen in Figure 5. A two-component, high-strength (33.8 MPa), high-modulus (3.5 GPa) impregnating epoxy resin was used as adhesive and primer. 


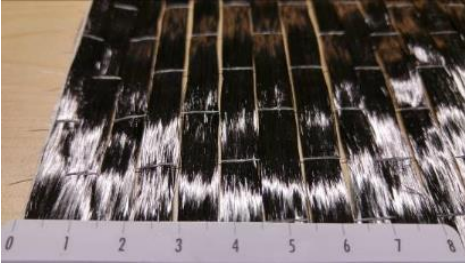

(M1)

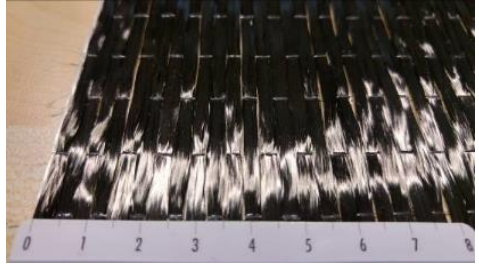

(M2)

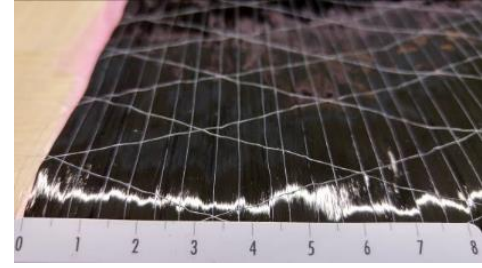

(M3)

Figure 5. Arrangement of the fibers of the used carbon fiber (CF) sheets.

Table 4. Properties of used CFRP materials.

\begin{tabular}{cccccc}
\hline $\begin{array}{c}\text { CFRP Type } \\
{[-]}\end{array}$ & $\begin{array}{c}\text { Density } \\
{\left[\mathbf{g} / \mathbf{m}^{\mathbf{3}}\right]}\end{array}$ & $\begin{array}{c}\text { Axial Tensile } \\
\text { Strength } \\
{[\mathbf{M P a}]}\end{array}$ & $\begin{array}{c}\text { Axial Modulus } \\
\text { of Elasticity } \\
{[\mathrm{GPa}]}\end{array}$ & $\begin{array}{c}\text { Rupture Strain } \\
\text { (axial) } \\
{[\%]}\end{array}$ & $\begin{array}{c}\text { Weight Per } \\
\text { Square Meter } \\
{\left[\mathrm{g} / \mathbf{m}^{2}\right]}\end{array}$ \\
\hline M1 & 1.80 & 3900 & 230 & 1.70 & 200 \\
M2 & 1.80 & 4100 & 230 & 1.78 & 220 \\
M3 & 1.79 & 4800 & 240 & 2.00 & 200 \\
\hline
\end{tabular}

\subsection{Preparation of the Test Specimens}

Prior to the strengthening process, the concrete surface was ground until aggregates $>4 \mathrm{~mm}$ could be seen. Additionally, the top and bottom of the cylinders were ground plane and parallel to ensure uniform load distribution. Seven days prior to the compression tests, the CFRP jacket was applied in a dry lay-up process; after the application of a primer coat to the surface of the concrete, the CF sheets were laminated continuously around the cylinders. The overlap length of the CFRPs was $100 \mathrm{~mm}$, as specified by the manufacturers. The application process is shown in Figure 6.
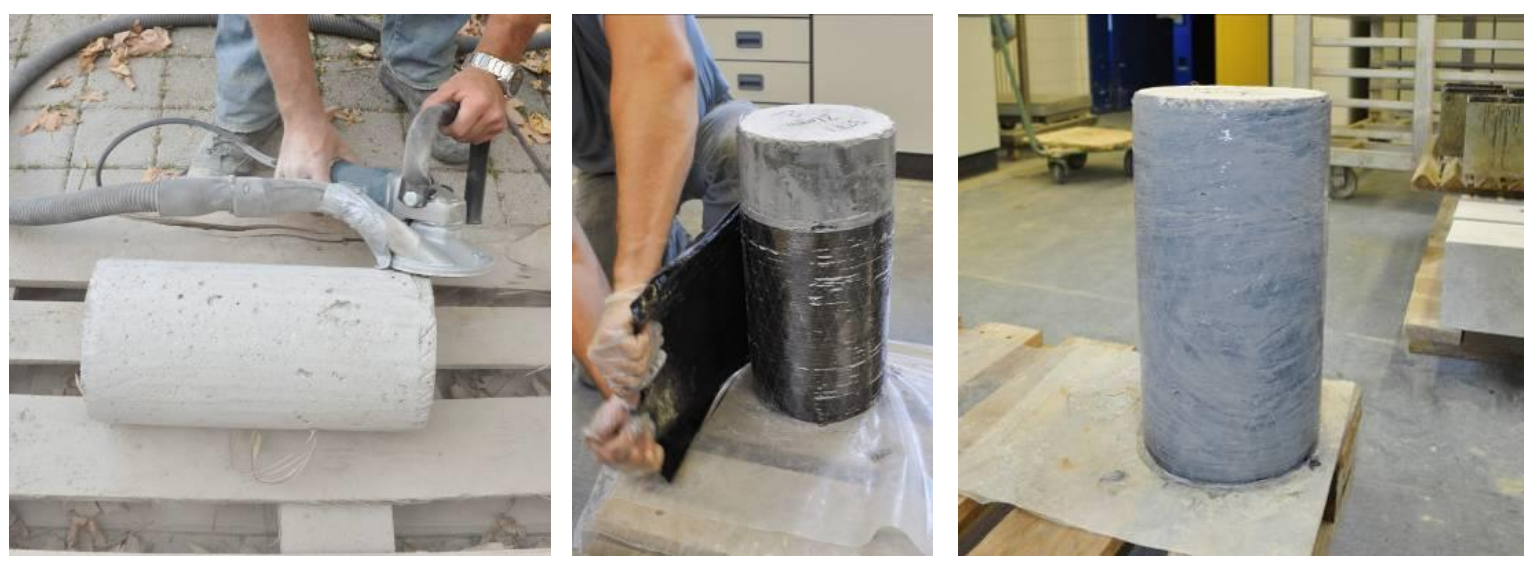

Figure 6. Preparation of the test specimens and application of the CFRP jacket.

\subsection{Test Setup and Instrumentation}

The specimens were tested under uni-axial compression through monotonically applied loading using a hydraulic press with a $5000 \mathrm{MPa}$ load-carrying capacity. The testing machine was set to a displacement-controlled mode with a constant rate of $0.01 \mathrm{~mm} / \mathrm{s}$. The axial displacements were measured using linear variable differential transformers (LVDTs). Lateral strains of the CFRP jacket were measured using strain gauges bonded to the specimens at mid-height. In cases where the specimens have internal reinforcement, steel strain gauges were applied on the rebar surface of the transverse reinforcement test specimen at mid-height (Figure 7). 

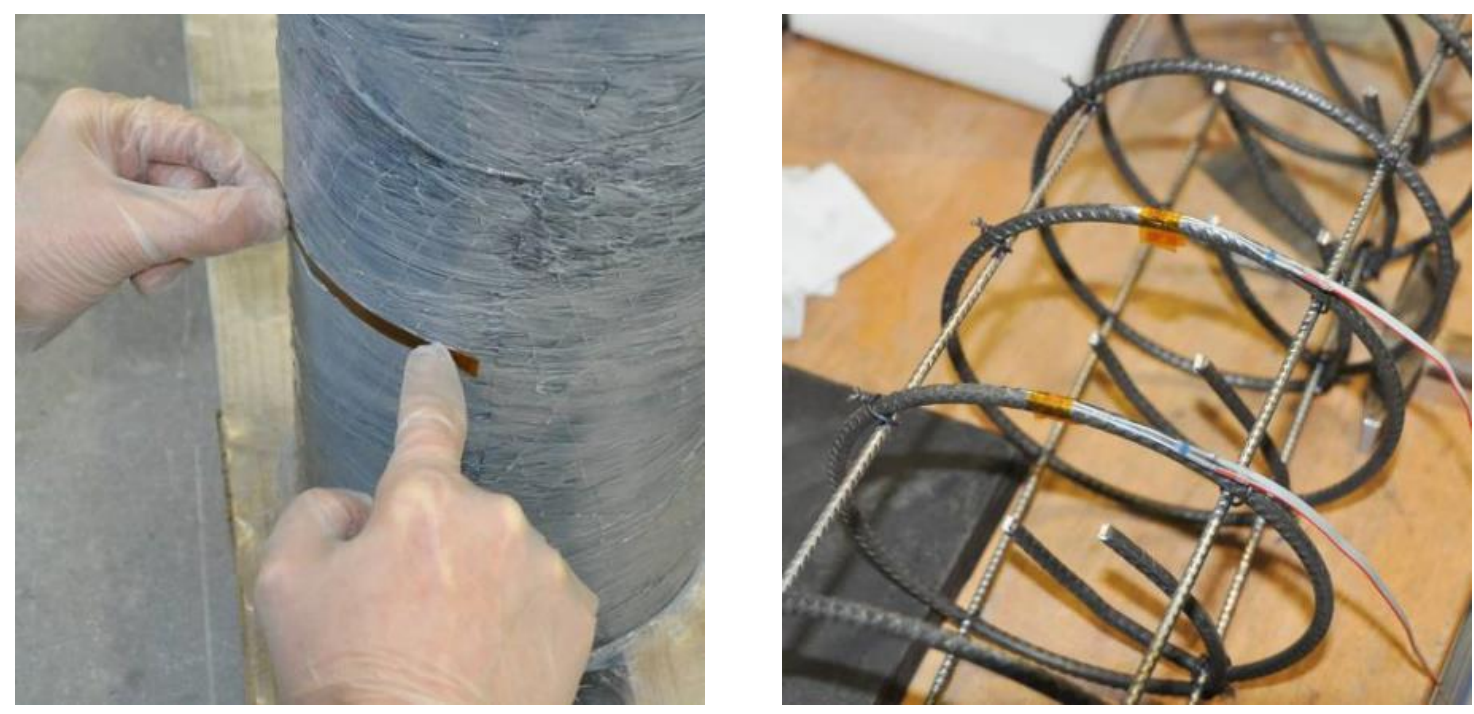

Figure 7. Preparation of the test specimens and application of the CFRP jacket.

Figure 8 provides a schematic description and a picture of the setup during testing.
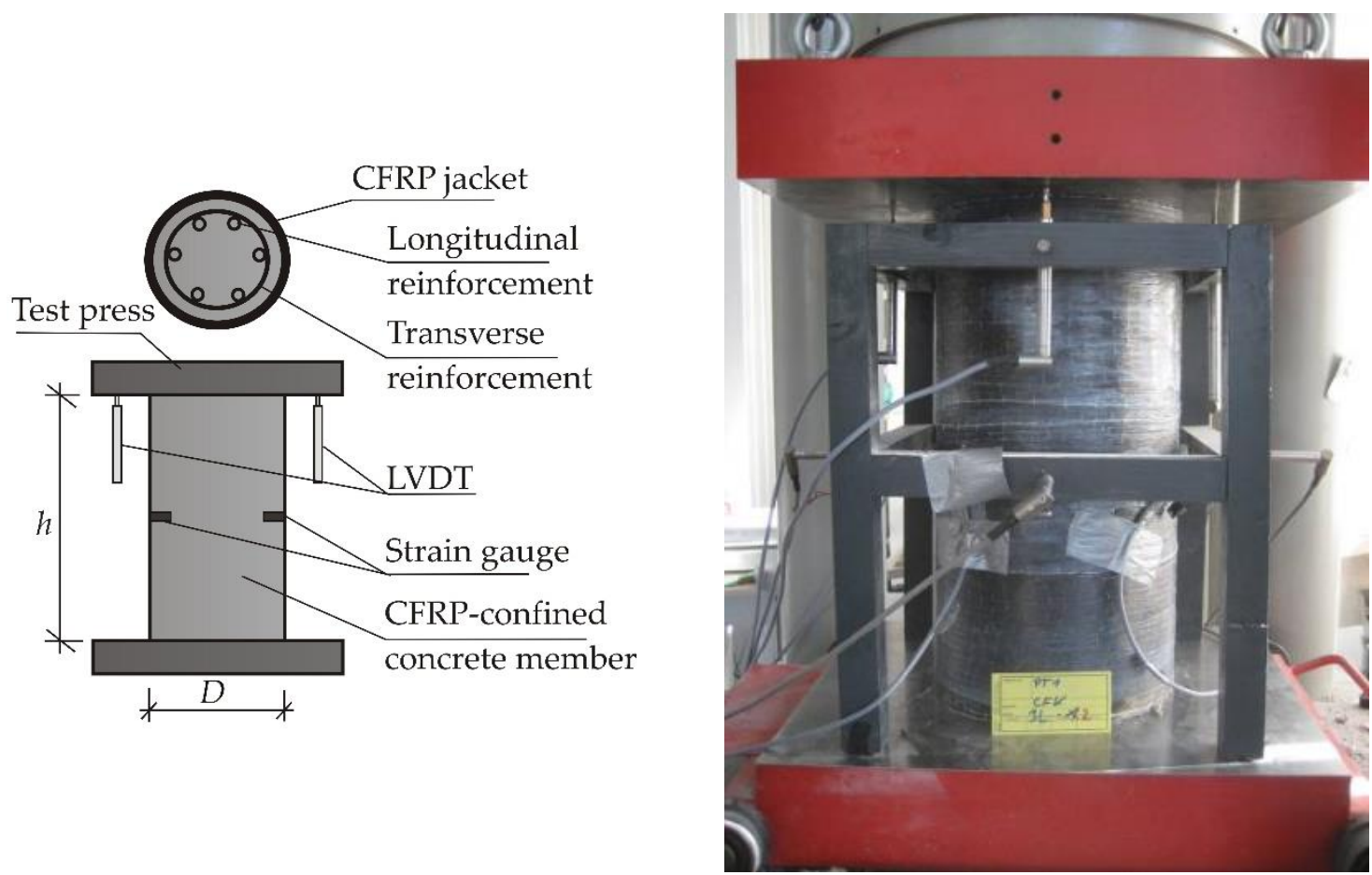

Figure 8. Test set-up.

\subsection{Test Matrix}

Table 5 shows an overview of the experimental program. The reinforced series with a diameter of $150 \mathrm{~mm}$ (i.e., D15-TR) were equipped with six longitudinal reinforcing bars of Type T8 according to Table 3. Series D20-TR-M2-2L-3 was split into three subseries including four (a), six (b), and eight (c) longitudinal reinforcing bars of type T12. Any further reinforced series (D20-TR, D25-SR, D25-TR, and D30-SR) were equipped with 6 longitudinal reinforcing bars of the type T12. In all reinforced series, the concrete cover was $15 \mathrm{~mm}$. In series D15-P-M2-2L-2 to D-15-P-M2-2L-5, the targeted compressive strength was altered deliberately through different concrete mixtures to assess the impact of $f_{\mathrm{c} 0}$ on 
the material behavior of the confined specimens. Furthermore, series D15-P-M2-2L-6 additionally contained a grit aggregate to examine the impact of the aggregate form and type.

Table 5. Experimental program.

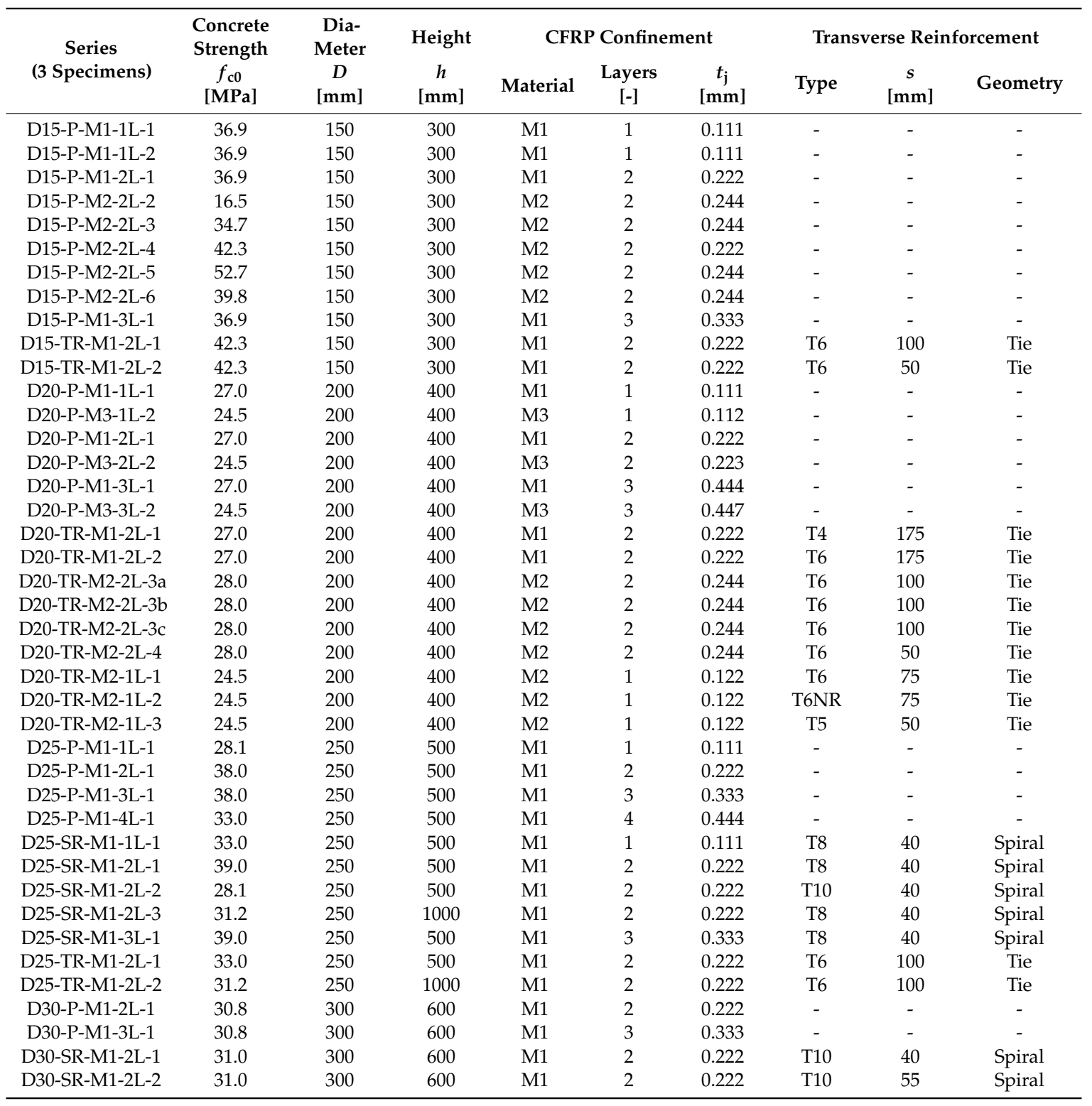

\section{Experimental Findings}

\subsection{Evaluation Methods}

The evaluation focused on the stress-strain behavior of the confined plain and RC specimens. Therefore, the axial stress was determined by the ratio of the applied load to the cross-sectional area of the concrete, disregarding the thickness of the CFPR and its possible axial resistance. Axial and lateral strains were obtained from the applied LVTDs and strain gauges. The stress-strain behavior (longitudinal and transverse) of the CFRP-confined specimens was bilinear in general, and consisted of a three-phase behavior like that predicted by the material model illustrated in Figure 2. The second modulus could be observed in the longitudinal $\left(E_{2}\right)$ as well as in the transverse $\left(E_{2, t}\right)$ direction. As an example, Figure 9 shows the stress-strain curves of single specimens of series D15-P-M1-1L-1, D15-P-M1-2L-1, and D15-P-M1-3L-1, illustrating the interrelation between $E_{2}$ and the volumetric ratio 
of the CFRP jacket. An increase in the applied CFRP layers led to higher second moduli and higher ultimate states of strength $\left(f_{\mathrm{cc}}\right)$ and strain $\left(\varepsilon_{\mathrm{ccu}}\right)$.

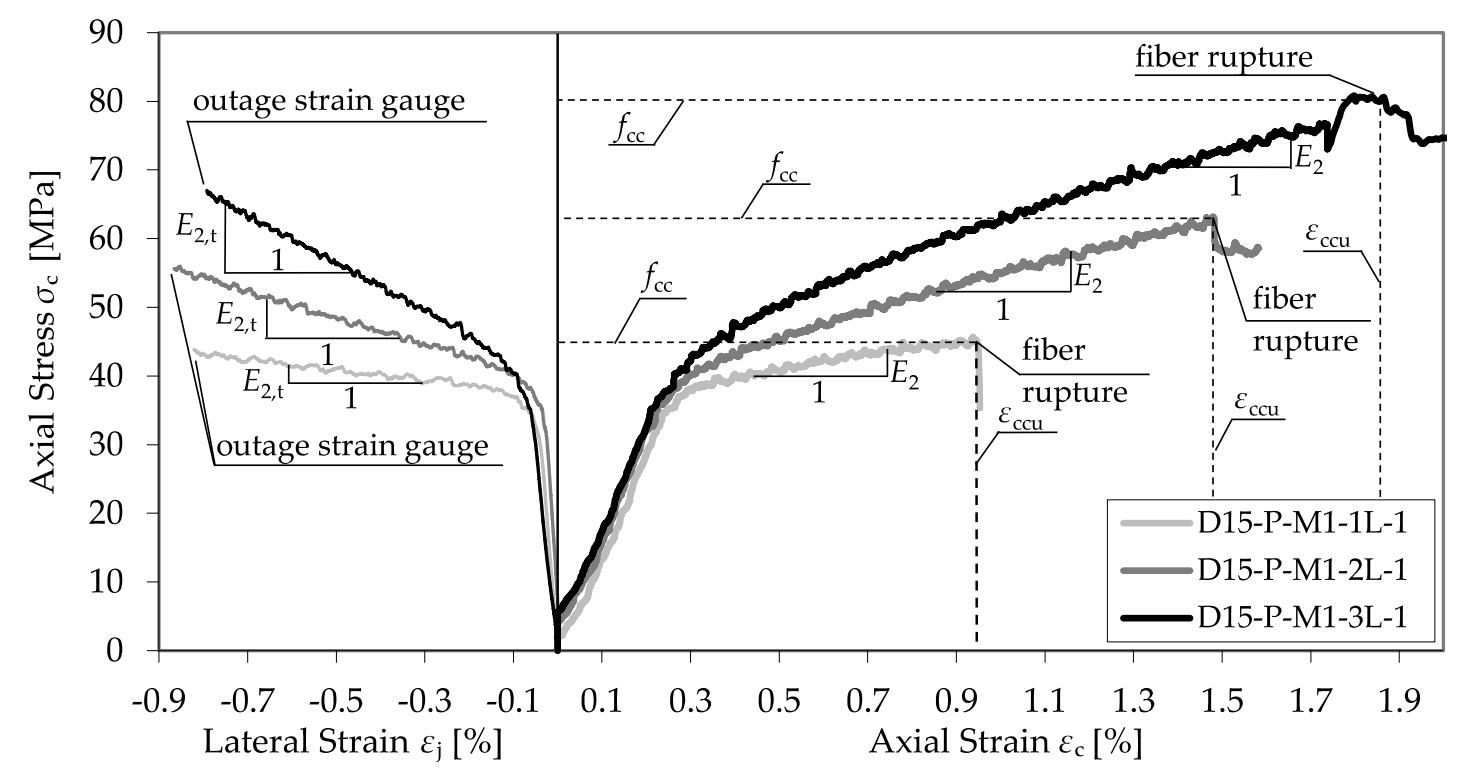

Figure 9. Stress-strain curves of series D15-P-M1-1L-1, D15-P-M1-2L-1, and D15-P-M1-3L-1.

The failure of the CFRP-confined plain or steel reinforced specimens was caused by a sudden and noisy fracture of the CFRP sheets at ultimate strength, $f_{\mathrm{cc}}$, and strain, $\varepsilon_{\mathrm{ccu}}$. Typical examples of failed confined plain and RC specimens can be seen in Figures 10 and 11.
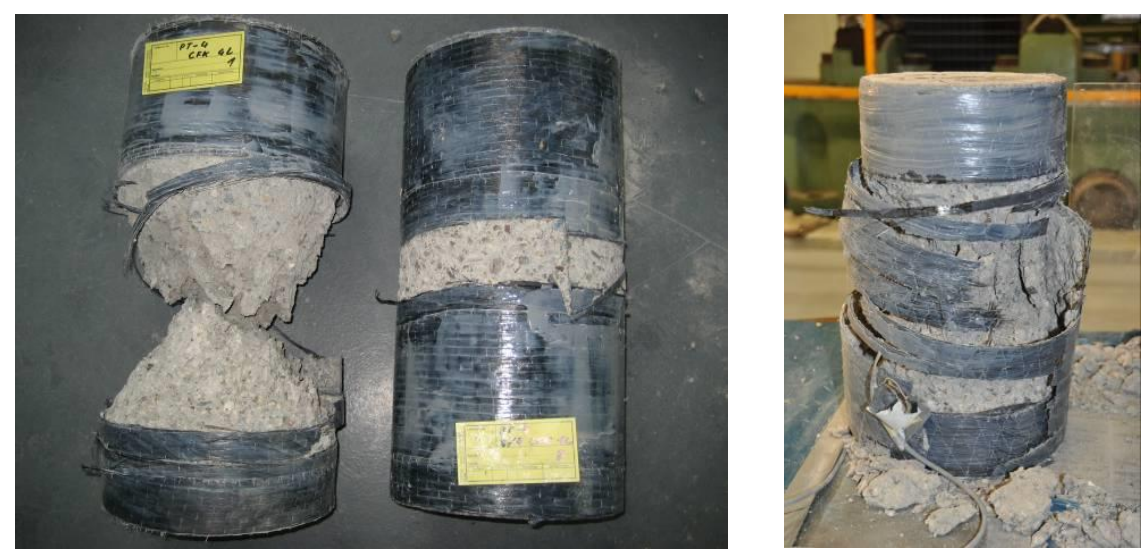

Figure 10. Typical failure of CFRP-confined plain concrete cylinders. 

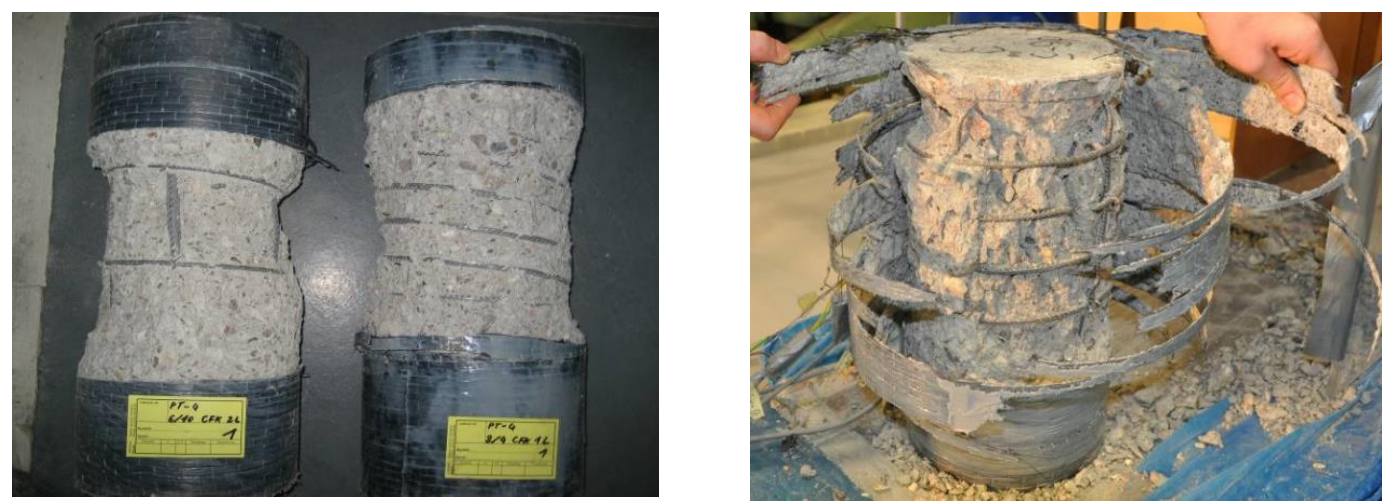

Figure 11. Typical failure of CFRP-confined RC cylinders.

In addition to the stress-strain relationships, the development in the comparative diagrams showing the axial-transverse strain responses and the axial-confinement stress responses of the CFRP-confined concrete specimens was an important aspect of the evaluation process. These diagrams enable the analysis of the factor $k_{1}$ (cf. Equation (1)) and the second Poisson's ratio of the confined member $v_{2}$. Typical examples are shown in Figure 12.

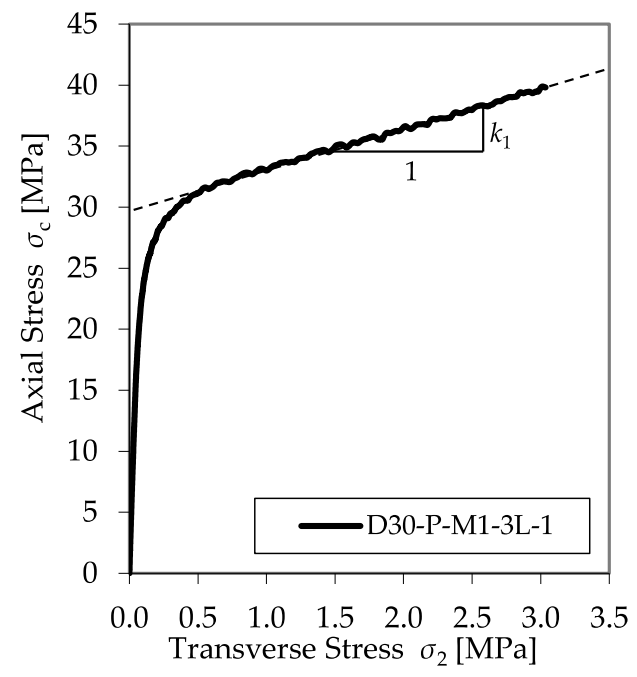

(a)

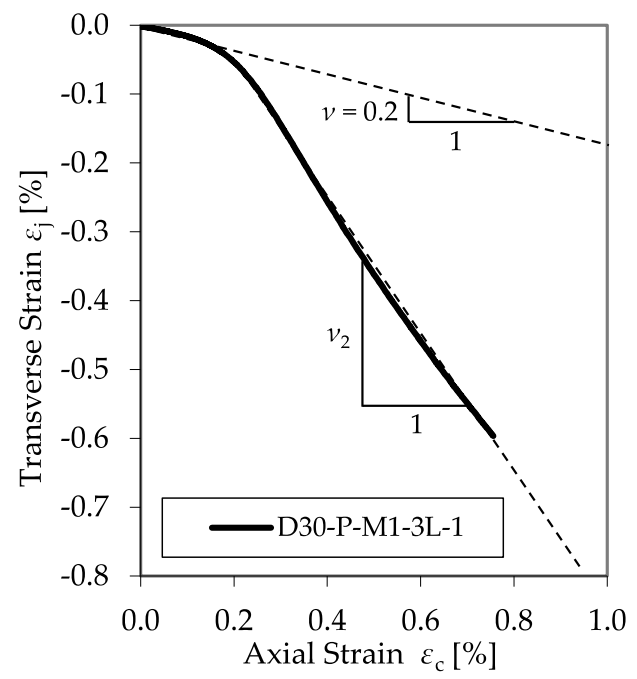

(b)

Figure 12. Typical axial-transverse stress (a) and axial-transverse strain responses (b).

In most cases, the initial slopes of the axial strain and transverse strain relationships matched well the typical initial Poisson's ratio for concrete of 0.2 . As the axial strain increased, the ratio between the transverse and axial strain also increased, indicating the acceleration of the expansion of the concrete. This second linear slope describes the second Poisson's ratio $v_{2}$. Furthermore, the axial-confinement stress response explains the design factor, $k_{1}$. Once the axial stress exceeds the unconfined concrete strength, the curves converge to flatter linear relationships compared to that of the initial behavior, expressing the empirical confinement effectiveness coefficient $k_{1}$.

\subsection{CFRP-Confined Concrete Specimens}

Table 6 shows the results obtained from the CFRP-confined plain concrete specimens without internal reinforcement.

For the following analysis, the specific values $\rho_{\mathrm{j}}, E_{\mathrm{j} 1}$, and $f_{\mathrm{lj}}$ had to be determined for each series. Set in relation to the unconfined concrete strength, the ratios $E_{\mathrm{j} 1} / f_{\mathrm{c} 0}, E_{\mathrm{j} 1} / f_{\mathrm{c} 0}{ }^{2}$, and $f_{\mathrm{lj}} / f_{\mathrm{c} 0}$ can be defined (Table 7). 
Table 6. Test results of CFRP-confined plain concrete specimens.

\begin{tabular}{|c|c|c|c|c|c|c|c|c|c|}
\hline Series & Specimens & $\begin{array}{c}f_{\mathrm{c} 0} \\
{[\mathrm{MPa}]}\end{array}$ & $\begin{array}{c}f_{\mathrm{cc}} \\
{[\mathrm{MPa}]}\end{array}$ & $\begin{array}{l}\varepsilon_{\mathrm{ccu}} \\
{[\%]}\end{array}$ & $\begin{array}{c}E_{2, \mathrm{t}} \\
{[\mathrm{MPa}]}\end{array}$ & $\begin{array}{c}E_{2} \\
{[\mathrm{MPa}]}\end{array}$ & $\begin{array}{l}v_{2} \\
{[-]}\end{array}$ & $\begin{array}{l}k_{1} \\
{[-]}\end{array}$ & $\begin{array}{l}k_{\varepsilon} \\
{[-]}\end{array}$ \\
\hline \multirow{4}{*}{ D15-P-M1-1L-1 } & 1 & \multirow{4}{*}{36.9} & 42.23 & 0.761 & 497 & 960 & 1.857 & 1.581 & 0.546 \\
\hline & 2 & & 45.34 & 0.939 & 750 & 1112 & 1.747 & 2.196 & 0.649 \\
\hline & 3 & & 47.39 & 1.017 & 647 & 1094 & 1.681 & 1.893 & 0.737 \\
\hline & Mean: & & 44.99 & 0.906 & 631 & 1055 & 1.762 & 1.890 & 0.644 \\
\hline \multirow{4}{*}{ D15-P-M1-1L-2 } & 1 & \multirow{4}{*}{36.9} & 44.90 & 0.868 & 670 & 1039 & 1.532 & 1.974 & 0.590 \\
\hline & 2 & & 46.72 & 1.001 & 536 & 999 & 1.800 & 1.553 & 0.867 \\
\hline & 3 & & 44.11 & 0.890 & 517 & 1008 & 1.948 & 1.739 & 0.767 \\
\hline & Mean: & & 45.24 & 0.920 & 574 & 1015 & 1.760 & 1.755 & 0.741 \\
\hline \multirow{4}{*}{ D15-P-M1-2L-1 } & 1 & \multirow{4}{*}{36.9} & 55.43 & 1.089 & 1996 & 2079 & 1.033 & 3.031 & 0.516 \\
\hline & 2 & & 61.87 & 1.450 & 2166 & 2018 & 0.897 & 3.210 & 0.625 \\
\hline & 3 & & 62.82 & 1.480 & 1932 & 2055 & 1.047 & 2.855 & 0.749 \\
\hline & Mean: & & 60.04 & 1.340 & 2031 & 2051 & 0.992 & 3.032 & 0.630 \\
\hline \multirow{4}{*}{ D15-P-M2-2L-2 } & 1 & \multirow{4}{*}{16.5} & 54.16 & 3.138 & 3273 & 1209 & 0.394 & 4.270 & 0.600 \\
\hline & 2 & & 54.53 & 2.908 & 2854 & 1292 & 0.533 & 3.807 & 0.743 \\
\hline & 3 & & 47.02 & 2.730 & 3120 & 1266 & 0.395 & 4.295 & 0.522 \\
\hline & Mean: & & 51.90 & 2.925 & 3082 & 1256 & 0.441 & 4.124 & 0.622 \\
\hline \multirow{4}{*}{ D15-P-M2-2L-3 } & 1 & \multirow{4}{*}{34.7} & 64.07 & 1.652 & 2553 & 1895 & 0.811 & 3.339 & 0.651 \\
\hline & 2 & & 67.37 & 1.920 & 2754 & 1862 & 0.956 & 3.674 & 0.729 \\
\hline & 3 & & 69.73 & 2.030 & 2634 & 1757 & 0.894 & 3.514 & 0.752 \\
\hline & Mean: & & 67.06 & 1.867 & 2647 & 1838 & 0.887 & 3.509 & 0.711 \\
\hline \multirow{5}{*}{ D15-P-M2-2L-4 } & 1 & \multirow{4}{*}{42.3} & 72.68 & 1.570 & 1867 & 2023 & 1.115 & 2.715 & 0.885 \\
\hline & 2 & & 67.36 & 1.240 & 1750 & 2135 & 1.325 & 2.495 & 0.737 \\
\hline & 3 & & 68.36 & 1.390 & 1956 & 2221 & 1.253 & 2.789 & 0.758 \\
\hline & Mean: & & 69.47 & 1.400 & 1858 & 2126 & 1.231 & 2.666 & 0.793 \\
\hline & 1 & \multirow{3}{*}{52.7} & 75.25 & 1.397 & 1255 & 1470 & 1.499 & 2.046 & 0.785 \\
\hline \multirow[t]{2}{*}{ D15-P-M2-2L-5 } & 2 & & 71.07 & 1.235 & 989 & 1291 & 1.561 & 1.919 & 0.785 \\
\hline & Mean: & & 73.16 & 1.316 & 1122 & 1381 & 1.530 & 1.983 & 0.785 \\
\hline \multirow{4}{*}{ D15-P-M2-2L-6 } & 1 & \multirow{4}{*}{39.8} & 69.55 & 1.820 & 1949 & 1758 & 1.009 & 2.514 & 0.505 \\
\hline & 2 & & 66.42 & 1.938 & 1773 & 1602 & 1.031 & 2.352 & 0.841 \\
\hline & 3 & & 67.85 & 1.926 & 2124 & 1672 & 0.987 & 2.676 & 0.774 \\
\hline & Mean: & & 67.94 & 1.895 & 1949 & 1677 & 1.009 & 2.514 & 0.707 \\
\hline & 1 & & 81.16 & 1.867 & 3180 & 2672 & 0.825 & 3.125 & 0.722 \\
\hline & 2 & & 80.43 & 1.869 & 3482 & 2432 & 0.754 & 3.497 & 0.699 \\
\hline D15-P-M1-3L-1 & 3 & 36.9 & 81.05 & 2.125 & 3137 & 2350 & 0.795 & 3.087 & 0.719 \\
\hline & Mean: & & 80.88 & 1.954 & 3266 & 2485 & 0.791 & 3.236 & 0.713 \\
\hline & 1 & & 36.68 & 1.128 & 559 & 928 & 1.626 & 2.189 & 0.802 \\
\hline & 2 & & 37.39 & 1.226 & 679 & 893 & 1.311 & 2.654 & 0.790 \\
\hline D20-P-M1-1L-1 & 3 & 27.0 & 36.66 & 1.000 & 625 & 1066 & 2.035 & 2.446 & 0.814 \\
\hline & Mean: & & 36.91 & 1.118 & 621 & 962 & 1.657 & 2.430 & 0.802 \\
\hline & 1 & & 39.17 & 0.824 & 563 & 1230 & 2.074 & 2.177 & 0.400 \\
\hline & 2 & & 42.25 & 0.949 & 932 & 1447 & 1.986 & 3.174 & 0.475 \\
\hline D20-P-M3-1L-2 & 3 & 24.5 & 39.73 & 0.741 & 1059 & 1816 & 1.920 & 3.303 & 0.420 \\
\hline & Mean: & & 40.38 & 0.838 & 851 & 1498 & 1.993 & 2.885 & 0.432 \\
\hline & 1 & & 45.81 & 1.266 & 1600 & 1810 & 1.089 & 3.253 & 0.661 \\
\hline & 2 & & 54.16 & 1.738 & 2220 & 2057 & 0.963 & 4.349 & 0.743 \\
\hline D20-P-M1-2L-1 & 3 & 27.0 & 53.99 & 1.681 & 2084 & 2017 & 0.961 & 4.150 & 0.767 \\
\hline & Mean: & & 51.32 & 1.562 & 1968 & 1961 & 1.004 & 3.917 & 0.724 \\
\hline & 1 & & 58.29 & 1.411 & 2126 & 2065 & 1.146 & 4.337 & 0.530 \\
\hline & 2 & & 61.90 & 1.653 & 2032 & 1977 & 1.218 & 4.048 & 0.640 \\
\hline D20-P-M3-2L-2 & 3 & 24.5 & 48.99 & 1.018 & 2399 & 2597 & 1.091 & 4.825 & 0.370 \\
\hline & Mean: & & 56.39 & 1.361 & 2186 & 2213 & 1.152 & 4.403 & 0.513 \\
\hline & 1 & & 71.72 & 2.140 & 3584 & 2705 & 0.752 & 4.509 & 0.729 \\
\hline & 2 & & 71.15 & 2.264 & 3136 & 2305 & 0.772 & 3.738 & 0.749 \\
\hline D20-P-M1-3L-1 & 3 & 27.0 & 71.30 & 2.350 & 3440 & 2254 & 0.648 & 4.077 & 0.721 \\
\hline & Mean: & & 71.39 & 2.251 & 3387 & 2421 & 0.724 & 4.108 & 0.733 \\
\hline
\end{tabular}


Table 6. Cont

\begin{tabular}{|c|c|c|c|c|c|c|c|c|c|}
\hline Series & Specimens & $\begin{array}{c}f_{\mathrm{c} 0} \\
{[\mathrm{MPa}]}\end{array}$ & $\begin{array}{c}f_{\mathrm{cc}} \\
{[\mathrm{MPa}]}\end{array}$ & $\begin{array}{l}\varepsilon_{\text {ccu }} \\
{[\%]}\end{array}$ & $\begin{array}{c}E_{2, \mathrm{t}} \\
{[\mathrm{MPa}]}\end{array}$ & $\begin{array}{c}E_{2} \\
{[\mathrm{MPa}]}\end{array}$ & $\begin{array}{l}v_{2} \\
{[-]}\end{array}$ & $\begin{array}{l}k_{1} \\
{[-]}\end{array}$ & $\begin{array}{l}k_{\varepsilon} \\
{[-]}\end{array}$ \\
\hline \multirow{4}{*}{ D20-P-M3-3L-2 } & 1 & \multirow{4}{*}{24.5} & 67.24 & 1.614 & 3151 & 2244 & 0.802 & 4.128 & 0.480 \\
\hline & 2 & & 68.77 & 1.570 & 2788 & 2457 & 1.004 & 3.597 & 0.500 \\
\hline & 3 & & 76.45 & 2.000 & 3156 & 2286 & 0.966 & 4.146 & 0.625 \\
\hline & Mean: & & 70.82 & 1.728 & 3032 & 2329 & 0.924 & 3.957 & 0.535 \\
\hline \multirow{4}{*}{ D25-P-M1-1L-1 } & 1 & \multirow{4}{*}{28.1} & 30.11 & 0.834 & 600 & 1027 & 1.724 & 2.933 & 0.722 \\
\hline & 2 & & 29.92 & 0.893 & 660 & 1049 & 1.582 & 3.231 & 0.696 \\
\hline & 3 & & 29.85 & 0.894 & 1033 & 1202 & 1.130 & 5.088 & 0.484 \\
\hline & Mean: & & 29.96 & 0.874 & 764 & 1093 & 1.479 & 3.751 & 0.634 \\
\hline \multirow{4}{*}{ D25-P-M1-2L-1 } & 1 & \multirow{4}{*}{38.0} & 44.87 & 0.798 & 675 & 991 & 1.994 & 1.650 & 0.413 \\
\hline & 2 & & 46.33 & 0.905 & 634 & 1000 & 1.584 & 1.550 & 0.590 \\
\hline & 3 & & 44.20 & 0.877 & 429 & 550 & 1.091 & 1.050 & 0.413 \\
\hline & Mean: & & 45.13 & 0.860 & 579 & 847 & 1.556 & 1.417 & 0.472 \\
\hline \multirow{4}{*}{ D25-P-M1-3L-1 } & 1 & \multirow{4}{*}{38.0} & 59.54 & 1.511 & 1564 & 1820 & 1.151 & 2.551 & 0.678 \\
\hline & 2 & & 56.89 & 1.300 & 1692 & 1727 & 1.030 & 2.759 & 0.548 \\
\hline & 3 & & 56.94 & 1.195 & 1437 & 1709 & 1.224 & 2.343 & 0.590 \\
\hline & Mean: & & 57.79 & 1.335 & 1564 & 1752 & 1.135 & 2.551 & 0.605 \\
\hline \multirow{4}{*}{ D25-P-M1-4L-1 } & 1 & \multirow{4}{*}{33.0} & 75.80 & 2.270 & 3140 & 2448 & 0.804 & 3.870 & 0.826 \\
\hline & 2 & & 66.20 & 1.840 & 2890 & 2249 & 0.850 & 3.571 & 0.708 \\
\hline & 3 & & 77.80 & 2.470 & 3314 & 2503 & 0.783 & 4.121 & 0.826 \\
\hline & Mean: & & 73.27 & 2.193 & 3115 & 2400 & 0.812 & 3.854 & 0.787 \\
\hline \multirow{4}{*}{ D30-P-M1-2L-1 } & 1 & \multirow{4}{*}{30.8} & 41.50 & 1.206 & 719 & 1152 & 1.580 & 2.167 & 0.944 \\
\hline & 2 & & 40.85 & 1.115 & 1178 & 1476 & 1.146 & 3.690 & 0.578 \\
\hline & 3 & & 43.33 & 1.319 & 860 & 1371 & 1.432 & 2.909 & 0.885 \\
\hline & Mean: & & 41.89 & 1.213 & 919 & 1333 & 1.386 & 2.922 & 0.802 \\
\hline \multirow{4}{*}{ D30-P-M1-3L-1 } & 1 & \multirow{4}{*}{30.8} & 50.75 & 1.459 & 1657 & 1859 & 1.126 & 3.280 & 0.740 \\
\hline & 2 & & 51.08 & 1.539 & 1852 & 1869 & 1.007 & 3.645 & 0.708 \\
\hline & 3 & & 47.68 & 1.345 & 1991 & 1876 & 0.880 & 3.957 & 0.546 \\
\hline & Mean: & & 49.84 & 1.448 & 1833 & 1868 & 1.004 & 3.627 & 0.665 \\
\hline
\end{tabular}

Table 7. Specific values for the CFRP-confined plain concrete specimens.

\begin{tabular}{ccccccc}
\hline Series & $\begin{array}{c}\rho_{\mathbf{j}} \\
{[\%]}\end{array}$ & $\begin{array}{c}f_{\mathbf{l j}} \\
{[\mathbf{M P a}]}\end{array}$ & $\begin{array}{c}E_{\mathbf{j} 1} \\
{[\mathbf{M P a}]}\end{array}$ & $\begin{array}{c}E_{\mathrm{j} 1} / f_{\mathbf{c} 0} \\
{[-]}\end{array}$ & $\begin{array}{c}E_{\mathrm{j} 1} / f_{\mathrm{c} 0}{ }^{2} \\
{[-]}\end{array}$ & $\begin{array}{c}f_{\mathbf{l j}} / f_{\mathrm{c} 0} \\
{[-]}\end{array}$ \\
\hline D15-P-M1-1L-1 & 0.296 & 4.00 & 340 & 9.24 & 0.250 & 0.109 \\
D15-P-M1-1L-2 & 0.296 & 4.00 & 340 & 9.24 & 0.250 & 0.109 \\
D15-P-M1-2L-1 & 0.593 & 8.01 & 682 & 18.474 & 0.501 & 0.217 \\
D15-P-M2-2L-2 & 0.652 & 9.44 & 750 & 45.38 & 2.747 & 0.571 \\
D15-P-M2-2L-3 & 0.652 & 9.44 & 750 & 21.63 & 0.624 & 0.272 \\
D15-P-M2-2L-4 & 0.593 & 8.01 & 682 & 16.13 & 0.382 & 0.190 \\
D15-P-M2-2L-5 & 0.652 & 9.44 & 750 & 14.22 & 0.270 & 0.179 \\
D15-P-M2-2L-6 & 0.652 & 9.44 & 750 & 18.83 & 0.473 & 0.237 \\
D15-P-M1-3L-1 & 0.889 & 12.02 & 1022 & 27.71 & 0.751 & 0.326 \\
D20-P-M1-1L-1 & 0.222 & 3.00 & 256 & 9.48 & 0.352 & 0.111 \\
D20-P-M3-1L-2 & 0.223 & 2.65 & 268 & 10.92 & 0.445 & 0.108 \\
D20-P-M1-2L-1 & 0.444 & 6.00 & 511 & 18.96 & 0.703 & 0.223 \\
D20-P-M3-2L-2 & 0.447 & 5.30 & 536 & 21.85 & 0.890 & 0.216 \\
D20-P-M1-3L-1 & 0.733 & 10.62 & 843 & 31.28 & 1.160 & 0.394 \\
D20-P-M3-3L-2 & 0.670 & 7.94 & 805 & 32.77 & 1.335 & 0.323 \\
D25-P-M1-1L-1 & 0.178 & 2.40 & 204 & 7.28 & 0.259 & 0.086 \\
D25-P-M1-2L-1 & 0.356 & 4.81 & 409 & 10.76 & 0.283 & 0.126 \\
D25-P-M1-3L-1 & 0.533 & 7.21 & 613 & 16.14 & 0.425 & 0.190 \\
D25-P-M1-4L-1 & 0.711 & 9.61 & 818 & 24.77 & 0.750 & 0.291 \\
D30-P-M1-2L-1 & 0.296 & 4.00 & 341 & 11.06 & 0.359 & 0.130 \\
D30-P-M1-3L-1 & 0.444 & 6.00 & 511 & 16.59 & 0.538 & 0.195 \\
\hline
\end{tabular}


The variation in the diameter of the cylinder, as well as the thickness of the CFRP, led to varying volumetric ratios of the CFRP jackets, $\rho_{\mathrm{j}}$. The volumetric ratio and the material properties of the CFRP jacket define its maximum confinement pressure, $f_{\mathrm{lj}}$, as shown in Equation (3). As expected, $f_{\mathrm{lj}}$ had a significant impact on $f_{\mathrm{cc}}$ and $\varepsilon_{\mathrm{ccu}}$. Furthermore, the investigations indicated that the unconfined concrete strength, $f_{\mathrm{c} 0}$, is a second impact factor. Figure 13 illustrates the dependence of the strength enhancement, $\Delta f_{\mathrm{cc}}\left(\Delta f_{\mathrm{cc}}=f_{\mathrm{cc}}-f_{\mathrm{c} 0}\right)$ and the ultimate strain, $\varepsilon_{\mathrm{ccu}}$, on the initial concrete strength, $f_{\mathrm{c} 0}$.

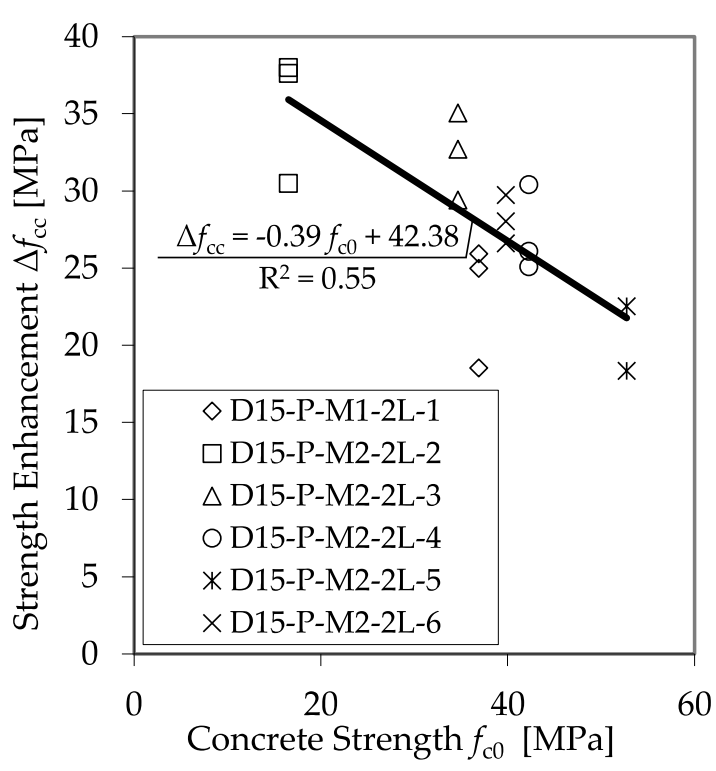

(a)

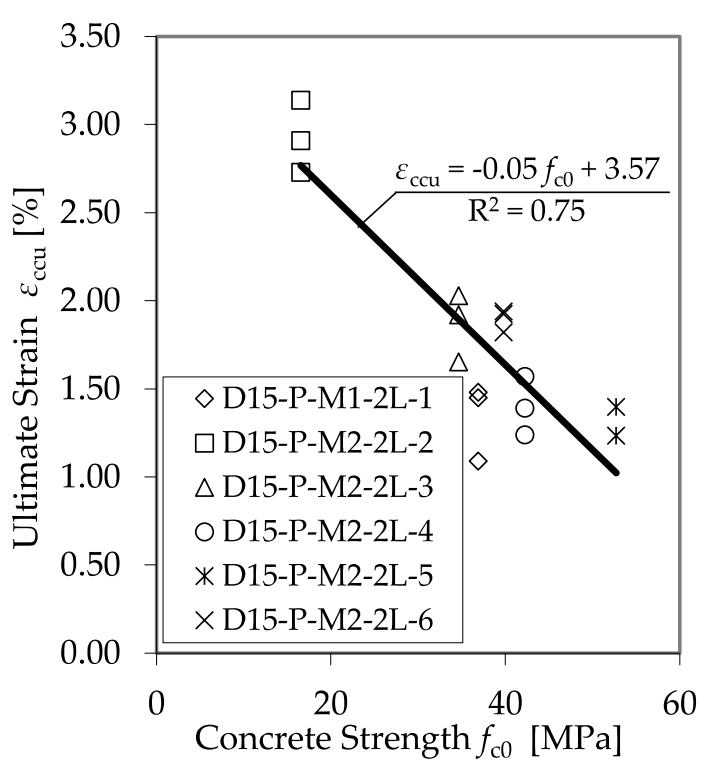

(b)

Figure 13. Dependence of $\Delta f_{\mathrm{cc}}(\mathbf{a})$ and $\varepsilon_{\mathrm{ccu}}(\mathbf{b})$ on the unconfined concrete strength, $f_{\mathrm{c} 0}$.

For this comparison, only $f_{\mathrm{c} 0}$ was changed. Only test specimens with equal diameters (150 $\left.\mathrm{mm}\right)$ and properties of the applied CFRP system were used, while the concrete strength, $f_{\mathrm{c} 0}$, varied. An impact of $f_{\mathrm{c} 0}$ on $f_{\mathrm{cc}}$ and $\varepsilon_{\mathrm{ccu}}$ can be recognized, but a sufficient correlation is pending. Therefore, the proposal of Xiao and $\mathrm{Wu}$ [13] was applied to involve the unconfined strength into the analysis. If $f_{1}$ is set in relation to $f_{\mathrm{c} 0}$, satisfying regressions for the prediction of $f_{\mathrm{cc}}$ and $\varepsilon_{\mathrm{ccu}}$ can be found. Figure 14 shows the results of all plain test specimens defined using the CFRP system, as listed in Table 6, and the regression curves for the strength enhancement, $\Delta f_{\mathrm{cc}}$, and the ultimate strain, $\varepsilon_{\mathrm{ccu}}$.

The high coefficients of determination of the regression curves indicate the reliability of the ratio between confinement pressure and unconfined concrete strength to predict the load-bearing capacity of a CFRP-confined concrete member.

Further analysis confirmed that relating the confinement modulus $E_{\mathrm{j} 1}$ to the divisor $f_{\mathrm{c} 0}$ enables the prediction of $E_{2, t}$, as well as $v_{2}$. Figure 15 shows the results of all plain test specimens as listed in Table 6, as well as the regression curves for the second modulus $E_{2, t}$ and the second Poisson's ratio, $v_{2}$.

The comparison of the variation in the cross-sectional diameter showed no significant size effect on the FRP-confined concrete. The use of the confinement modulus $E_{\mathrm{j} 1}$ and the calculated confinement pressure $f_{\mathrm{lj}}$ are sufficient for the consideration of the varying diameter. 


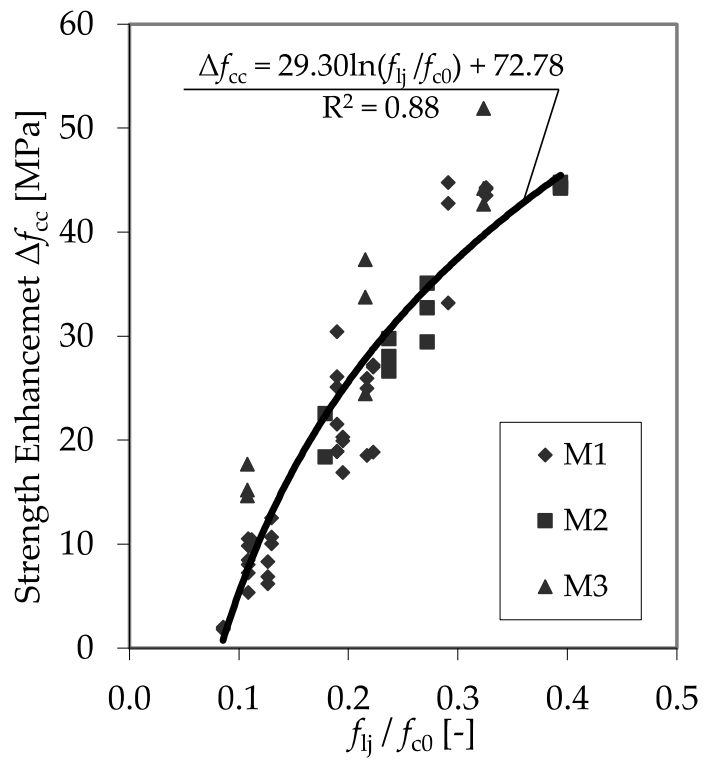

(a)

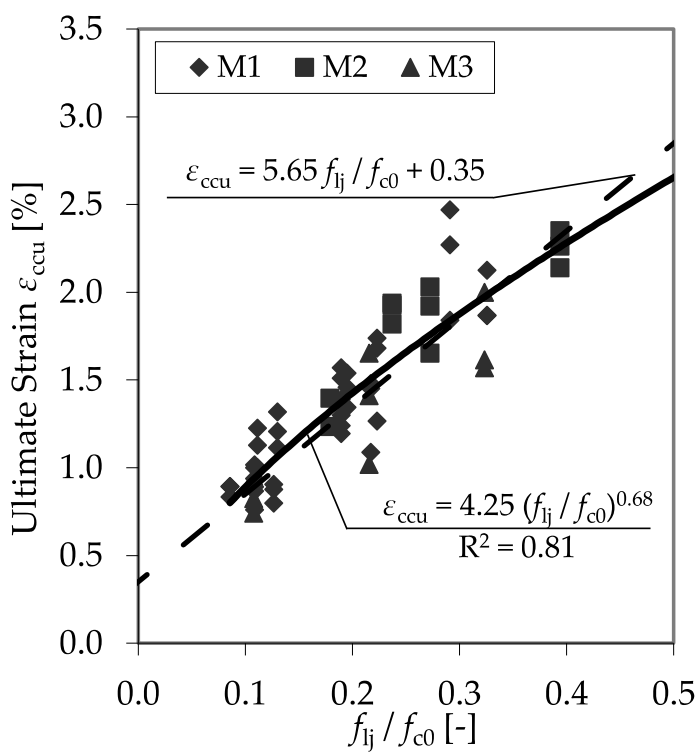

(b)

Figure 14. Strength enhancement $\Delta f_{\mathrm{cc}}(\mathbf{a})$ and ultimate strain $\varepsilon_{\mathrm{ccu}}(\mathbf{b})$ as functions of the relationship between confinement pressure and unconfined concrete strength.

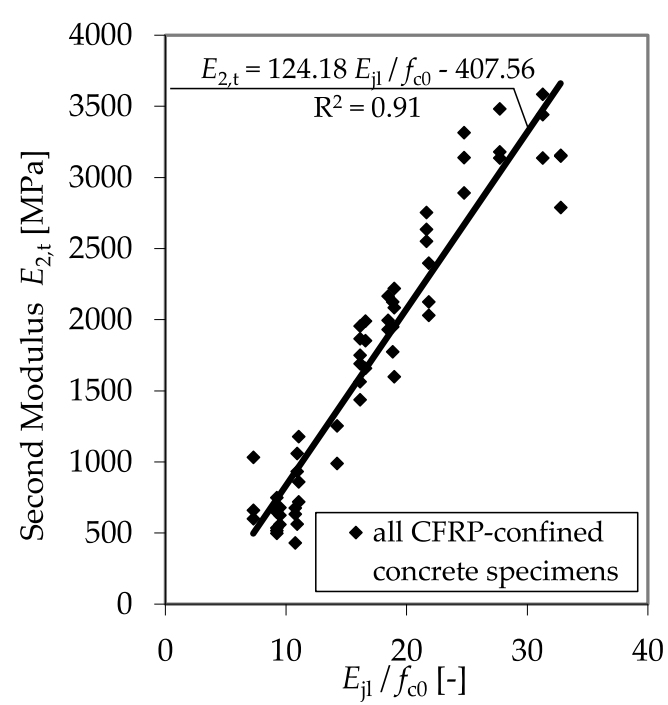

(a)

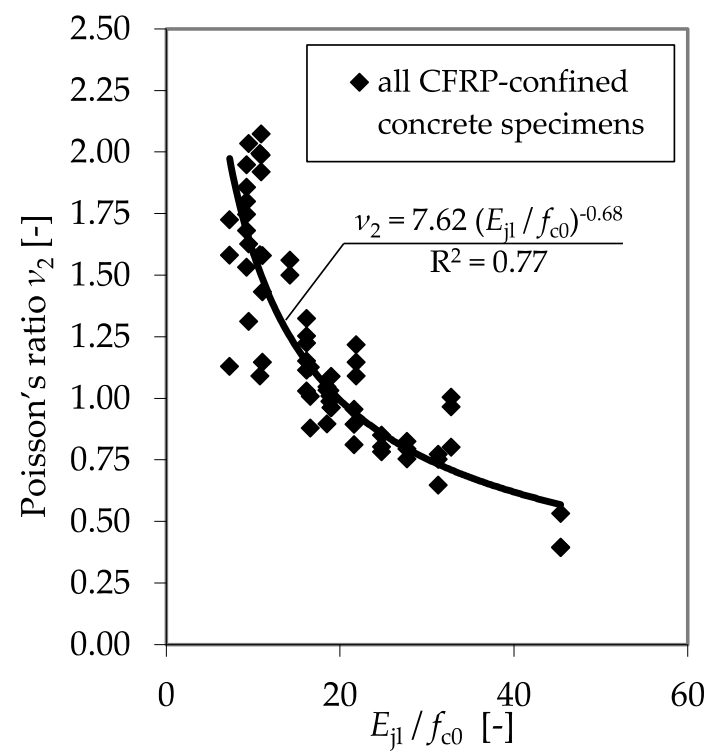

(b)

Figure 15. Second modulus $E_{2, t}(\mathbf{a})$ and second Poisson's ratio $v_{2}(\mathbf{b})$ as functions of the relationship between the confinement modulus and the unconfined concrete strength.

\subsection{FRP Rupture Strain and Accompanied Partial Safety Factors}

Regarding the CFRP's rupture strain reached by the CFRP jacket, the investigations correspond with the findings of Lam and Teng [6,23]. In almost all cases, the rupture strain was considerably lower than the ultimate tensile strain found from flat coupon tensile tests. Therefore, a factor $k_{\varepsilon}<1.0$ should be mandatory. An overview of different approaches to determine $k_{\varepsilon}$ is given in Table 8 . 
Table 8. Suggested approaches to determine $k_{\varepsilon}$.

\begin{tabular}{cccc}
\hline \multicolumn{1}{c}{ Source } & FRP-Confined Plain Concrete & $\begin{array}{c}\text { FRP-Confined Reinforced } \\
\text { Concrete }\end{array}$ \\
\hline Niedermeier & {$[33,40]$} & $k_{\varepsilon}=0.66, k_{\varepsilon \mathrm{k}}=0.50$ & $k_{\varepsilon}=0.50, k_{\varepsilon \mathrm{k}}=0.25$ \\
\hline Lam and Teng & {$[6,23]$} & $\begin{array}{c}k_{\varepsilon}=0.586 \text { (Carbon), } \\
k_{\varepsilon}=0.669 \text { (Glass) }\end{array}$ & no information \\
\hline Toutanji et al. & {$[41]$} & $k_{\varepsilon}=0.6$ & no information \\
\hline Smith et al. & {$[21]$} & $k_{\varepsilon}=0.8$ & no information \\
\hline $\begin{array}{c}\text { Pellegrino and } \\
\text { Modena }\end{array}$ & {$[8]$} & $k_{\varepsilon}=0.25+0.25 \cdot\left(\frac{2 \cdot R_{\mathrm{c}}}{b}\right)$ & $k_{\varepsilon}=\gamma \cdot C^{-0.7} \leq 0.8$ with $C=\frac{E_{\mathrm{s}} \cdot \rho_{1}}{E_{\mathrm{j}} \cdot \rho_{\mathrm{j}}}$ \\
\hline
\end{tabular}

Abbreviations: $R_{\mathrm{c}}=$ corner radius; $E_{\mathrm{S}}=$ elastic modulus steel reinforcement; $\rho_{\mathrm{l}}=$ longitudinal steel ratio.

While most approaches suggest a common, universally valid reduction factor for CFRP systems, the conducted experimental program shows significant differences, even between the used carbon fibers. The average value for the three different CFRP systems differed remarkably between $k_{\varepsilon}=0.49$ and $k_{\varepsilon}=0.70$. The use of a mean value $k_{\varepsilon}$, as mainly suggested in literature, can, therefore, be uncertain. Due to the large scattering of the test results, the conservative approach introduced by Niedermeier $[33,40]$ was adopted, using characteristic values, $k_{\varepsilon \mathrm{k}}$. In accordance with EN 1990:2002 [42], characteristic values for the tested specimens were determined; the results can be seen in Figure 16. In summary, the evaluation revealed the dependence of the efficiency factors $k_{\varepsilon}$ on the used CFRP material.

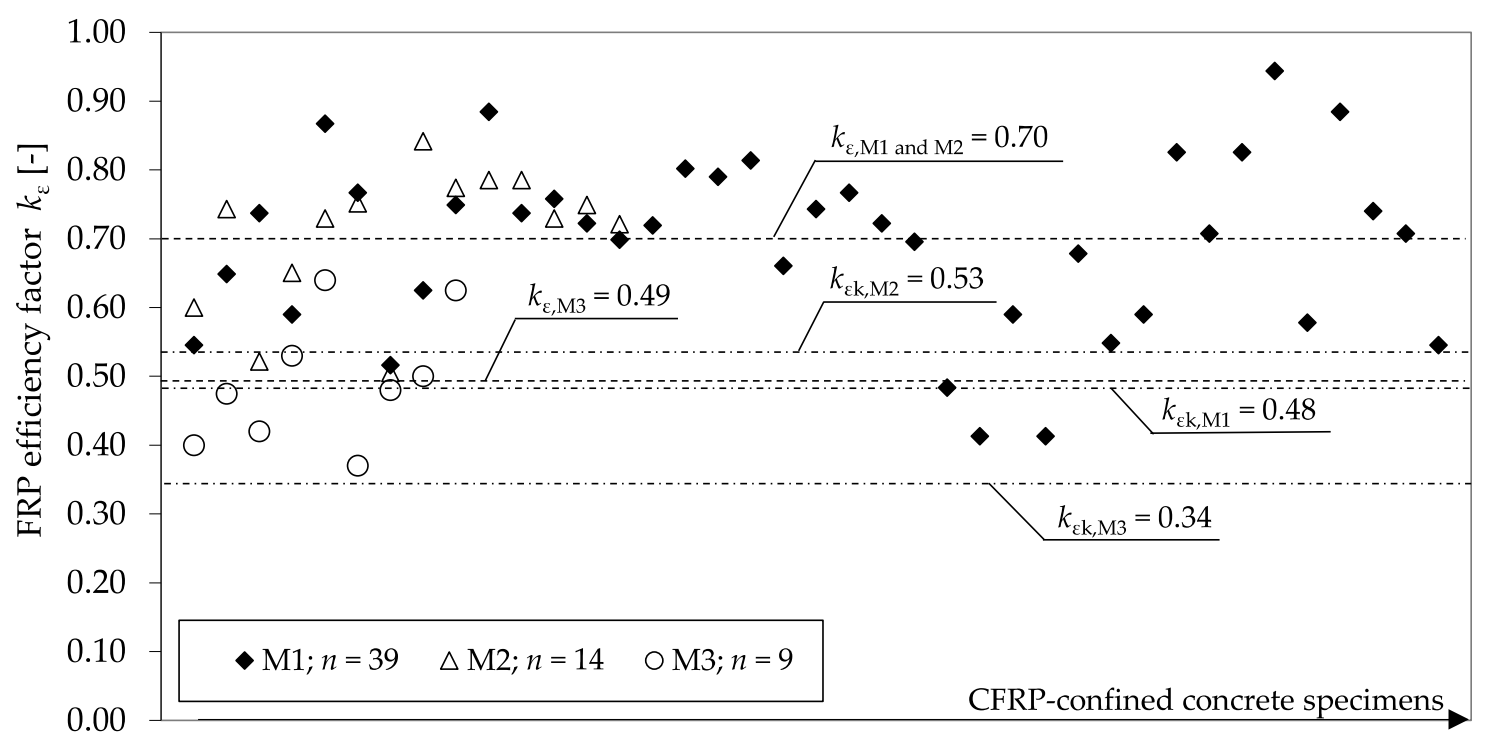

Figure 16. Values for $k_{\varepsilon}$ determined from tests with different CFRP materials and calculated characteristic values $k_{\varepsilon \mathrm{k}}$ (according to EN 1990:2002 [42]).

Furthermore, the findings enabled the derivation of particular partial factors $\gamma_{j}$ for the used CFRP materials. The approach introduced in the fib bulletin 80 [43] was used for the calculation:

$$
\gamma_{\mathrm{j}}=\frac{\exp \left(-1.645 \cdot V_{\mathrm{x}}\right)}{\exp \left(-\alpha_{\mathrm{R}} \cdot \beta \cdot V_{\mathrm{x}}\right)} \cdot \gamma_{\mathrm{Rd} 1} \cdot \gamma_{\mathrm{Rd} 2},
$$

where $\alpha_{\mathrm{R}}$ is the sensitivity factor $\left(\alpha_{\mathrm{R}}=0.8\right), V_{\mathrm{x}}$ is the presumed coefficient of variation of the rupture strain $\varepsilon_{\mathrm{FRP}}, \beta$ is the reliability factor $(\beta=3.8), \gamma_{\mathrm{Rd} 1}$ is a factor considering model uncertainties, and $\gamma_{\mathrm{Rd} 2}$ is a factor considering geometrical uncertainties. 
As shown in Table 9, the variation coefficients $V_{\mathrm{x}}$ vary remarkably between the used CFRP materials. Hence, $\gamma_{j}$ should be determined separately for each FRP system-for instance, within a technical approval procedure.

For the derivation of the displayed partial factors according to Equation (7), $\gamma_{\text {Rd1 }}$ was predicted with a value of 1.20 because model uncertainties are comparable to that of models for shear design. In contrast, $\gamma_{\text {Rd2 }}$ was determined with a value of 1.0. For columns with a circular cross section, the geometrical uncertainties are negligible, as $k_{\varepsilon}$ persisted at a constant value independent of the column diameter.

Table 9. Calculated partial factors $\gamma_{\mathrm{j}}$ for the CFRP materials used.

\begin{tabular}{ccc}
\hline CFRP Sheet & $\boldsymbol{V}_{\mathbf{x}}$ & $\boldsymbol{\gamma}_{\mathbf{j}}$ \\
\hline M1 & 0.200 & 1.59 \\
M2 & 0.155 & 1.50 \\
M3 & 0.189 & 1.57 \\
\hline
\end{tabular}

In comparison, the calculated safety factors are significantly higher than those suggested by current recommendations, codes, and guidelines, as listed in Table 10. These partial safety factors originated from flat coupon tests of CFRP laminates and were not conditional on the application. However, this is a potential unsafe approach, as $\gamma_{\mathrm{j}}$ depends on $V_{\mathrm{x}}$ of the FRP jacket's hoop strain applied to the column perimeter. The same applies for the characteristic values of the FRP strength and rupture strain.

Table 10. Recommended FRP material safety factors $\gamma_{j}$.

\begin{tabular}{ccc}
\hline \multicolumn{2}{c}{ Recommendation/Code } & $\gamma_{\mathbf{j}}$ \\
\hline CNR-DT 200 R1/2013 & {$[27]$} & 1.21 \\
GB 50608-2010 & {$[28]$} & 1.40 \\
DAfStb-Guideline & {$[30]$} & 1.35 \\
fib Technical Report & {$[44]$} & 1.35 \\
\hline
\end{tabular}

\subsection{CFRP-Confined Reinforced Concrete Specimens}

Table 11 shows the results obtained from the tests using the CFRP-confined concrete specimens with internal reinforcement, confirming a joint confinement effect by the external CFRP confinement and internal transverse reinforcement. Dual confinement strongly increases the load-bearing capacity in general. Therefore, the confinement pressures of the CFRP jacket and the transverse steel reinforcement have to be summed according to the work in [3]:

$$
f_{1(\mathrm{j}+\mathrm{w})}=f_{\mathrm{lj}}+f_{\mathrm{l}, \mathrm{wy}}=\frac{1}{2} \cdot \rho_{\mathrm{j}} \cdot E_{\mathrm{j}} \cdot \varepsilon_{\mathrm{ju}}+\frac{1}{2} \cdot \rho_{\mathrm{st}} \cdot f_{\mathrm{y}} \cdot k_{\mathrm{e}} \text { with } k_{\mathrm{e}}=\left(\frac{D_{\mathrm{c}}-\mathrm{s} / 2}{D}\right)^{2} \text { and } \rho_{\mathrm{st}}=\frac{\pi \cdot \varnothing_{\mathrm{w}}{ }^{2}}{D_{\mathrm{c}} \cdot \mathrm{s}}
$$

where $\rho_{\mathrm{st}}$ is the transverse steel volumetric ratio, $f_{\mathrm{y}}$ is the yield stress, $k_{\mathrm{e}}$ is the coefficient of lateral and vertical efficiency of the transverse steel reinforcement according to Niedermeier [33], $D_{\mathrm{c}}$ is the horizontal center distance of the spiral or tie reinforcement, $\varnothing_{\mathrm{w}}$ is the diameter of the transverse steel reinforcement, and $s$ is the vertical spacing between the spiral or tie bars. 
Table 11. Test results of the CFRP-confined RC specimens.

\begin{tabular}{|c|c|c|c|c|c|c|c|c|c|}
\hline Series & Specimens & $\begin{array}{c}f_{\mathrm{c} 0} \\
{[\mathrm{MPa}]}\end{array}$ & $\begin{array}{l}k_{\mathrm{e}} \\
{[-]}\end{array}$ & $\begin{array}{l}f_{1(j+w)} \\
{[\mathrm{MPa}]}\end{array}$ & $\begin{array}{c}f_{\mathrm{cc}} \\
{[\mathrm{MPa}]}\end{array}$ & $\begin{array}{c}\Delta f_{\mathrm{cc}} \\
{[\mathrm{MPa}]}\end{array}$ & $\begin{array}{l}\varepsilon_{\mathrm{ccu}} \\
{[\%]}\end{array}$ & $\begin{array}{c}E_{2, \mathrm{t}} \\
{[\mathrm{MPa}]}\end{array}$ & $\begin{array}{l}v_{2} \\
{[-]}\end{array}$ \\
\hline \multirow{4}{*}{ D15-TR-M1-2L-1 } & 1 & \multirow{4}{*}{42.3} & \multirow{4}{*}{0.352} & \multirow{4}{*}{9.93} & 83.80 & 36.70 & 1.254 & 5178 & 0.873 \\
\hline & 2 & & & & 89.46 & 42.36 & 1.680 & 5376 & 0.951 \\
\hline & 3 & & & & 86.15 & 39.05 & 1.720 & 4886 & 0.990 \\
\hline & Mean: & & & & 86.47 & 39.37 & 1.551 & 5147 & 0.938 \\
\hline \multirow{4}{*}{ D15-TR-M1-2L-2 } & 1 & \multirow{4}{*}{42.3} & \multirow{4}{*}{0.182} & \multirow{4}{*}{8.51} & 83.25 & 36.16 & 1.620 & 3745 & 1.120 \\
\hline & 2 & & & & 81.92 & 34.82 & 1.430 & 3129 & 1.293 \\
\hline & 3 & & & & 73.03 & 25.94 & 1.180 & 4485 & 0.996 \\
\hline & Mean: & & & & 79.40 & 32.31 & 1.410 & 3786 & 1.136 \\
\hline \multirow{5}{*}{ D20-TR-M1-2L-1 } & 1 & \multirow{4}{*}{27.0} & \multirow{4}{*}{0.154} & \multirow{4}{*}{6.08} & 65.08 & 27.08 & 1.980 & 3241 & 0.814 \\
\hline & 2 & & & & 69.37 & 31.37 & 2.176 & 2595 & 0.930 \\
\hline & 3 & & & & 67.76 & 29.76 & 2.106 & 2552 & 0.959 \\
\hline & Mean: & & & & 67.40 & 29.40 & 2.087 & 2796 & 0.901 \\
\hline & 1 & \multirow{4}{*}{27.0} & \multirow{3}{*}{0.146} & & 64.99 & 26.99 & 1.977 & 3216 & 0.655 \\
\hline \multirow{3}{*}{ D20-TR-M1-2L-2 } & 2 & & & & 64.43 & 26.43 & 1.915 & 2602 & 0.784 \\
\hline & 3 & & & 6.17 & 60.75 & 22.75 & 1.746 & 2839 & 0.749 \\
\hline & Mean: & & & & 63.93 & 25.39 & 1.879 & 2886 & 0.729 \\
\hline & 1 & & & & 66.10 & 30.77 & 1.660 & 3945 & 0.647 \\
\hline & 2 & & & & 68.70 & 33.38 & 1.630 & 3476 & 0.736 \\
\hline D20-1R-M2-2L-3a & 3 & 28.0 & $0.32 b$ & 7.69 & 67.05 & 31.72 & 1.690 & 2860 & 0.971 \\
\hline & Mean: & & & & 67.28 & 31.96 & 1.660 & 3427 & 0.785 \\
\hline & 1 & & & & 72.80 & 33.75 & 1.690 & 3298 & 0.937 \\
\hline & 2 & & & & 75.91 & 36.85 & 1.860 & 3277 & 0.895 \\
\hline D20-TR-M2-2L-3b & 3 & 28.0 & 0.325 & 7.69 & 72.84 & 33.78 & 1.660 & 3339 & 0.882 \\
\hline & Mean: & & & & 73.85 & 34.79 & 1.737 & 3305 & 0.905 \\
\hline & 1 & & & & 76.32 & 33.47 & 1.781 & 3631 & 0.811 \\
\hline ז 2 & 2 & 200 & 0205 & 760 & 77.08 & 34.23 & 1.796 & 4370 & 0.769 \\
\hline$D 2 U-1 K-N 1 M 2-\angle L-3 C$ & 3 & 28.0 & 0.320 & 7.69 & 78.39 & 35.54 & 1.926 & 3524 & 0.781 \\
\hline & Mean: & & & & 77.26 & 34.41 & 1.834 & 3842 & 0.787 \\
\hline & 1 & & & & 76.97 & 37.92 & 1.877 & 3738 & 0.727 \\
\hline DOP-TR-MP & 2 & 280 & 0483 & 801 & 77.06 & 38.00 & 1.834 & 4424 & 0.654 \\
\hline DZU-1R-MLL-ZL-4 & 3 & 28.0 & 0.483 & 8.91 & 78.06 & 39.00 & 1.867 & 3973 & 0.709 \\
\hline & Mean: & & & & 77.36 & 38.31 & 1.859 & 4045 & 0.697 \\
\hline & 1 & & & & 51.64 & 26.29 & 1.094 & 2830 & 0.880 \\
\hline D20-TR-M2-1L-1 & 2 & 24.5 & 0.400 & 4.55 & 54.32 & 28.97 & 1.257 & 3190 & 0.865 \\
\hline & Mean: & & & & 52.98 & 27.63 & 1.176 & 3010 & 0.873 \\
\hline & 1 & & & & 49.07 & 23.71 & 1.065 & 2452 & 0.941 \\
\hline D20-TR-M2-1L-2 & 2 & 245 & 0490 & 510 & 57.04 & 31.69 & 1.180 & 2043 & 1.228 \\
\hline & 3 & 24.5 & 0.490 & 5.10 & 56.68 & 31.33 & 1.249 & 2303 & 1.072 \\
\hline & Mean: & & & & 54.26 & 28.91 & 1.165 & 2266 & 1.080 \\
\hline & 1 & & & & 56.65 & 31.30 & 1.193 & 3871 & 0.783 \\
\hline D20-TR-M2-1L-3 & 2 & 24.5 & & & 57.77 & 32.42 & 1.310 & 3129 & 0.921 \\
\hline D20-TR-M2-1L-3 & 3 & 24.5 & 0.400 & 4.92 & 52.07 & 26.71 & 1.450 & 3621 & 0.891 \\
\hline & Mean: & & & & 55.50 & 30.14 & 1.318 & 3540 & 0.865 \\
\hline & 1 & & & & 60.65 & 20.62 & 1.473 & 3125 & 0.799 \\
\hline & 2 & & & & 59.80 & 19.77 & 1.490 & - & - \\
\hline D25-SR-M1-1L-1 & 3 & 33.0 & 0.590 & 6.25 & 60.84 & 20.81 & 1.616 & 3361 & 0.780 \\
\hline & Mean: & & & & 60.43 & 20.40 & 1.526 & 3243 & 0.790 \\
\hline & 1 & & & & 76.51 & 30.50 & 1.850 & 3140 & 0.776 \\
\hline D25_SP_M1_- 1 & 2 & 390 & 0500 & 865 & 75.79 & 29.78 & 1.966 & 3140 & 0.835 \\
\hline DZ5-SK-MII-ZL-1 & 3 & 39.0 & 0.590 & 8.65 & 76.69 & 30.68 & 2.036 & 3412 & 0.811 \\
\hline & Mean: & & & & 76.33 & 30.32 & 1.951 & 3230 & 0.807 \\
\hline & 1 & & & & - & - & - & 5257 & 0.475 \\
\hline P25_SR_M1_-2I & 2 & 281 & 0.578 & $107-3$ & - & - & - & 4634 & 0.503 \\
\hline DZJ-SK-MII-ZL-2 & 3 & 28.1 & $0.5 / 8$ & 10.75 & - & - & - & 4783 & 0.476 \\
\hline & Mean: & & & & - & - & - & 4891 & 0.485 \\
\hline & 1 & & & & 68.08 & 29.86 & 1.911 & 3538 & 0.632 \\
\hline D25-SR-M1-2L-3 & 2 & 31.2 & 0.590 & 8.65 & 68.96 & 30.74 & 2.214 & 4374 & 0.490 \\
\hline & Mean: & & & & 68.52 & 30.30 & 2.063 & 3956 & 0.561 \\
\hline
\end{tabular}


Table 11. Cont.

\begin{tabular}{|c|c|c|c|c|c|c|c|c|c|}
\hline Series & Specimens & $\begin{array}{c}f_{\mathrm{c} 0} \\
{[\mathrm{MPa}]}\end{array}$ & $\begin{array}{l}k_{\mathrm{e}} \\
{[-]}\end{array}$ & $\begin{array}{l}f_{1(j+w)} \\
{[\mathrm{MPa}]}\end{array}$ & $\begin{array}{c}f_{\mathrm{cc}} \\
{[\mathrm{MPa}]}\end{array}$ & $\begin{array}{c}\Delta f_{\mathrm{cc}} \\
{[\mathrm{MPa}]}\end{array}$ & $\begin{array}{l}\varepsilon_{\mathrm{ccu}} \\
{[\%]}\end{array}$ & $\begin{array}{c}E_{2, \mathrm{t}} \\
{[\mathrm{MPa}]}\end{array}$ & $\begin{array}{l}v_{2} \\
{[-]}\end{array}$ \\
\hline \multirow{5}{*}{ D25-SR-M1-3L-1 } & 1 & \multirow{4}{*}{39.0} & \multirow{4}{*}{0.590} & \multirow{4}{*}{11.06} & 87.95 & 41.94 & 2.350 & 4545 & 0.583 \\
\hline & 2 & & & & 87.25 & 41.24 & 2.220 & 4603 & 0.589 \\
\hline & 3 & & & & 85.88 & 39.87 & 2.100 & 4377 & 0.616 \\
\hline & Mean: & & & & 87.03 & 41.02 & 2.223 & 4508 & 0.596 \\
\hline & 1 & \multirow{4}{*}{33.0} & \multirow{4}{*}{0.430} & \multirow{4}{*}{5.43} & 60.90 & 20.86 & 1.800 & 2884 & 0.832 \\
\hline \multirow{3}{*}{ D25-TR-M1-2L-1 } & 2 & & & & 57.57 & 17.54 & 1.605 & 2726 & 0.786 \\
\hline & 3 & & & & 50.83 & 10.80 & 1.258 & 2338 & 0.991 \\
\hline & Mean: & & & & 56.43 & 16.40 & 1.554 & 2649 & 0.870 \\
\hline \multirow{5}{*}{ D25-TR-M1-2L-2 } & 1 & \multirow{4}{*}{31.2} & \multirow{4}{*}{0.430} & \multirow{4}{*}{5.43} & 54.02 & 15.80 & 1.466 & 2870 & 0.731 \\
\hline & 2 & & & & 50.83 & 12.61 & 1.289 & 2968 & 0.704 \\
\hline & 3 & & & & 54.64 & 16.42 & 1.564 & 2845 & 0.717 \\
\hline & Mean: & & & & 53.16 & 14.94 & 1.440 & 2894 & 0.717 \\
\hline & 1 & \multirow{4}{*}{31.0} & \multirow{4}{*}{0.651} & \multirow{4}{*}{7.44} & - & - & - & 4922 & 0.480 \\
\hline \multirow{3}{*}{ D30-SR-M1-2L-1 } & 2 & & & & - & - & - & 4846 & 0.521 \\
\hline & 3 & & & & - & - & - & 4380 & 0.577 \\
\hline & Mean: & & & & - & - & - & 4716 & 0.526 \\
\hline \multirow{4}{*}{ D30-SR-M1-2L-2 } & 1 & \multirow{4}{*}{31.0} & \multirow{4}{*}{0.601} & \multirow{4}{*}{7.63} & - & - & - & 4832 & 0.473 \\
\hline & 2 & & & & 65.20 & 29.34 & 1.880 & 3813 & 0.587 \\
\hline & 3 & & & & - & - & - & 3888 & 0.600 \\
\hline & Mean: & & & & 65.20 & 29.34 & 1.880 & 4178 & 0.553 \\
\hline
\end{tabular}

For the following analysis, the provided confinement pressure and confinement stiffness had to be determined for each series. The specific values are shown in Table 12. Additionally, the cross-sectional area of the longitudinal reinforcement $A_{\mathrm{sl}}$ and the maximum stress carried by the longitudinal reinforcement during the compression test $\sigma_{\mathrm{sl}}$ are specified. The strength enhancement $\Delta f_{\mathrm{cc}}$ is defined as $\Delta f_{\mathrm{cC}}=f_{\mathrm{cC}}-f_{\mathrm{c} 0}-\sigma_{\mathrm{sl}}$.

Table 12. Specific values of the CFRP-confined RC specimens.

\begin{tabular}{cccccc}
\hline Series & $\begin{array}{c}f_{\mathbf{l j}} \\
{[\mathbf{M P a}]}\end{array}$ & $\begin{array}{c}f_{\mathbf{l , w y}} \\
{[\mathbf{M P a}]}\end{array}$ & $\begin{array}{c}A_{\mathbf{s l}} \\
{\left[\mathbf{m m}^{2}\right]}\end{array}$ & $\begin{array}{c}\sigma_{\mathbf{s l}} \\
{[\mathbf{M P a}]}\end{array}$ & $\begin{array}{c}f_{\mathbf{l}(\mathbf{j}+\mathbf{w})} / f_{\mathrm{c} 0} \\
{[-]}\end{array}$ \\
\hline D15-TR-M1-2L-1 & 8.01 & 1.92 & 170 & 4.85 & 0.235 \\
D15-TR-M1-2L-2 & 8.01 & 0.50 & 170 & 4.85 & 0.201 \\
D20-TR-M1-2L-1 & 6.01 & 0.07 & 679 & 11.04 & 0.226 \\
D20-TR-M1-2L-2 & 6.01 & 0.16 & 679 & 11.04 & 0.229 \\
D20-TR-M2-2L-3a & 7.08 & 0.62 & 452 & 7.31 & 0.275 \\
D20-TR-M2-2L-3b & 7.08 & 0.62 & 679 & 11.04 & 0.275 \\
D20-TR-M2-2L-3c & 7.08 & 0.62 & 905 & 14.83 & 0.275 \\
D20-TR-M2-2L-4 & 7.08 & 1.83 & 679 & 11.04 & 0.318 \\
D20-TR-M2-1L-1 & 3.54 & 1.01 & 50 & 0.80 & 0.185 \\
D20-TR-M2-1L-2 & 3.54 & 1.56 & 50 & 0.80 & 0.208 \\
D20-TR-M2-1L-3 & 3.54 & 1.38 & 50 & 0.80 & 0.200 \\
D25-SR-M1-1L-1 & 2.40 & 3.85 & 679 & 7.01 & 0.189 \\
D25-SR-M1-2L-1 & 4.81 & 3.85 & 679 & 7.01 & 0.222 \\
D25-SR-M1-2L-2 & 4.81 & 5.94 & 679 & 7.01 & 0.383 \\
D25-SR-M1-2L-3 & 4.81 & 3.85 & 679 & 7.01 & 0.277 \\
D25-SR-M1-3L-1 & 7.21 & 3.85 & 679 & 7.01 & 0.283 \\
D25-TR-M1-2L-1 & 4.81 & 0.63 & 679 & 7.01 & 0.164 \\
D25-TR-M1-2L-2 & 4.81 & 0.63 & 679 & 7.01 & 0.174 \\
D30-SR-M1-2L-1 & 4.01 & 3.43 & 679 & 4.85 & 0.240 \\
D30-SR-M1-2L-2 & 4.01 & 3.63 & 679 & 4.85 & 0.246 \\
\hline
\end{tabular}

In the diagrams of Figure 17, the experimental results for the strength enhancement, as well as the ultimate strain reached for both the confined plain and the RC cylinders are shown as functions of the 
ratio between $f_{1(j+w)}$ and $f_{\mathrm{c} 0}$. As for the results of the sole confined plain concrete specimens, satisfying regressions for the prediction of $f_{\mathrm{cc}}$ and $\varepsilon_{\mathrm{ccu}}$ can be found.

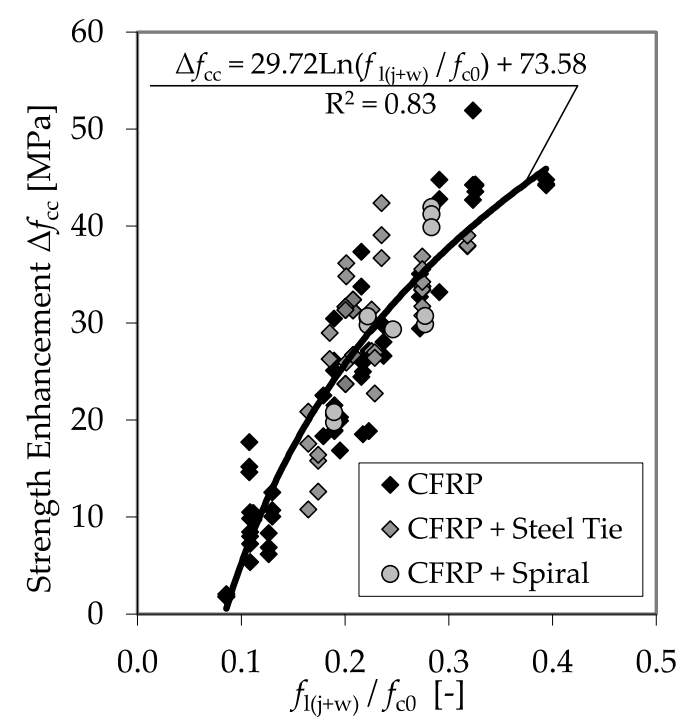

(a)

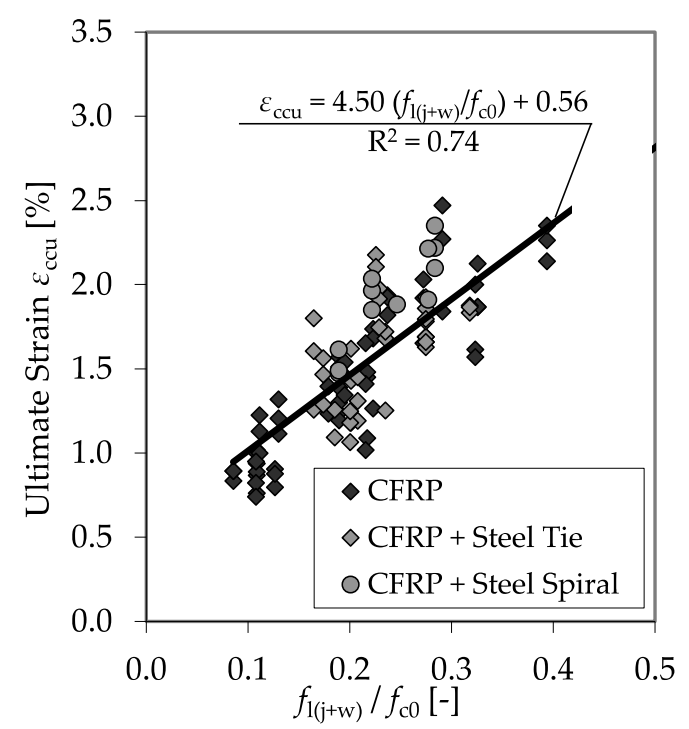

(b)

Figure 17. Strength enhancement (a), $\Delta f_{\mathrm{cc}}$, and ultimate strain $(\mathbf{b}), \varepsilon_{\mathrm{ccu}}$, as functions of the ratio between $f_{1(j+w)}$ and $f_{\mathrm{c} 0}$

As observed for the plain concrete, the bearing behavior of the confined RC is defined by a decrease in the specimens' axial rigidity. However, the transition zone is smoother and prolonged.

Figure 18 shows the differences in bearing behavior, comparing a CFRP-confined plain concrete specimen and a column dually confined by a transverse spiral reinforcement and a CFRP jacket. In detail, a single specimen of series D30-SR-M1-2L-2 with a diameter of $300 \mathrm{~mm}$ and a spiral $(\varnothing=10 \mathrm{~mm}, s=55 \mathrm{~mm})$ was compared to a specimen of the same diameter and confinement but without reinforcement (series D30-P-M1-2L-1). As explained by Equation (7), a constant confining pressure of the yielding steel transverse reinforcement can be assumed. The second modulus is similar to $E_{2}$ observed in confined plain concrete, as further strength enhancement depends on the linear elastic CFRP jacket.

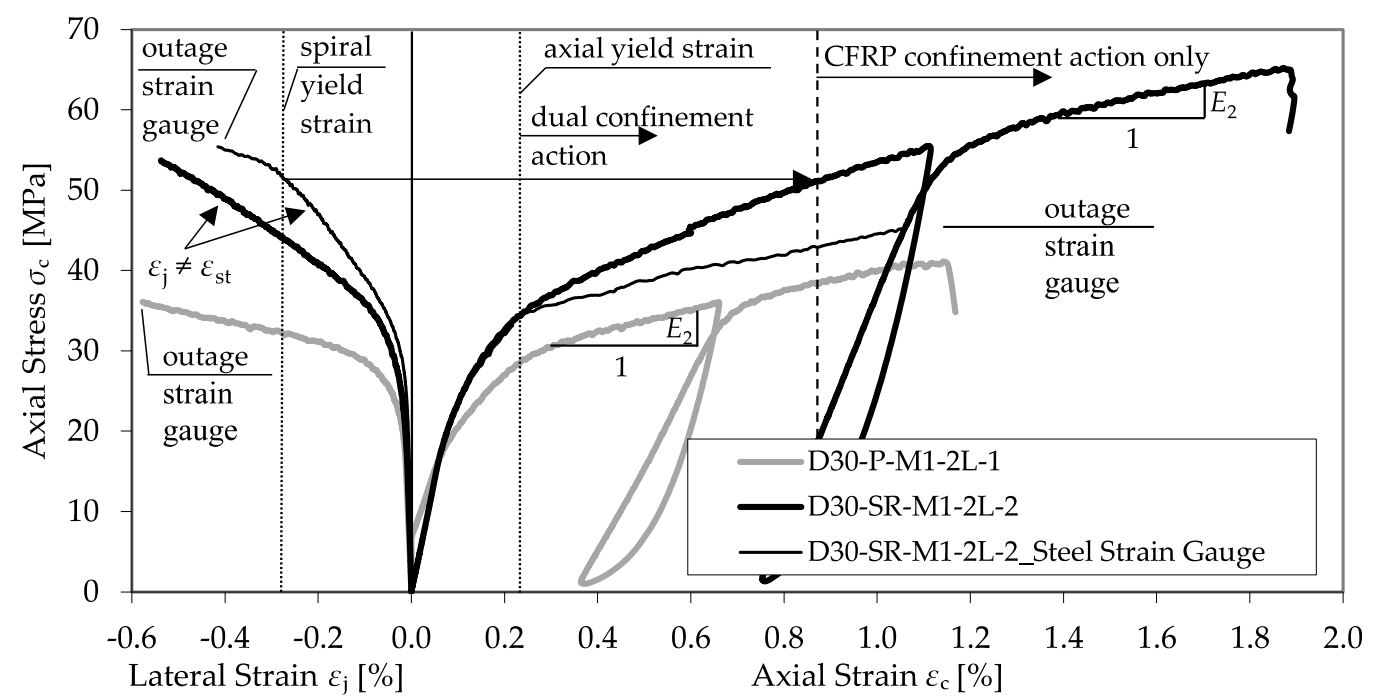

Figure 18. Comparison between a confined concrete specimen (D30-P-M1-2L-1) and an RC specimen (D30-SR-M1-2L-2). 
In addition to the amount of transverse reinforcement, the reinforcement type was varied by the application of normal ties and heavy spirals. A comparison between both reinforcement types is given in Figure 19. Herein, a CFRP-confined specimen of series D25-SR-M1-2L-3 with a diameter of $250 \mathrm{~mm}$ and a spiral $(\varnothing=8 \mathrm{~mm}, s=40 \mathrm{~mm}$ ) was compared to a specimen of series D25-TR-M1-2L-2 with the same diameter and CFRP confinement but with tie reinforcement $(\varnothing=6 \mathrm{~mm}, s=100 \mathrm{~mm})$.

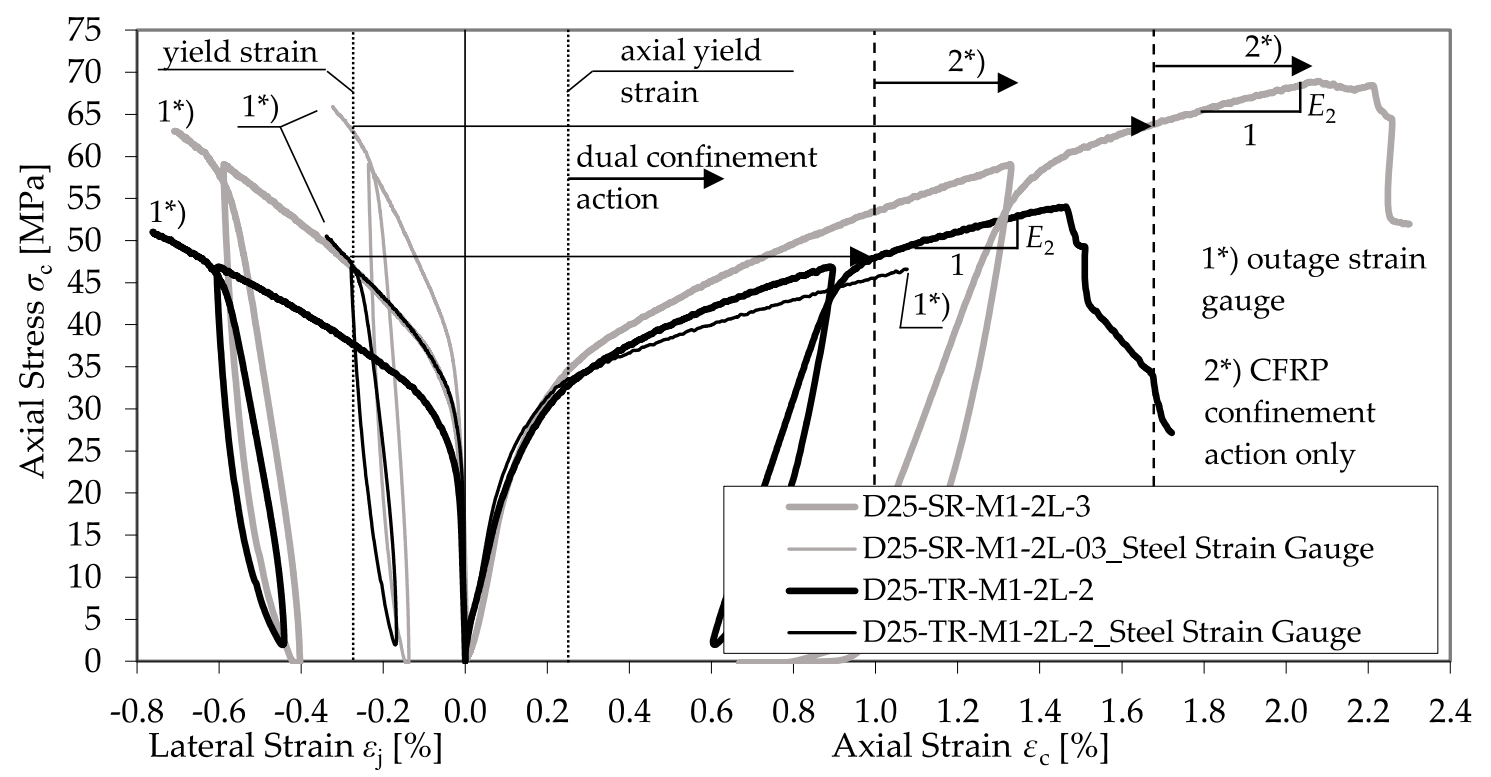

Figure 19. Comparison between a confined spiral-reinforced specimen (D25-SR-M1-2L-3) and a tie RC specimen (D25-TR-M1-2L-2).

The transition zone between the first linear increase and second linear branch, $E_{2}$, of the spiral reinforced specimen is more extended. Until its yielding strength is reached, the spiral reinforcement can activate a significantly higher confinement pressure, leading to a higher $f_{\mathrm{cc}}$ and $\varepsilon_{\mathrm{ccu}}$. However, the $E_{2}$ reached is almost similar. In addition, Figures 18 and 19 reveal a discrepancy between the strain development of the CFRP jacket and the transverse reinforcement. Exceeding the elastic range of the concrete, the strain of the transverse reinforcement $\varepsilon_{\text {st }}$ increased more slowly compared to the CFRP jacket, $\varepsilon_{\mathrm{j}}$. This behavior is contradictory to the assumptions of most material models, e.g., Hu et al. [5] or Eid and Paultre [3]. These models suppose an equal strain distribution of $\varepsilon_{\mathrm{j}}$ and $\varepsilon_{\text {st }}$. Figure 20 shows the deviations in the axial-transverse strain responses and the axial-confinement stress responses for series D30-SR-M1-2L-2. 


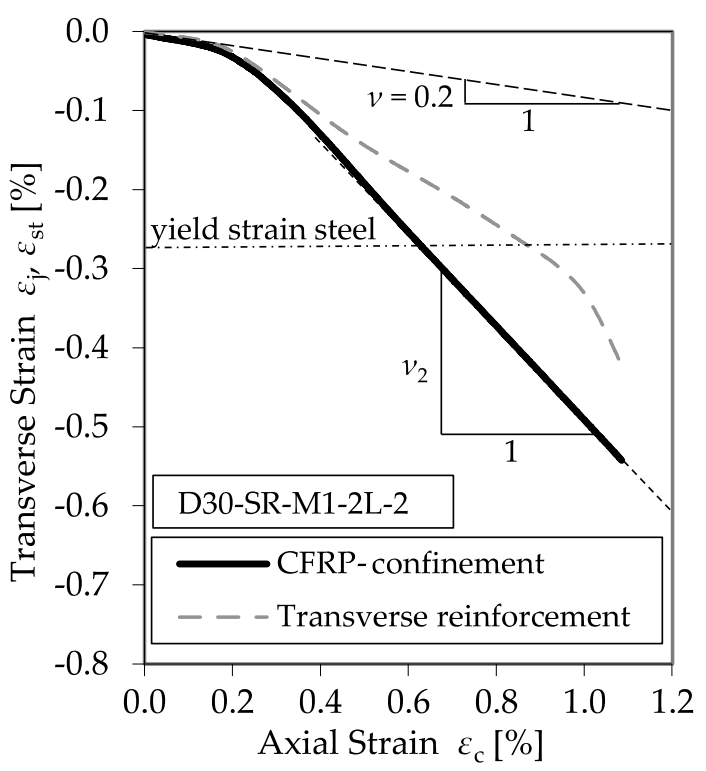

(a)

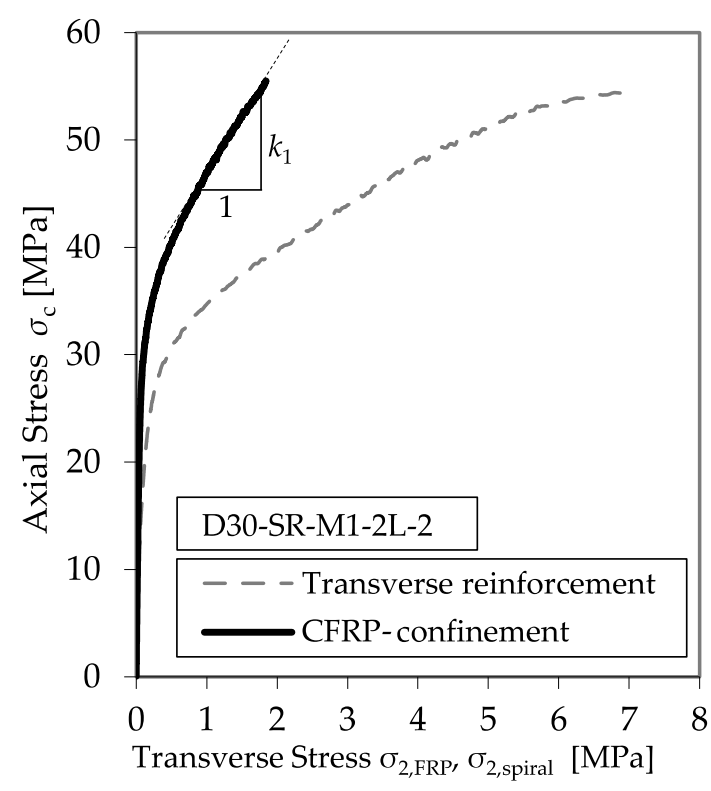

(b)

Figure 20. Typical axial-transverse strain (a) and stress (b) responses of external CFRP confinement and internal transverse reinforcement (specimen D30-SR-M1-2L-2)

\subsection{Impact of the Longitudinal Reinforcement on the CFRP Jacket's Rupture Strain}

Previous investigations on the impact of longitudinal reinforcement on the CFRP jacket's rupture strain, e.g., by Pellegrino and Modena [8] and Bai et al. [45], suppose additional effects of the buckling steel bars on the reduction factor $k_{\varepsilon}$. Niedermeier [33,40] followed this proposal and suggested a mean value $k_{\varepsilon}=0.50$ and a characteristic value $k_{\varepsilon \mathrm{k}}=0.25$. This procedure was adopted by the German Guideline for FRP Strengthening of Concrete Structures by DAfStb [30].

The experimental investigations did not confirm the assumption suggested in [8]. In general, the longitudinal reinforcement had no impact on the ultimate rupture strain of the CFRP jacket. Figure 21 shows a comparison of series D20-TR-M2-2L-3a, D20-TR-M2-2L-3b, and D20-TR-M2-2L-3c. Therein, CFRP-confined specimens with a diameter of $200 \mathrm{~mm}$ and the same tie configuration $(\varnothing=6 \mathrm{~mm}$, $s=100 \mathrm{~mm})$ with a different number of longitudinal reinforcing bars $(\varnothing=12 \mathrm{~mm})$ were compared, showing that the number of bars differed between 4,6 , and 8 . In all cases, approximately the same maximum axial strain, $\varepsilon_{\mathrm{ccu}}$, was reached. A strong impact of the longitudinal reinforcement on $\varepsilon_{\mathrm{ju}}$ should influence the confinement pressure, $f_{1}$; because of this, the diagram on the left of Figure 21 explains the determination of $k_{\varepsilon}$ for the three longitudinal bar configurations by using the proposal of Pellegrino and Modena [8]. As the number of bars increases, $k_{\varepsilon}$ should decrease and, therefore, reduce $\varepsilon_{\text {ccu }}$; however, the tests could not confirm these assumptions.

In conclusion, the reduction factor $k_{\varepsilon}$ remains constant independent of the applied longitudinal reinforcement. Low reduction values such as $k_{\varepsilon \mathrm{k}}=0.25$ are highly conservative and may provoke an unnecessary loss of load-bearing capacity. 


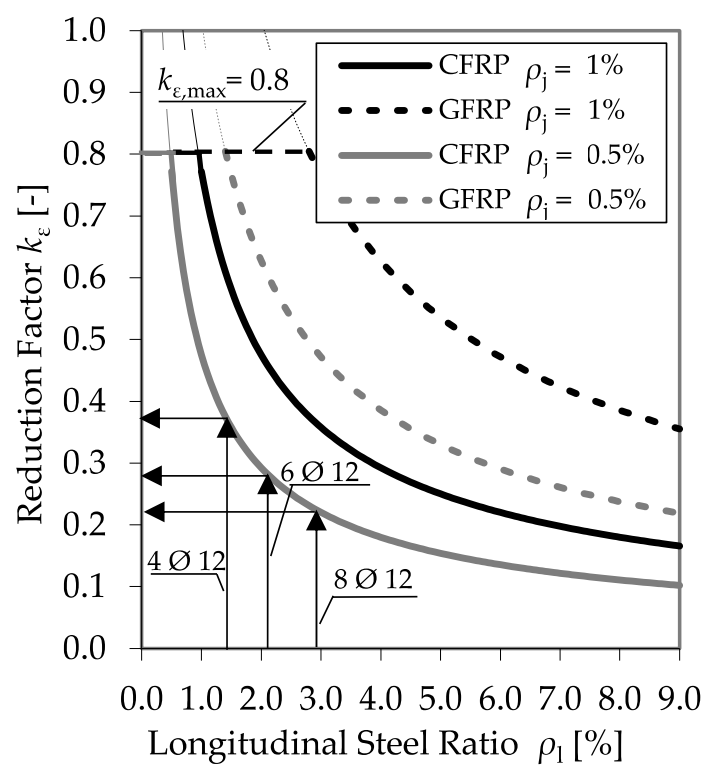

(a)

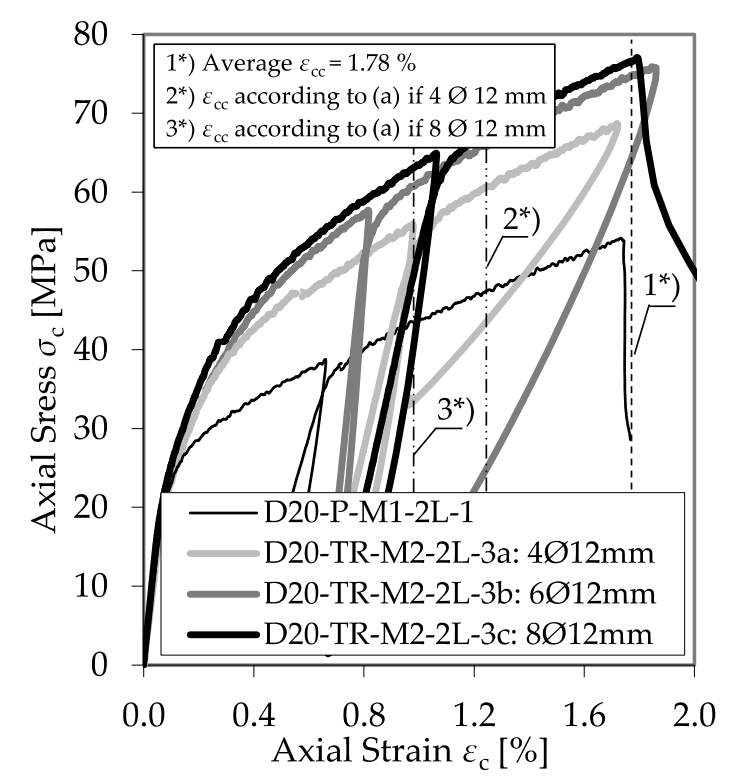

(b)

Figure 21. Proposal of Pellegrino and Modena [8] concerning $k_{\varepsilon}(\mathbf{a})$ and a comparison between confined $\mathrm{RC}$ specimens with different numbers of longitudinal bars $(\mathbf{b})$.

\section{Implementation of the Experimental Results from the Literature}

\subsection{Included Experimental Programs}

The obtained test database was enlarged with the test results of Eid et al. [4], Xiao and Wu [13], Lee et al. [46], Matthys et al. [47], Lam and Teng [48,49] and Ilki et al. [50]. The sufficient documentation, including all geometrical and mechanical parameters needed for analysis, was the main reason for the specific selection. Furthermore, the listed experimental programs provide an adequate variation in initial concrete strengths and properties of the used CFRP composites. In addition, the investigations contained several CFRP-confined RC specimens and large-scaled tests. Table 13 specifies the general properties of the used materials for those experiments.

Table 13. Included experimental programs from the literature.

\begin{tabular}{|c|c|c|c|c|}
\hline \multicolumn{3}{|c|}{ Authors } & \multirow{2}{*}{$\begin{array}{c}\text { Used Materials } \\
\text { CFRP 1: } \\
E_{\mathrm{j}}=96 \mathrm{GPa}, \varepsilon_{\mathrm{FRP}}=1.64 \%, t_{\mathrm{j}, \mathrm{n}=1}=0.39 \mathrm{~mm} \\
\text { CFRP 2: } \\
E_{\mathrm{j}}=78 \mathrm{GPa}, \varepsilon_{\mathrm{FRP}}=1.59 \%, t_{\mathrm{j}, \mathrm{n}=1}=0.56 \mathrm{~mm}\end{array}$} & \multirow{2}{*}{$\begin{array}{c}\text { Number of Specimens }^{1} \\
14(\mathrm{U}), \\
42(\mathrm{U}) k_{1} \text { and } v_{2} \text { analysis } \\
\text { only }\end{array}$} \\
\hline Xiao and $\mathrm{Wu}$ & (2003) & [13] & & \\
\hline Lee et al. & (2004) & {$[46]$} & $\begin{array}{c}\text { CFRP: } \\
E_{\mathrm{j}}=250 \mathrm{GPa}, \varepsilon_{\mathrm{FRP}}=1.80 \%, t_{\mathrm{j}, \mathrm{n}=1}=0.11 \mathrm{~mm} \\
\text { Spiral Reinforcement: } \\
f_{\mathrm{y}}=1200 \mathrm{MPa}, D_{\mathrm{c}}=130 \mathrm{~mm} \\
\text { No Longitudinal Reinforcement }\end{array}$ & $\begin{array}{l}5(\mathrm{U}) \\
15(\mathrm{R})\end{array}$ \\
\hline Matthys et al. & (2005) & {$[47]$} & $\begin{array}{c}\text { CFRP } 1(\mathrm{C} 240): \\
E_{\mathrm{j}}=198 \mathrm{GPa}, \varepsilon_{\mathrm{FRP}}=1.31 \% \\
\text { CFRP } 2(\mathrm{C} 640): \\
E_{\mathrm{j}}=480 \mathrm{GPa}, \varepsilon_{\mathrm{FRP}}=0.23 \% \\
\text { GFRP }(\mathrm{TU} 600 / 25): \\
E_{\mathrm{j}}=60 \mathrm{GPa}, \varepsilon_{\mathrm{FRP}}=1.30 \% \\
\text { Hybrid }(\mathrm{TU} 360 \mathrm{G} 160 \mathrm{C} / 27 \mathrm{G}): \\
E_{\mathrm{j}}=120 \mathrm{GPa}, \varepsilon_{\mathrm{FRP}}=0.92 \% \\
\text { Transverse Reinforcement: } \\
f_{\mathrm{y}}=560 \mathrm{MPa}, D_{\mathrm{c}}=370 \mathrm{~mm} \\
\text { Longitudinal Reinforcement: } \\
f_{\mathrm{y}}=620 \mathrm{MPa}, n=10, \varnothing=12 \mathrm{~mm}\end{array}$ & $5(\mathrm{R})$ \\
\hline
\end{tabular}


Table 13. Cont.

\begin{tabular}{|c|c|c|c|c|}
\hline & Authors & & Used Materials & Number of Specimens ${ }^{1}$ \\
\hline Lam et al. & $(2004 / 2006)$ & {$[48,49]$} & $\begin{array}{c}\text { CFRP }(\mathrm{C}): \\
E_{\mathrm{j}}=230 \mathrm{GPa}, \varepsilon_{\mathrm{FRP}}=1.49 \%, t_{\mathrm{j}, \mathrm{n}=1}=0.165 \mathrm{~mm} \\
\operatorname{GFRP}(\mathrm{G}): \\
E_{\mathrm{j}}=22 \mathrm{GPa}, \varepsilon_{\mathrm{FRP}}=2.00 \%, t_{\mathrm{j}, \mathrm{n}=1}=1.27 \mathrm{~mm}\end{array}$ & $18(\mathrm{U})$ \\
\hline Ilki et al. & (2008) & [50] & $\begin{array}{c}\text { CFRP: } \\
E_{\mathrm{j}}=230 \mathrm{GPa}, \varepsilon_{\mathrm{FRP}}=1.50 \%, t_{\mathrm{j}, \mathrm{n}=1}=0.165 \mathrm{~mm} \\
\text { Transverse Reinforcement: } \\
f_{\mathrm{y}}=476 \mathrm{MPa}, D_{\mathrm{c}}=200 \mathrm{~mm} \\
\text { Longitudinal Reinforcement: } \\
f_{\mathrm{y}}=367 \mathrm{MPa}, n=6, \varnothing=10 \mathrm{~mm}\end{array}$ & $4(\mathrm{R})$ \\
\hline Eid et al. & (2009) & [4] & $\begin{array}{c}\text { CFRP: } \\
E_{\mathrm{j}}=78 \mathrm{GPa}, \varepsilon_{\mathrm{FRP}}=1.35 \%, t_{\mathrm{j}, \mathrm{n}=1}=0.38 \mathrm{~mm} \\
\text { Transverse Reinforcement: } \\
f_{\mathrm{y}}=456 \mathrm{MPa}, D_{\mathrm{c}}=253 \mathrm{~mm} \\
\text { Longitudinal Reinforcement: } \\
f_{\mathrm{y}}=423 \mathrm{MPa}, n=6, \varnothing=16 \mathrm{~mm}\end{array}$ & $\begin{array}{c}36(\mathrm{U}), \\
15(\mathrm{R})\end{array}$ \\
\hline
\end{tabular}

${ }^{1} \mathrm{U}$, unreinforced specimens; $\mathrm{R}$, reinforced specimens.

The implemented databases enabled the consideration of different FRP materials (particularly different $E_{\mathrm{j}}$ ), concrete mixtures with variable unconfined concrete strengths (until a high-performance area $>100 \mathrm{MPa}$ ), and different reinforcement approaches. In Tables 14 and 15, the collected test data regarding CFRP-confined plain and reinforced concrete specimens were collated.

Table 14. Summarized results regarding the tests of the CFRP-confined plain concrete specimens.

\begin{tabular}{|c|c|c|c|c|c|c|c|c|c|c|c|}
\hline Series & Specimens & $\begin{array}{c}D \\
{[\mathrm{~mm}]}\end{array}$ & $\begin{array}{c}f_{\mathrm{c} 0} \\
{[\mathrm{MPa}]}\end{array}$ & $\begin{array}{c}t_{\mathrm{j}} \\
{[\mathrm{mm}]}\end{array}$ & $\begin{array}{c}f_{1 \mathrm{j}} \\
\text { [MPa] }\end{array}$ & $\begin{array}{c}f_{\mathrm{cc}} \\
{[\mathrm{MPa}]}\end{array}$ & $\begin{array}{l}\mathcal{E}_{\mathrm{ccu}} \\
{[\%]}\end{array}$ & $\begin{array}{c}E_{2, \mathrm{t}} \\
{[\mathrm{MPa}]}\end{array}$ & $\begin{array}{l}k_{\varepsilon} \\
{[-]}\end{array}$ & $\begin{array}{l}k_{1} \\
{[-]}\end{array}$ & $\begin{array}{l}v_{2} \\
{[-]}\end{array}$ \\
\hline \multicolumn{12}{|c|}{ Xiao and $\mathrm{Wu}(2003)$ [13] } \\
\hline \multirow{5}{*}{ CFRP1-1L } & 1 & \multirow{5}{*}{152} & \multirow{5}{*}{33.7} & & \multirow{4}{*}{4.68} & 48.0 & 1.35 & 1250 & 0.58 & - & - \\
\hline & 2 & & & \multirow{3}{*}{0.39} & & 50.0 & 1.24 & 1417 & 0.70 & - & - \\
\hline & 3 & & & & & 50.0 & 1.40 & 1583 & 0.61 & - & - \\
\hline & Mean: & & & & & 49.3 & 1.33 & 1417 & 0.63 & - & - \\
\hline & 1 & & & & & 64.0 & 1.64 & 3167 & 0.55 & - & - \\
\hline \multirow{3}{*}{ CFRP1-2L } & 2 & \multirow{2}{*}{152} & \multirow{2}{*}{33.7} & \multirow{2}{*}{0.78} & \multirow{2}{*}{9.35} & 72.0 & 2.17 & 3300 & 0.61 & - & - \\
\hline & 3 & & & & & 75.0 & 2.25 & 3750 & 0.61 & - & - \\
\hline & Mean: & & & & & 70.3 & 2.02 & 3406 & 0.59 & - & - \\
\hline \multirow{5}{*}{ CFRP1-3L } & 1 & \multirow{5}{*}{152} & \multirow{5}{*}{33.7} & \multirow{5}{*}{1.17} & \multirow{4}{*}{14.03} & 83.0 & 2.48 & 5333 & 0.50 & - & - \\
\hline & 2 & & & & & 87.0 & 2.45 & 6000 & 0.49 & - & - \\
\hline & 3 & & & & & 95.5 & 3.00 & 6500 & 0.55 & - & - \\
\hline & Mean: & & & & & 88.5 & 2.64 & 5944 & 0.51 & - & - \\
\hline & 1 & & & & & 52.0 & 0.65 & 900 & 0.47 & - & - \\
\hline \multirow{3}{*}{ CFRP2-1L } & 2 & \multirow{2}{*}{152} & \multirow{2}{*}{43.6} & \multirow{2}{*}{0.56} & \multirow{2}{*}{4.22} & 54.5 & 0.78 & 1000 & 0.48 & - & - \\
\hline & 3 & & & & & - & - & - & - & - & - \\
\hline & Mean: & & & & & 53.25 & 0.72 & 950 & 0.48 & - & - \\
\hline \multirow{4}{*}{ CFRP2-1,5L } & 1 & \multirow{4}{*}{152} & \multirow{4}{*}{43.6} & \multirow{4}{*}{0.84} & \multirow{4}{*}{6.33} & 67.8 & 1.13 & 3150 & 0.45 & - & - \\
\hline & 2 & & & & & 72.5 & 1.24 & 3350 & 0.41 & - & - \\
\hline & 3 & & & & & 76.0 & 1.37 & 3760 & 0.50 & - & - \\
\hline & Mean: & & & & & 72.1 & 1.25 & 3420 & 0.45 & - & - \\
\hline \multicolumn{12}{|c|}{ Lee et al. (2004) [46] } \\
\hline \multirow{5}{*}{$\mathrm{SOF}$} & 1 & \multirow{5}{*}{150} & & 0.11 & 4.05 & 41.7 & 1.00 & 517 & 0.64 & 1.41 & - \\
\hline & 2 & & & 0.22 & 8.10 & 57.8 & 1.50 & 2381 & 0.51 & 3.25 & 0.67 \\
\hline & 3 & & 36.2 & 0.33 & 12.14 & 69.1 & 2.00 & 3311 & 0.55 & 3.01 & 0.47 \\
\hline & 4 & & & 0.44 & 16.19 & 85.4 & 2.70 & 3854 & 0.69 & 2.63 & 0.54 \\
\hline & 5 & & & 0.55 & 20.24 & 104.3 & 3.10 & 5477 & 0.67 & 2.99 & 0.38 \\
\hline
\end{tabular}


Table 14. Cont.

\begin{tabular}{|c|c|c|c|c|c|c|c|c|c|c|c|}
\hline Series & Specimens & $\begin{array}{c}D \\
{[\mathrm{~mm}]}\end{array}$ & $\begin{array}{c}f_{\mathrm{c} 0} \\
{[\mathrm{MPa}]}\end{array}$ & $\begin{array}{c}t_{\mathrm{j}} \\
{[\mathrm{mm}]}\end{array}$ & $\begin{array}{c}f_{1 \mathrm{j}} \\
{[\mathrm{MPa}]}\end{array}$ & $\begin{array}{c}f_{\mathrm{cc}} \\
{[\mathrm{MPa}]}\end{array}$ & $\begin{array}{l}\varepsilon_{\mathrm{ccu}} \\
{[\%]}\end{array}$ & $\begin{array}{c}E_{2, \mathrm{t}} \\
{[\mathrm{MPa}]}\end{array}$ & $\begin{array}{l}k_{\varepsilon} \\
{[-]}\end{array}$ & $\begin{array}{l}k_{1} \\
{[-]}\end{array}$ & $\begin{array}{l}v_{2} \\
{[-]}\end{array}$ \\
\hline \multicolumn{12}{|c|}{ Lam et al. $(2004 / 2006)[48,49]$} \\
\hline \multirow{5}{*}{$\mathrm{C} 1$} & 1 & \multirow{4}{*}{152} & \multirow{4}{*}{35.9} & & \multirow{4}{*}{4.88} & 50.4 & 1.27 & 1375 & 0.65 & 2.75 & 0.91 \\
\hline & 2 & & & \multirow{3}{*}{0.165} & & 47.2 & 1.11 & 1375 & 0.67 & 2.75 & 1.09 \\
\hline & 3 & & & & & 53.2 & 1.29 & 1813 & 0.77 & 3.63 & 0.83 \\
\hline & Mean: & & & & & 50.3 & 1.22 & 1521 & 0.70 & 3.04 & 0.94 \\
\hline & 1 & \multirow{3}{*}{152} & \multirow{3}{*}{35.9} & \multirow{3}{*}{0.330} & \multirow{3}{*}{9.76} & 68.7 & 1.68 & 3125 & 0.67 & 3.13 & 0.53 \\
\hline \multirow{4}{*}{ C2 } & 2 & & & & & 69.9 & 1.96 & 3125 & 0.65 & 3.13 & 0.54 \\
\hline & 3 & & & & & 71.6 & 1.85 & 3438 & 0.69 & 3.44 & 0.55 \\
\hline & Mean: & & & & & 70.1 & 1.83 & 3229 & 0.67 & 3.23 & 0.54 \\
\hline & 1 & \multirow{4}{*}{152} & \multirow{4}{*}{34.3} & & & 82.6 & 2.05 & 5625 & 0.54 & 3.75 & 0.38 \\
\hline \multirow{3}{*}{ C3 } & 2 & & & 0495 & 1464 & 90.4 & 2.41 & 5363 & 0.61 & 3.58 & 0.42 \\
\hline & 3 & & & 0.495 & 14.64 & 97.3 & 2.52 & 5938 & 0.66 & 3.96 & 0.40 \\
\hline & Mean: & & & & & 90.1 & 2.33 & 5642 & 0.60 & 3,76 & 0.40 \\
\hline & 1 & & & & & 56.2 & - & - & - & - & - \\
\hline G1 & 2 & 152 & 385 & & & 51.9 & 1.32 & 800 & 0.71 & 2.41 & 1.25 \\
\hline & 3 & 152 & 38.5 & 1.27 & 6.36 & 58.3 & 1.46 & 900 & 0.96 & 2.13 & 1.33 \\
\hline & Mean: & & & & & 55.5 & 1.39 & 850 & 0.84 & 2.27 & 1.29 \\
\hline & 1 & & & & & 75.7 & 2.46 & 2000 & 0.83 & 2.66 & 0.95 \\
\hline & 2 & & & & & 77.3 & 2.19 & 2227 & 0.88 & 2.97 & 0.89 \\
\hline G2 & 3 & 152 & 38.5 & 2.54 & 12.72 & 75.2 & - & - & - & - & - \\
\hline & Mean: & & & & & 76.1 & 2.32 & 2114 & 0.86 & 2.82 & 0.92 \\
\hline & 1 & & & & & 76.8 & 1.91 & - & - & - & - \\
\hline & 2 & & & & & 79.1 & 2.08 & - & - & - & - \\
\hline Cा1-M & 3 & 152 & 38.9 & 0.33 & 9.76 & 65.8 & 1.25 & - & - & - & - \\
\hline & Mean: & & & & & 73.9 & 1.75 & - & - & - & - \\
\hline & & & & Eid & al. (200 & ) [4] & & & & & \\
\hline & 1 & & & & & 39.0 & 1.00 & 1000 & 0.60 & 2.56 & 0.80 \\
\hline & 2 & & & & & 41.0 & 1.08 & 1083 & 0.62 & 2.77 & 0.92 \\
\hline $\mathrm{N} 1$ & 3 & 152 & 32.1 & 0.381 & 3.83 & 41.0 & 1.08 & 1083 & 0.62 & 2.77 & 0.92 \\
\hline & Mean: & & & & & 40.3 & 1.05 & 1055 & 0.61 & 2.70 & 0.88 \\
\hline & 1 & & & & & 58.0 & 2.00 & 2617 & 0.74 & 3.35 & 0.48 \\
\hline N2 & 2 & 152 & 321 & 0762 & 765 & 57.5 & 1.79 & 2500 & 0.67 & 3.20 & 0.50 \\
\hline $\mathrm{N} 2$ & 3 & 152 & 32.1 & 0.162 & 7.63 & 57.5 & 1.79 & 2583 & 0.69 & 3.30 & 0.51 \\
\hline & Mean: & & & & & 57.7 & 1.86 & 2567 & 0.70 & 3.28 & 0.50 \\
\hline & 1 & & & & & 72.5 & 2.23 & 4333 & 0.63 & 3.69 & 0.39 \\
\hline & 2 & & & & & 75.0 & 2.32 & 4417 & 0.65 & 3.77 & 0.40 \\
\hline N3 & 3 & 152 & 33.6 & 1.143 & 11.48 & 77.0 & 2.43 & 4583 & 0.65 & 3.91 & 0.40 \\
\hline & Mean: & & & & & 74.8 & 2.33 & 4444 & 0.64 & 3.79 & 0.40 \\
\hline & 1 & & & & & 57.0 & 0.62 & 500 & 0.58 & 1.28 & - \\
\hline M1 & 2 & 152 & & 0381 & 383 & 60.5 & 0.66 & 500 & 0.66 & 1.28 & 1.75 \\
\hline MI & 3 & 152 & 48.0 & 0.381 & 3.83 & 62.0 & 0.78 & 700 & 0.63 & 1.79 & 1.79 \\
\hline & Mean: & & & & & 59.8 & 0.69 & 567 & 0.62 & 1.45 & 1.77 \\
\hline & 1 & & & & & 79.5 & 1.23 & 2050 & 0.82 & 2.62 & 1.10 \\
\hline M2 & 2 & 152 & & 0762 & 765 & 79.5 & 1.23 & 2050 & 0.82 & 2.62 & 1.14 \\
\hline M2 & 3 & 152 & 48.0 & 0.762 & 7.65 & 81.0 & 1.18 & 2500 & 0.98 & 3.20 & 1.03 \\
\hline & Mean: & & & & & 80.0 & 1.21 & 2200 & 0.87 & 2.81 & 1.09 \\
\hline & 1 & & & & & 97.0 & 1.48 & 3200 & 0.88 & 2.73 & 0.94 \\
\hline M3 & 2 & & & & & 101.0 & 1.60 & 3200 & 1.06 & 2.73 & 1.04 \\
\hline M3 & 3 & 152 & 48.0 & 1.143 & 11.48 & 102.0 & 1.70 & 3200 & 1.06 & 2.73 & 1.07 \\
\hline & Mean: & & & & & 100.0 & 1.59 & 3200 & 1.00 & 2.73 & 1.02 \\
\hline & 1 & & & & & 57.5 & 0.63 & - & 0.59 & - & - \\
\hline & 2 & & & & & 61.5 & 0.67 & - & 0.73 & - & - \\
\hline H11 & 3 & 152 & 67.7 & 0.381 & 3.83 & 66.0 & 0.69 & - & 0.77 & - & - \\
\hline & Mean: & & & & & 61.7 & 0.66 & - & 0.70 & - & - \\
\hline & 1 & & & & & 72.5 & 0.89 & - & 0.71 & - & - \\
\hline & 2 & & & & & 83.0 & 1.08 & 417 & 0.91 & 0.53 & 1.90 \\
\hline H12 & 3 & 152 & 67.7 & 0.762 & 7.65 & 84.0 & 1.14 & 667 & 1.00 & 0.85 & 1.44 \\
\hline & Mean: & & & & & 79.8 & 1.04 & 542 & 0.87 & 0.69 & 1.67 \\
\hline
\end{tabular}


Table 14. Cont.

\begin{tabular}{|c|c|c|c|c|c|c|c|c|c|c|c|}
\hline Series & Specimens & $\begin{array}{c}D \\
{[\mathrm{~mm}]}\end{array}$ & $\begin{array}{c}f_{\mathrm{c} 0} \\
{[\mathrm{MPa}]}\end{array}$ & $\begin{array}{c}t_{\mathrm{j}} \\
{[\mathrm{mm}]}\end{array}$ & $\underset{[\mathbf{M P a}]}{f_{1 \mathrm{j}}}$ & $\begin{array}{c}f_{\mathrm{cc}} \\
{[\mathbf{M P a}]}\end{array}$ & $\begin{array}{l}\varepsilon_{\mathrm{ccu}} \\
{[\%]}\end{array}$ & $\begin{array}{c}E_{2, \mathrm{t}} \\
{[\mathrm{MPa}]}\end{array}$ & $\begin{array}{l}k_{\varepsilon} \\
{[-]}\end{array}$ & $\begin{array}{l}k_{1} \\
{[-]}\end{array}$ & $\begin{array}{l}v_{2} \\
{[-]}\end{array}$ \\
\hline \multirow{4}{*}{ H13 } & 1 & \multirow{4}{*}{152} & \multirow{4}{*}{75.9} & \multirow{4}{*}{1.143} & \multirow{4}{*}{11.48} & 89.0 & 1.01 & - & 0.87 & - & - \\
\hline & 2 & & & & & 97.0 & 1.08 & 750 & 0.74 & 0.64 & 1.56 \\
\hline & 3 & & & & & 97.0 & 1.20 & 1083 & 0.89 & 0.92 & 1.19 \\
\hline & Mean: & & & & & 94.3 & 1.10 & 917 & 0.83 & 0.78 & 1.38 \\
\hline \multirow{4}{*}{ H21 } & 1 & \multirow{4}{*}{152} & \multirow{4}{*}{107.7} & \multirow{4}{*}{0.381} & \multirow{4}{*}{3.83} & 91.0 & 0.52 & - & 0.56 & - & - \\
\hline & 2 & & & & & 91.0 & 0.52 & - & 0.56 & - & - \\
\hline & 3 & & & & & 92.5 & 0.54 & - & 0.53 & - & - \\
\hline & Mean: & & & & & 91.5 & 0.53 & - & 0.55 & - & - \\
\hline \multirow{4}{*}{ H22 } & 1 & \multirow{4}{*}{152} & \multirow{4}{*}{107.7} & \multirow{4}{*}{0.762} & \multirow{4}{*}{7.65} & 88.0 & 0.85 & - & 0.81 & - & - \\
\hline & 2 & & & & & 95.5 & 0.73 & - & 0.56 & - & - \\
\hline & 3 & & & & & 105.5 & 0.79 & - & 0.67 & - & - \\
\hline & Mean: & & & & & 96.3 & 0.79 & - & 0.68 & - & - \\
\hline \multirow{4}{*}{$\mathrm{H} 23$} & 1 & \multirow{4}{*}{152} & \multirow{4}{*}{107.7} & \multirow{4}{*}{1.143} & \multirow{4}{*}{11.48} & 105.0 & 1.00 & - & 0.74 & - & - \\
\hline & 2 & & & & & 112.5 & 0.71 & - & 0.53 & - & - \\
\hline & 3 & & & & & 117.0 & 0.88 & - & 0.65 & - & - \\
\hline & Mean: & & & & & 111.5 & 0.86 & - & 0.64 & - & - \\
\hline
\end{tabular}

Table 15. Summarized results regarding the tests of the CFRP-confined RC specimens.

\begin{tabular}{|c|c|c|c|c|c|c|c|c|c|c|}
\hline Series & $\begin{array}{c}D \\
{[\mathrm{~mm}]}\end{array}$ & $\begin{array}{c}f_{\mathrm{c} 0} \\
{[\mathrm{MPa}]}\end{array}$ & $\begin{array}{c}t_{\mathrm{j}} \\
{[\mathrm{mm}]}\end{array}$ & $\begin{array}{c}f_{1 \mathrm{j}} \\
{[\mathrm{MPa}]}\end{array}$ & $\begin{array}{c}s \\
{[\mathrm{~mm}]}\end{array}$ & $\begin{array}{c}\emptyset_{\mathrm{w}} \\
{[\mathrm{mm}]}\end{array}$ & $\begin{array}{l}k_{\mathrm{e}} \\
{[-]}\end{array}$ & $\begin{array}{c}f_{1, \mathrm{wy}} \\
{[\mathrm{MPa}]}\end{array}$ & $\begin{array}{c}f_{\mathrm{cc}} \\
{[\mathrm{MPa}]}\end{array}$ & $\begin{array}{l}\varepsilon_{\mathrm{ccu}} \\
{[\%]}\end{array}$ \\
\hline \multicolumn{11}{|c|}{ Lee et al. (2004) [46] } \\
\hline S6F1 & 150 & 36.2 & 0.110 & 4.05 & 60 & 5.5 & 0.44 & 3.25 & 50.37 & 1.70 \\
\hline S6F2 & 150 & 36.2 & 0.220 & 8.10 & 60 & 5.5 & 0.44 & 3.25 & 68.52 & 2.50 \\
\hline S6F4 & 150 & 36.2 & 0.440 & 16.19 & 60 & 5.5 & 0.44 & 3.25 & 99.49 & 3.40 \\
\hline S6F5 & 150 & 36.2 & 0.550 & 20.24 & 60 & 5.5 & 0.44 & 3.25 & 114.64 & 3.60 \\
\hline S4F1 & 150 & 36.2 & 0.110 & 4.05 & 40 & 5.5 & 0.54 & 5.90 & 60.00 & 1.90 \\
\hline $\mathrm{S} 4 \mathrm{~F} 2$ & 150 & 36.2 & 0.220 & 8.10 & 40 & 5.5 & 0.54 & 5.90 & 74.77 & 2.30 \\
\hline S4F3 & 150 & 36.2 & 0.330 & 12.14 & 40 & 5.5 & 0.54 & 5.90 & 73.85 & 2.90 \\
\hline S4F4 & 150 & 36.2 & 0.440 & 16.19 & 40 & 5.5 & 0.54 & 5.90 & 104.15 & 3.00 \\
\hline S4F5 & 150 & 36.2 & 0.550 & 20.24 & 40 & 5.5 & 0.54 & 5.90 & 123.64 & 3.60 \\
\hline S2F1 & 150 & 36.2 & 0.110 & 4.05 & 20 & 5.5 & 0.64 & 14.04 & 72.87 & 2.20 \\
\hline $\mathrm{S} 2 \mathrm{~F} 2$ & 150 & 36.2 & 0.220 & 8.10 & 20 & 5.5 & 0.64 & 14.04 & 92.68 & 3.60 \\
\hline S2F3 & 150 & 36.2 & 0.330 & 12.14 & 20 & 5.5 & 0.64 & 14.04 & 108.01 & 3.90 \\
\hline $\mathrm{S} 2 \mathrm{~F} 4$ & 150 & 36.2 & 0.440 & 16.19 & 20 & 5.5 & 0.64 & 14.04 & 115.72 & 3.80 \\
\hline S2F5 & 150 & 36.2 & 0.550 & 20.24 & 20 & 5.5 & 0.64 & 14.04 & 150.80 & 4.30 \\
\hline \multicolumn{11}{|c|}{ Matthys et al. (2005) [47] } \\
\hline $\mathrm{K} 2$ & 400 & 34.3 & 0.585 & 4.64 & 140 & 8 & 0.53 & 0.59 & 59.36 & 1.20 \\
\hline K3 & 400 & 34.3 & 0.940 & 5.89 & 140 & 8 & 0.53 & 0.59 & 59.60 & 0.43 \\
\hline K4 & 400 & 39.3 & 1.800 & 4.21 & 140 & 8 & 0.53 & 0.59 & 60.32 & 0.69 \\
\hline K5 & 400 & 39.3 & 0.600 & 1.40 & 140 & 8 & 0.53 & 0.59 & 42.38 & 0.38 \\
\hline K8 & 400 & 39.1 & 0.492 & 1.49 & 140 & 8 & 0.53 & 0.59 & 49.58 & 0.60 \\
\hline \multicolumn{11}{|c|}{ Ilki et al. (2008) [50] } \\
\hline NSR-C-050-3 & 250 & 27.6 & 0.495 & 9.51 & 50 & 8 & 0.45 & 2.22 & 77.59 & 3.40 \\
\hline NSR-C-100-3 & 250 & 27.6 & 0.495 & 9.51 & 100 & 8 & 0.32 & 0.80 & 72.60 & 2.80 \\
\hline NSR-C-145-3 & 250 & 27.6 & 0.495 & 9.51 & 145 & 8 & 0.23 & 0.39 & 71.95 & 3.30 \\
\hline NSR-C-145-5 & 250 & 27.6 & 0.825 & 15.85 & 145 & 8 & 0.23 & 0.39 & 94.45 & 4.50 \\
\hline
\end{tabular}


Table 15. Cont.

\begin{tabular}{ccccccccccc}
\hline Series & $\begin{array}{c}\boldsymbol{D} \\
{[\mathbf{m m}]}\end{array}$ & $\begin{array}{c}f_{\mathbf{c 0}} \\
{[\mathbf{M P a}]}\end{array}$ & $\begin{array}{c}\boldsymbol{t}_{\mathbf{j}} \\
{[\mathbf{m m}]}\end{array}$ & $\begin{array}{c}f_{\mathbf{l j}} \\
{[\mathbf{M P a}]}\end{array}$ & $\begin{array}{c}\boldsymbol{s} \\
{[\mathbf{m m}]}\end{array}$ & $\begin{array}{c}\emptyset_{\mathbf{w}} \\
{[\mathbf{m m}]}\end{array}$ & $\begin{array}{c}k_{\mathbf{e}} \\
{[-]}\end{array}$ & $\begin{array}{c}f_{\mathbf{l , w y}} \\
{[\mathbf{M P a}]}\end{array}$ & $\begin{array}{c}f_{\mathrm{cc}} \\
{[\mathbf{M P a}]}\end{array}$ & $\begin{array}{c}\varepsilon_{\mathbf{c c u}} \\
{[\%]}\end{array}$ \\
\hline A5NP2C & 303 & 29.4 & 0.762 & 3.84 & 150 & 9.5 & 0.31 & 0.72 & 46.13 & 0.63 \\
A3NP2C & 303 & 31.7 & 0.762 & 3.84 & 70 & 9.5 & 0.47 & 2.37 & 60.06 & 1.24 \\
A1NP2C & 303 & 31.7 & 0.762 & 3.84 & 45 & 9.5 & 0.53 & 4.14 & 63.39 & 1.51 \\
C4NP2C & 303 & 31.7 & 0.762 & 3.84 & 100 & 11.3 & 0.40 & 1.51 & 51.37 & 0.77 \\
C4N1P2C & 303 & 36.0 & 0.762 & 3.84 & 100 & 11.3 & 0.40 & 1.51 & 56.87 & 0.84 \\
C4NP4C & 303 & 31.7 & 1.524 & 7.68 & 100 & 11.3 & 0.40 & 1.51 & 75.83 & 2.08 \\
B4NP2C & 303 & 31.7 & 0.762 & 3.84 & 100 & 11.3 & 0.40 & 1.51 & 58.00 & 1.36 \\
C4MP2C & 303 & 50.8 & 0.762 & 3.84 & 100 & 11.3 & 0.40 & 1.51 & 75.36 & 0.88 \\
C2NP2C & 303 & 31.7 & 0.762 & 3.84 & 65 & 11.3 & 0.48 & 2.78 & 55.94 & 1.32 \\
C2N1P2C & 303 & 36.0 & 0.762 & 3.84 & 65 & 11.3 & 0.48 & 2.78 & 62.44 & 1.03 \\
C2N1P4C & 303 & 36.0 & 1.524 & 7.68 & 65 & 11.3 & 0.48 & 2.78 & 75.71 & 1.84 \\
C2N1P2N & 303 & 36.0 & 0.762 & 4.60 & 65 & 11.3 & 0.68 & 3.98 & 75.57 & 1.55 \\
C2MP2C & 303 & 50.8 & 0.762 & 3.84 & 65 & 11.3 & 0.48 & 2.78 & 78.90 & 1.04 \\
C2MP4C & 303 & 50.8 & 1.524 & 7.68 & 65 & 11.3 & 0.48 & 2.78 & 97.94 & 1.64 \\
C2MP2N & 303 & 50.8 & 0.762 & 4.60 & 65 & 11.3 & 0.68 & 3.98 & 62.45 & 1.29 \\
\hline
\end{tabular}

In addition, Table 16 shows the collected data concerning $v_{2}$ and $k_{1}$ from Xiao and $\mathrm{Wu}$ [13].

Table 16. Additional data concerning $v_{2}$ and $k_{1}$.

\begin{tabular}{|c|c|c|c|}
\hline $\begin{array}{c}E_{\mathrm{j} 1} / f_{\mathrm{c} 0} \\
{[-]}\end{array}$ & $\begin{array}{l}v_{2} \\
{[-]}\end{array}$ & $\begin{array}{c}E_{\mathrm{j} 1} / f_{\mathrm{c0}}{ }^{2} \\
{[-]}\end{array}$ & $\begin{array}{l}k_{1} \\
{[-]}\end{array}$ \\
\hline 47.00 & 0.30 & 1.30 & 3.80 \\
\hline 47.00 & 0.35 & 1.30 & 4.00 \\
\hline 47.00 & 0.35 & 1.30 & 4.40 \\
\hline 36.00 & 0.40 & 0.88 & 3.20 \\
\hline 36.00 & 0.42 & 0.88 & 3.40 \\
\hline 36.00 & 0.45 & 0.88 & 4.00 \\
\hline 31.00 & 0.41 & 0.80 & 3.35 \\
\hline 31.00 & 0.42 & 0.80 & 3.75 \\
\hline 31.00 & 0.49 & 0.80 & 4.20 \\
\hline 28.50 & 0.55 & 0.78 & 3.25 \\
\hline 28.50 & 0.61 & 0.78 & 3.80 \\
\hline 28.50 & 0.61 & 0.78 & 3.80 \\
\hline 26.50 & 0.39 & 0.53 & 3.20 \\
\hline 26.50 & 0.44 & 0.53 & 3.50 \\
\hline 26.50 & 0.60 & 0.53 & 3.35 \\
\hline 24.00 & 0.55 & 0.50 & 2.70 \\
\hline 24.00 & 0.61 & 0.50 & 3.00 \\
\hline 24.00 & 0.73 & 0.50 & 3.20 \\
\hline 19.50 & 0.55 & 0.48 & 3.25 \\
\hline 19.50 & 0.60 & 0.48 & 3.25 \\
\hline 19.50 & 0.60 & 0.48 & 3.40 \\
\hline 17.50 & 0.58 & 0.43 & 3.70 \\
\hline 17.50 & 0.65 & 0.43 & 3.90 \\
\hline 17.50 & 0.73 & 0.43 & 4.20 \\
\hline 16.00 & 1.25 & 0.42 & 2.55 \\
\hline 16.00 & 1.30 & 0.42 & 2.75 \\
\hline 16.00 & 1.68 & 0.42 & 3.05 \\
\hline
\end{tabular}


Table 16. Cont.

\begin{tabular}{cccc}
\hline $\begin{array}{c}\boldsymbol{E}_{\mathrm{j} 1} / f_{\mathrm{c} 0} \\
{[-]}\end{array}$ & $\begin{array}{c}\boldsymbol{\nu}_{\mathbf{2}} \\
{[-]}\end{array}$ & $\begin{array}{c}E_{\mathrm{j} 1} / f_{\mathrm{c} \mathbf{c}^{2}} \\
{[-]}\end{array}$ & $\begin{array}{c}\boldsymbol{k}_{\mathbf{1}} \\
{[-]}\end{array}$ \\
\hline 15.50 & 0.75 & 0.31 & 0.45 \\
15.50 & 0.80 & 0.31 & 0.70 \\
15.50 & 0.85 & 0.31 & 1.00 \\
13.00 & 1.34 & 0.30 & 0.45 \\
13.00 & 1.71 & 0.30 & 1.20 \\
13.00 & 1.85 & 0.30 & 2.20 \\
10.50 & 1.45 & 0.28 & -0.95 \\
10.50 & 1.82 & 0.28 & 0.05 \\
8.50 & 1.10 & 0.28 & 1.75 \\
8.50 & 1.42 & 0.25 & 0.30 \\
6.00 & 1.45 & 0.25 & 0.75 \\
6.00 & 2.09 & 0.25 & 0.90 \\
6.00 & 2.45 & 0.16 & -4.30 \\
- & - & 0.16 & -1.00 \\
- & - & 0.16 & 0.65 \\
\hline
\end{tabular}

\subsection{CFRP-Confined Plain Concrete Specimens}

With the collected data, the database could be significantly extended. In Figure 22, the factors $E_{2, t}$ and $v_{2,}$ which are crucial for the description of the stress-strain behavior, are shown as functions of the ratio between the confinement modulus and the unconfined concrete strength. In both cases, the collected data validate the findings described in Section 3.2. Furthermore, the higher diversity of the results allowed for the assessment of a constant design factor, $k_{1}$, to predict $f_{\mathrm{cc}}$. In Figure 23, all of the gathered results concerning $k_{1}$ are presented as a function of the ratio $f_{1} / f_{\mathrm{c} 0}$.

Obviously, no established approach for the prediction of $k_{1}$ can fit the test database, exhibiting a considerable scatter. In conclusion, the design factor $k_{1}$ has to be reflected critically in general. The gathered data indicates an advantage in using the ratio between the confinement pressure and unconfined concrete strength to predict $f_{\mathrm{cc}}$ and $\varepsilon_{\mathrm{ccu}}$, as seen in Figure 24.

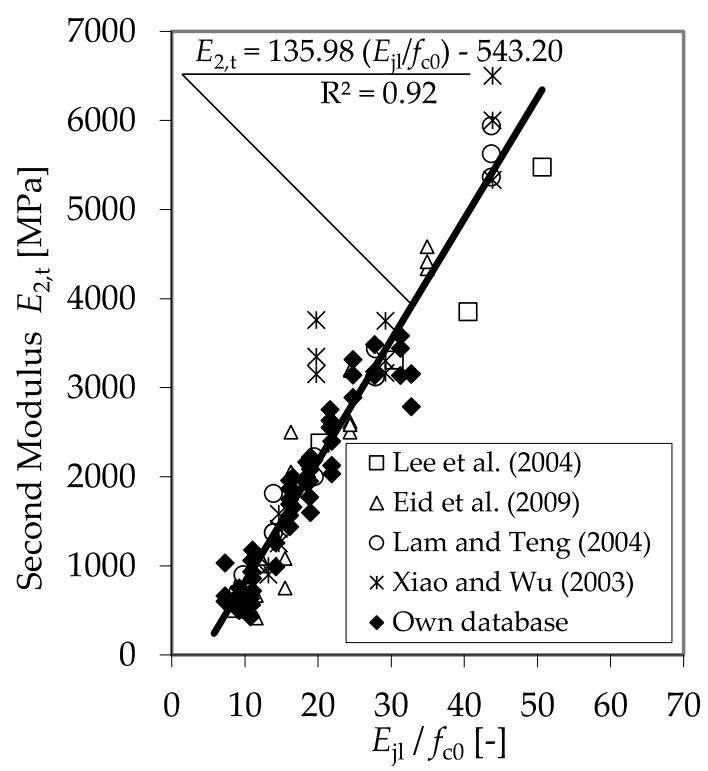

(a)

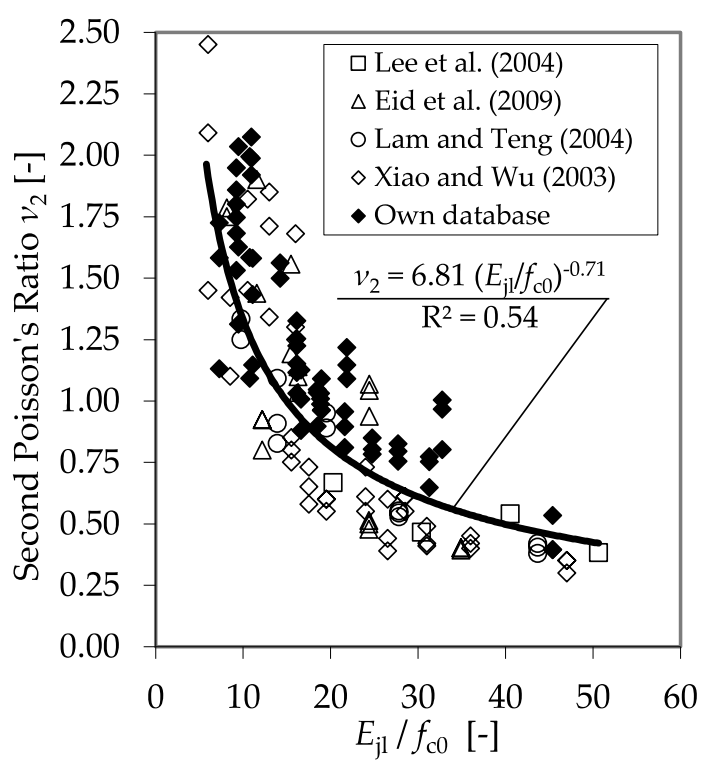

(b)

Figure 22. $E_{2, t}(\mathbf{a})$ and $v_{2}(\mathbf{b})$ as functions of the ratio between the confinement modulus and the unconfined concrete strength including the databases in $[4,13,46,48]$. 


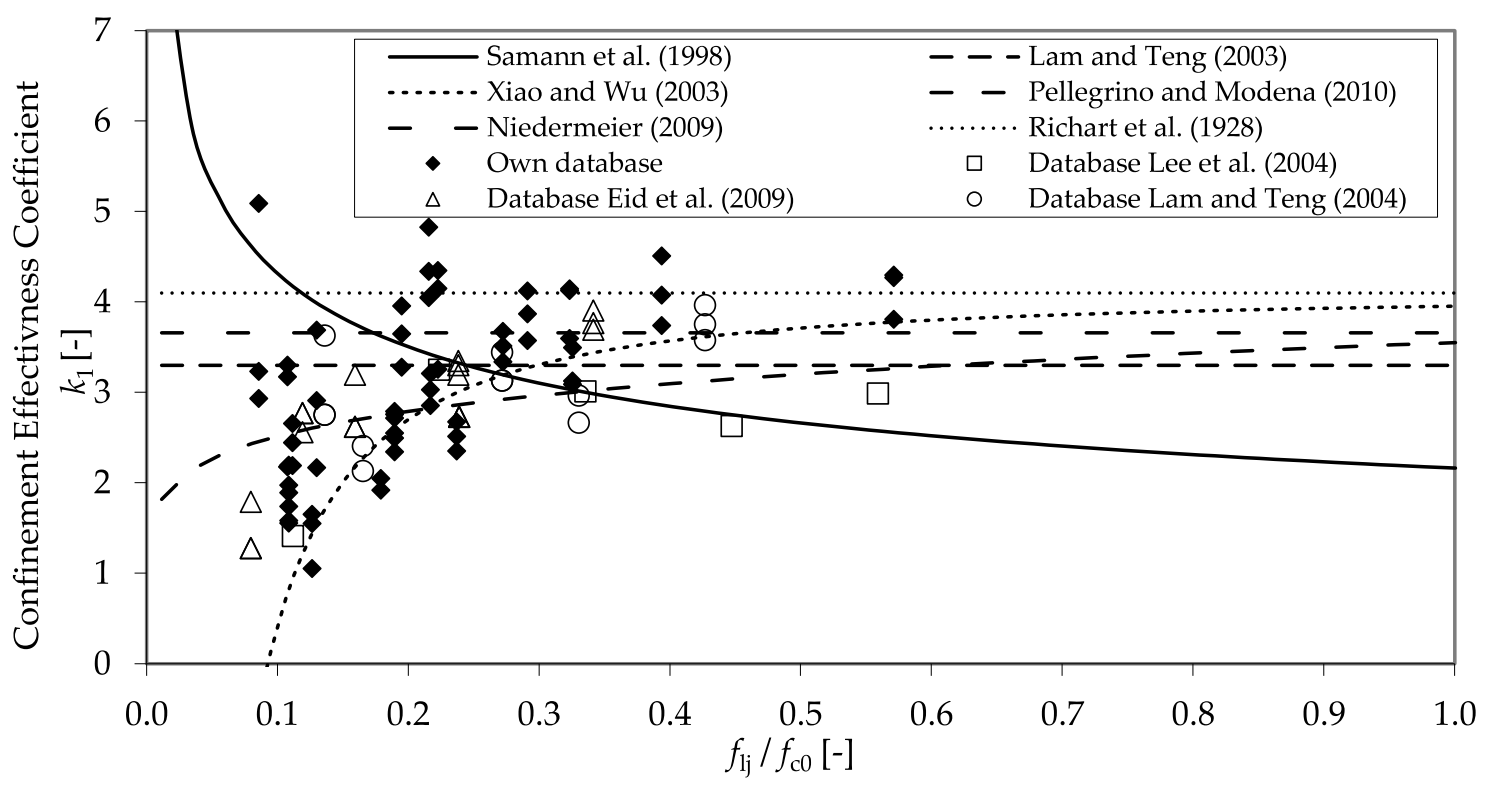

Figure 23. Relationship between factor $k_{1}$ and the ratio between the confinement pressure and the unconfined concrete strength. Comparison of design models in $[6,8,13,31-33]$ with experimental databases including those in $[4,46,48]$.

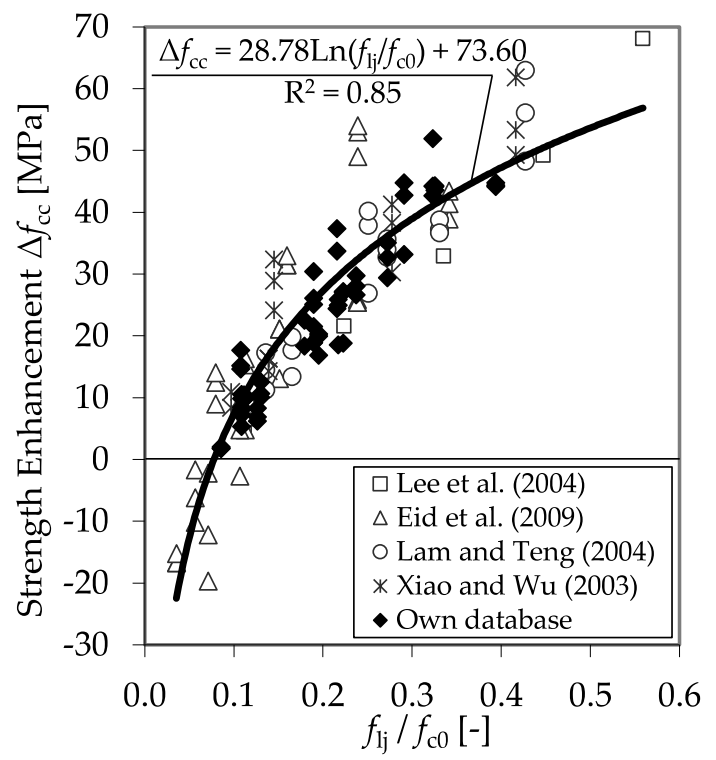

(a)

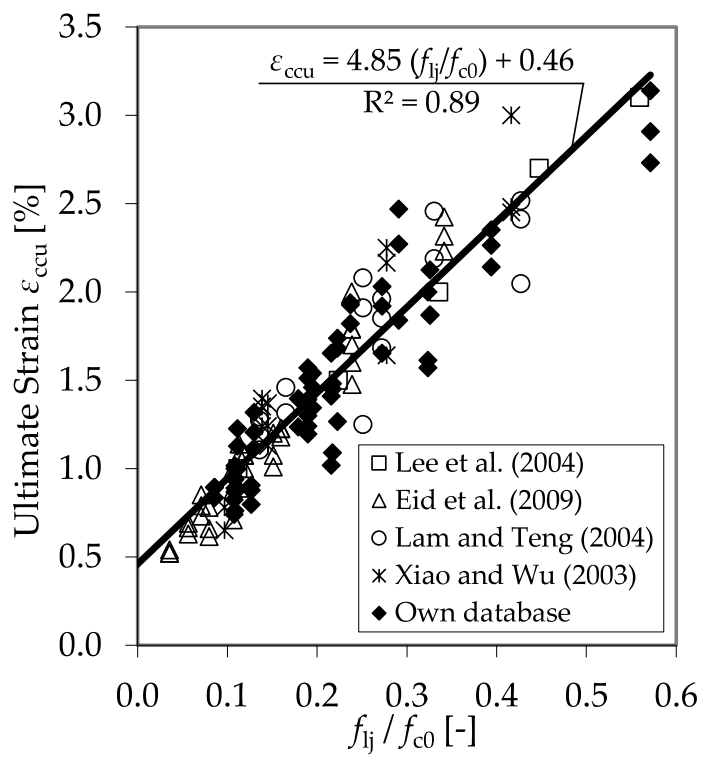

(b)

Figure 24. $f_{\mathrm{cc}}(\mathbf{a})$ and $\varepsilon_{\mathrm{ccu}}(\mathbf{b})$ as functions of the ratio between the confinement pressure and the unconfined concrete strength including the databases in $[4,13,46,48]$.

\subsection{CFRP-Confined Reinforced Concrete Specimens}

Only few references regarding tests with CFRP confined RC specimens offer sufficient and comprehensive data concerning the applied CFRP system, the arrangement and construction of the longitudinal and transverse reinforcement as well as detailed information on the reached $f_{\mathrm{cc}}$ and $\varepsilon_{\mathrm{ccu}}$. However, the considered data sets regarding CFRP confined RC columns only included 39 test results. Nevertheless, combined with the experimental results described in Section 3.4, the gathered database enabled satisfying regressions for the prediction of $f_{\mathrm{cc}}$ and $\varepsilon_{\mathrm{ccu}}$. Figure 25 shows the determined dependency of $\Delta f_{\mathrm{cc}}$ and $\varepsilon_{\mathrm{ccu}}$ on the ratio between the total confinement pressure $f_{1(\mathrm{j}+\mathrm{w})}$ and the unconfined concrete strength $f_{\mathrm{c} 0}$. 


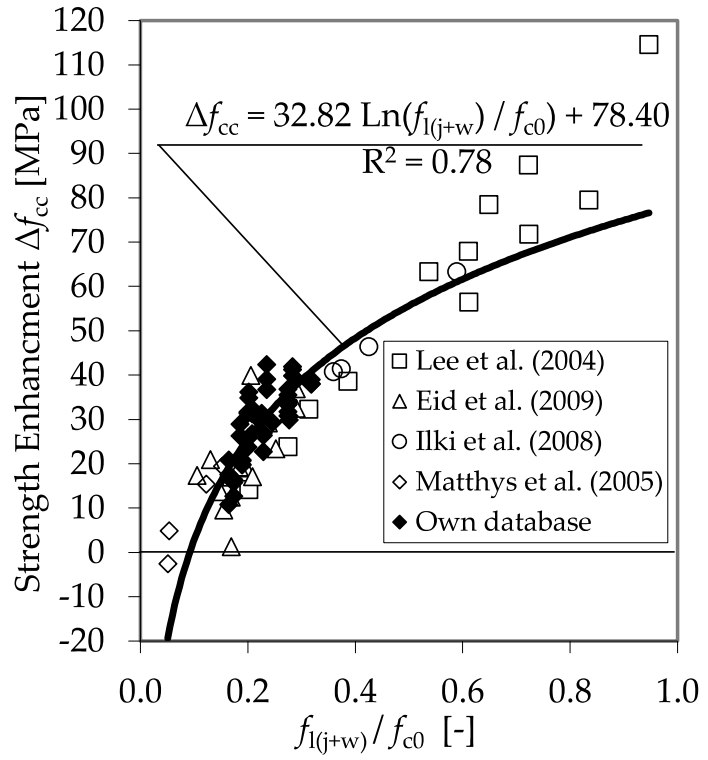

(a)

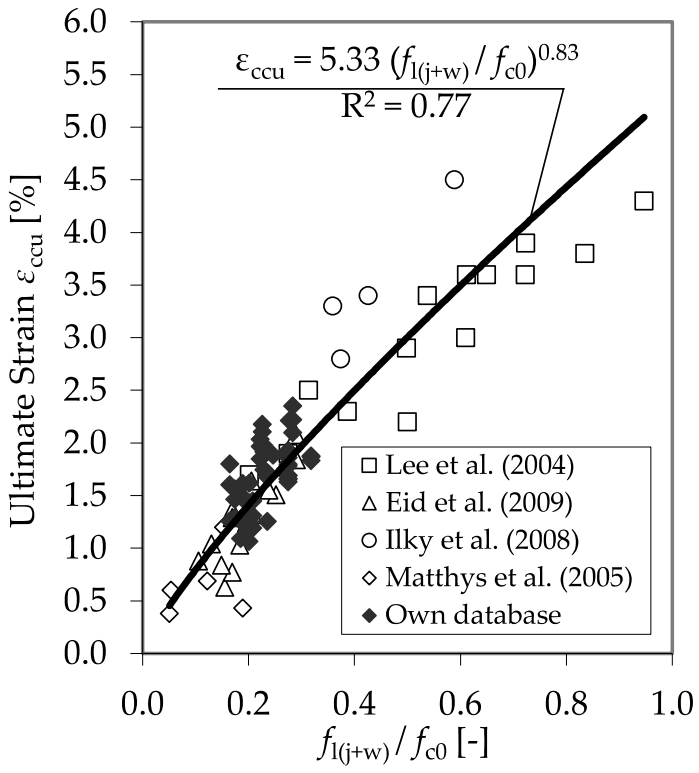

(b)

Figure 25. Strength enhancement $\Delta f_{\mathrm{cc}}(\mathbf{a})$ and maximum strain $\varepsilon_{\mathrm{ccu}}(\mathbf{b})$ as functions of the ratio between $f_{1(j+w)}$ and $f_{\mathrm{c} 0}$ including the databases of $[4,46,47,50]$.

The extent of the tested ratios $f_{1(\mathrm{j}+\mathrm{w})} / f_{\mathrm{c} 0}$ covered by the experimental results could be enlarged to values close to $f_{1(\mathrm{j}+\mathrm{w})} / f_{\mathrm{c} 0}=1.0$. In this case, the confinement pressure exceeded the unconfined concrete strength. The correlations in Figure 25 show the applicability of the ratio between the confinement pressure and the unconfined concrete strength for the description of the behavior of the CFRP-confined RC material.

\section{Model for CFRP-Confined Plain and Reinforced Concrete}

\subsection{Ultimate Concrete Strength and Accompanied Axial Strain}

For an overall evaluation of the achievable ultimate concrete strength, $f_{\mathrm{cc}}$, and strain, $\varepsilon_{\mathrm{ccu}}$, the results of the CFRP-confined plain concrete specimens, as well as the CFRP-confined RC specimens, were considered in a unified regression analysis. The database and the regression results are presented in Figure 26. In conclusion, general equations for the prediction of $f_{\mathrm{cc}}$ and $\varepsilon_{\mathrm{ccu}}$ could be determined as the following,

$$
\begin{gathered}
f_{\mathrm{cc}}=f_{\mathrm{c} 0}+30 \cdot \ln \left(\frac{f_{1(\mathrm{j}+\mathrm{w})}}{f_{\mathrm{c} 0}}\right)+75[\mathrm{MPa}], \\
\varepsilon_{\mathrm{ccu}}=\varepsilon_{\mathrm{c} 0} \cdot 1.75+0.05 \cdot \frac{f_{1(\mathrm{j}+\mathrm{w})}}{f_{\mathrm{c} 0}}[\%] .
\end{gathered}
$$

To allow the implementation of the results in modern limit state design concepts, Equation (10) presents an approach for the calculation of the characteristic strength, $f_{\text {cck }}$ :

$$
f_{\mathrm{cck}}=f_{\mathrm{ck}}+30 \cdot \ln \left(\frac{f_{\mathrm{lk}(j+\mathrm{w})}}{f_{\mathrm{c} 0}}\right)+63 \text { if } 0.75 \geq \frac{f_{\mathrm{lk}(j+\mathrm{w})}}{f_{\mathrm{cc}}} \geq 0.125 \text { with } f_{\mathrm{lk}(j+\mathrm{w})}=E_{\mathrm{jl}} \cdot \varepsilon_{\mathrm{juk}}+\frac{1}{2} \cdot \rho_{\mathrm{st}} \cdot f_{\mathrm{yk}} \cdot k_{\mathrm{e}}[\mathrm{MPa}] .
$$

where $f_{\mathrm{ck}}$ is the characteristic concrete compressive strength, $\varepsilon_{\text {juk }}$ is the characteristic rupture strain of the FRP jacket in the application of confinement $\left(\varepsilon_{\mathrm{juk}}=\varepsilon_{\mathrm{FRP}} \cdot k_{\varepsilon \mathrm{k}}\right)$, and $f_{\mathrm{yk}}$ is the characteristic yield stress of the steel reinforcement.

The limitations ensure that the calculation is within boundaries of the gathered experimental results. 


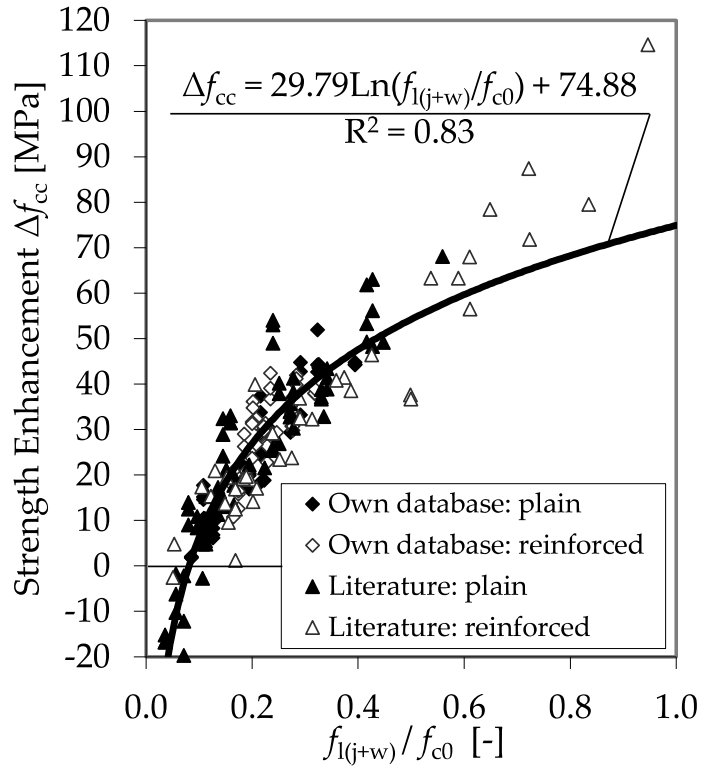

(a)

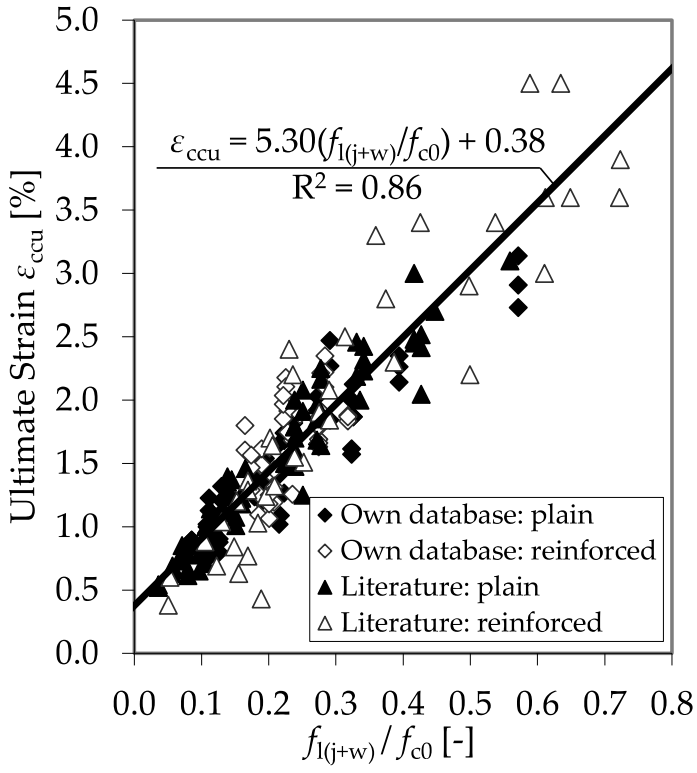

(b)

Figure 26. Strength enhancement (a), $\Delta f_{\mathrm{cc}}$, and maximum strain (b), $\varepsilon_{\mathrm{ccu}}$, as functions of the ratio between $f_{1(\mathrm{j}+\mathrm{w})}$ and $f_{\mathrm{c} 0}$ including the databases in $[4,13,46-50]$ (cf. Tables 14 and 15).

\subsection{Stress-Strain Relationships}

For the design of a stress-strain model, the stress-strain relationships proposed by Lam and Teng [6] (Equation (5)) were adopted. Analysis of the experimental results revealed a significant dependency between the second modulus in the transverse direction, $E_{2, t}$, the second Poison's ratio, $v_{2}$, and the second modulus in the axial direction, $E_{2}$. Therefore, the following equations for the prediction of $E_{2}$ can be proposed,

$$
\begin{gathered}
E_{2, \mathrm{t}}=135 \cdot \frac{E_{\mathrm{jl}}}{f_{\mathrm{c} 0}} 550[\mathrm{MPa}], \\
v_{2}=7 \cdot\left(\frac{E_{\mathrm{jl}}}{f_{\mathrm{c} 0}}\right)^{-0.7}, \\
E_{2}=E_{2, \mathrm{t}} \cdot v_{2} .
\end{gathered}
$$

Furthermore, the transition point between the parabolic curve and the straight-line second portion, $\varepsilon_{\mathrm{t}}$, can be described by the following equations,

$$
\begin{gathered}
f_{\mathrm{c}}^{*}=f_{\mathrm{cc}}-E_{2} \cdot \varepsilon_{\mathrm{ccu}}, \\
\varepsilon_{\mathrm{t}}=\frac{2 \cdot f_{\mathrm{c}}^{*}}{E_{\mathrm{c}}-E_{2}} .
\end{gathered}
$$

Finally, the stress-strain relationship is given as follows,

$$
\sigma_{\mathrm{c}}=\left\{\begin{array}{cl}
E_{\mathrm{c}} \cdot \varepsilon_{\mathrm{c}}-\frac{\left(E_{\mathrm{c}}-E_{2}\right)^{2}}{4 \cdot f_{\mathrm{c}}^{*}} \cdot \varepsilon_{\mathrm{c}}^{2} & \text { if } 0 \leq \varepsilon_{\mathrm{c}} \leq \varepsilon_{\mathrm{t}} \\
f_{\mathrm{c}}^{*}+E_{2} \cdot \varepsilon_{\mathrm{c}} & \text { if } \varepsilon_{\mathrm{t}} \leq \varepsilon_{\mathrm{c}} \leq \varepsilon_{\mathrm{ccu}}
\end{array}\right.
$$

\section{Conclusions}

FRP materials are gaining importance in construction. Especially for strengthening purposes, fiber-reinforced polymers show great potential [51,52]. FRP confinement can significantly increase the strength and ductility of concrete and RC. The present study confirmed the bilinear stress-strain 
model proposed by Lam and Teng [6] for confined plain and reinforced concrete. For enhancement of the ultimate strength and accompanied axial strains, the proposal of Xiao and Wu [13] using the ratio between the confinement modulus, $E_{\mathrm{j} 1}$, and the unconfined concrete strength, $f_{\mathrm{c} 0}$, proved to be the most correlated approach. The effect of a dual confinement on the stress-strain behavior could be explained by the individual confinement pressure provided by the CFRP jacket and the transverse steel reinforcement. Based on the model of Lam and Teng, an approach for the calculation of $f_{\mathrm{cc}}, \varepsilon_{\mathrm{ccu}}$, and $E_{2}$ could be developed. Furthermore, the findings led to additional knowledge concerning the prediction (in accordance with the limit state method) of the CFRP's hoop strain, $\varepsilon_{j u}$, and the related partial factor, $\gamma_{j}$. However, further research efforts are still pending. In particular, the confinement of low-strength concrete, as well as substandard concrete, was not examined in the current study. Furthermore, the effect of particularly high confinement pressures exceeding the unconfined concrete strength has yet not been sufficiently considered.

Author Contributions: Conceptualization, S.K. and K.H.; methodology, S.K.; validation, S.K.; investigation, S.K.; resources, S.K. and D.M.; writing-original draft preparation, S.K. and D.M.; writing-review and editing, S.K., D.M. and K.H.; supervision, K.H. All authors have read and agreed to the published version of the manuscript.

Funding: This research is co-financed by tax revenues on the basis of the budget adopted by the members of the Saxon Parliament (promotion reference: K-7531.20/496-8; SAB No. 100343197 and SAB No. 100119615). The APC was funded by Leipzig University of Applied Sciences.

Conflicts of Interest: The authors declare no conflict of interest.

\section{References}

1. Shahawy, M.; Mirmiran, A.; Beitelmann, T. Tests and modeling of carbon-wrapped concrete columns. Compos. Part B Eng. 2000, 31, 457-480. [CrossRef]

2. Cui, C.; Sheikh, S.A. Analytical Model for Circular Normal- and High-Strength Concrete Columns Confined with FRP. J. Compos. Constr. 2010, 14, 562-572. [CrossRef]

3. Eid, R.; Paultre, P. Analytical Model for FRP-Confined Circular Reinforced Concrete Columns. J. Compos. Constr. 2008, 12, 541-552. [CrossRef]

4. Eid, R.; Roy, N.; Paultre, P. Normal- and High-Strength Concrete Circular Elements Wrapped with FRP Composites. J. Compos. Constr. 2009, 13, 113-124. [CrossRef]

5. Hu, H.; Seracino, R. Analytical Model for FRP-and-Steel-Confined Circular Concrete Columns in Compression. J. Compos. Constr. 2014, 18. [CrossRef]

6. Lam, L.; Teng, J.G. Design-oriented stress-strain model for FRP-confined concrete. Constr. Build. Mat. 2003, 17, 471-489. [CrossRef]

7. Lin, G.; Yu, T.; Teng, J.G. Design-Oriented Stress-Strain Model for Concrete under Combined FRP-Steel Confinement. J. Compos. Constr. 2016, 20. [CrossRef]

8. Pellegrino, C.; Modena, C. Analytical Model for FRP Confinement of Concrete Columns with and without Internal Steel Reinforcement. J. Compos. Constr. 2010, 14, 693-705. [CrossRef]

9. Rousakis, T.C.; Karabinis, A.I. Adequately FRP confined reinforced concrete columns under axial compressive monotonic or cyclic loading. Mater. Struct. 2012, 45, 957-975. [CrossRef]

10. Rousakis, T.C.; Rakitizis, T.D.; Karabinis, A.I. Design-Oriented Strength Model for FRP-Confined Concrete Members. J. Compos. Constr. 2012, 16, 615-625. [CrossRef]

11. Teng, J.G.; Jiang, T.; Lam, L.; Luo, Y.Z. Refinement of a Design-Oriented Stress-Strain Model for FRP-Confined Concrete. J. Compos. Constr. 2009, 13, 269-278. [CrossRef]

12. Teng, J.G.; Lin, G.; Yu, T. Analysis-Oriented Stress-Strain Model for Concrete under Combined FRP-Steel Confinement. J. Compos. Constr. 2015, 19. [CrossRef]

13. Xiao, Y.; Wu, H. Compressive Behavior of Concrete Confined by Various Types of FRP Composite Jackets. J. Reinf. Plast. Compos. 2003, 22, 1187-1201. [CrossRef]

14. Al-Nimry, H.; Neqresh, M. Confinement effects of unidirectional CFRP sheets on axial and bending capacities of square RC columns. Eng. Struct. 2019, 196. [CrossRef]

15. Lin, G.; Teng, J.G. Stress-Strain Model for FRP-Confined Concrete in Eccentrically Loaded Circular Columns. J. Compos. Constr. 2019, 23. [CrossRef] 
16. Giamundo, V.; Lignola, G.P.; Prota, A.; Manfredi, G. Analytical Evaluation of FRP Wrapping Effectiveness in Restraining Reinforcement Bar Buckling. J. Struct. Eng. 2014, 140. [CrossRef]

17. Ferrotto, M.F.; Fischer, O.; Niedermeier, R. Experimental investigation on the compressive behavior of short-term preloaded carbon fiber reinforced polymer-confined concrete columns. Struct. Concr. 2017, 19, 988-1001. [CrossRef]

18. Mirmiran, A.; Shahawy, M.; Samaan, M.; El Echary, H.; Mastrapa, J.C.; Pico, O. Effect of Column Parameters on FRP-Confined Concrete. J. Compos. Constr. 1998, 2, 175-185. [CrossRef]

19. Spoelstra, M.R.; Monti, G. FRP-Confined Concrete Model. J. Compos. Constr. 1999, 3, 143-150. [CrossRef]

20. Jiang, T.; Teng, J.G. Analysis-oriented stress-strain models for FRP-confined concrete. Engineering Structures. 2007, 29, 2968-2986. [CrossRef]

21. Smith, S.T.; Kim, S.J.; Zhang, H. Behavior and Effectiveness of FRP Wrap in the Confinement of Large Concrete Cylinders. J. Compos. Constr. 2010, 14, 573-582. [CrossRef]

22. Meßerer, D.; Käseberg, S.; Weisbrich, M.; Holschemacher, K. Effect of substrate preparation on the load-bearing behaviour of CFRP-confined concrete. Beton- und Stahlbetonbau 2020. (In German) [CrossRef]

23. Lam, L.; Teng, J.G. Design-Oriented Stress-Strain Model for FRP-Confined Concrete in Rectangular Columns. J. Reinf. Plast. Compos. 2003, 22, 1149-1186. [CrossRef]

24. Kaeseberg, S.; Messerer, D.; Holschemacher, K. Assessment of Standards and Codes Dedicated to CFRP Confinement of RC Columns. Materials 2019, 12, 390. [CrossRef] [PubMed]

25. Kaeseberg, S.; Messerer, D.; Holschemacher, K. Comparison of standards and design guidelines for CFRP confinement of RC columns. In Proceedings of the 7th Asia-Pacific Conference on FRP in Structures (APFIS 2019), Surfers Paradise, Australia, 10-13 December 2019.

26. ACI 440.2R-17. Guide for the Design and Construction of Externally Bonded FRP Systems for Strengthening Concrete Structures; American Concrete Institute (ACI): Farmington Hills, MI, USA, 2017.

27. CNR-DT 200 R1/2013. Guide for the Design and Construction of Externally Bonded FRP Systems for Strengthening Existing Structures; National Research Council-Advisory Committee on Technical Recommendations for Construction: Rome, Italy, 2013; Available online: https://www.cnr.it/en/node/2636 (accessed on 27 August 2020).

28. GB50608-2010. Technical Code for Infrastructure Application of FRP Composites; Ministry of Housing and Urban-Rural Development, General Administration of Quality Supervision, Inspection and Quarantine: Beijing, China, 2010. (In Chinese)

29. CSA S806-2012 (R2017). Design and Construction of Building Structures with Fibre-Reinforced Polymers; Canadian Standards Association: Ontario, ON, Canada, 2012; (Reaffirmed 2017).

30. DAfStb RiLi VBgB. DAfStb-Richtlinie Verstärken von Betonbauteilen mit Geklebter Bewehrung; Deutscher Ausschuss für Stahlbeton e.V. (DAfStb): Berlin, Germany, 2012. (In German)

31. Richart, F.E.; Brandtzæg, A.; Brown, R.L. A Study of the Failure of Concrete under Combined Compressive Stresses; Engineering Experiment Station, Bulletin No. 185; University of Illinois: Urbana-Champaign, IL, USA, 1928; Available online: http://hdl.handle.net/2142/4277 (accessed on 27 August 2020).

32. Samaan, M.; Mirmiran, A.; Shahawy, M. Model of Concrete Confined by Fiber Composites. J. Struct. Eng. 1998, 124, 1025-1031. [CrossRef]

33. Niedermeier, R. Verstärkung von Stahlbetondruckgliedern durch Umschnürung. Ph.D. Thesis, Technical University of Munich, Munich, Germany, 2009. (In German).

34. Teng, J.G.; Huang, Y.L.; Lam, L.; Ye, L.P. Theoretical Model for Fiber-Reinforced Polymer-Confined Concrete. J. Compos. Constr. 2007, 11, 201-210. [CrossRef]

35. Rousakis, T.C.; Karabinis, A.I. Substandard reinforced concrete members subjected to compression: FRP confining effects. Mater. Struct. 2008, 41, 1595-1611. [CrossRef]

36. Chastre, C.; Silva, M.A.G. Monotonic axial behavior and modelling of RC circular columns confined with CFRP. Eng. Struct.. 2010, 32. [CrossRef]

37. EN 197-1:2011. Cement-Part 1: Composition, Specifications and Conformity Criteria for Common Cements; European Committee for Standardization (CEN): Brussels, Belgium, 2011.

38. EN 12390-3:2009. Testing Hardened Concrete-Part 3: Compressive Strength of Test Specimens; European Committee for Standardization (CEN): Brussels, Belgium, 2009.

39. DIN 488-1. Reinforcing Steels-Part 1: Grades, Properties, Marking; German Institute for Standardisation (DIN—Deutsches Institut für Normung e. V.): Berlin, Germany, 2009. (In German) 
40. Zilch, K.; Niedermeier, R.; Finckh, W. Geklebte Verstärkung mit CFK-Lamellen und Stahllaschen. In Beton-Kalender 2013, Lebensdauer und Instandsetzung, Brandschutz, 1st ed.; Bergmeister, K., Fingerloos, F., Wörner, J.-D., Eds.; Wilhelm Ernst \& Sohn: Berlin, Germany, 2013; pp. 469-552. (In German)

41. Toutanji, H.; Matthys, S.; Taerwe, L.; Audenaert, K. Behaviour of large-scale columns confined with FRP composites in compression. In Proceedings of the 2nd International Conference on FRP Composites in Civil Engineering (CICE 2004), Adelaide, Australia, 8-10 December 2004.

42. EN 1990. Basis of Structural Design; European Committee for Standardization (CEN): Brussels, Belgium, 2002.

43. fib Bulletin No. 80. Partial Factor Methods for Existing Concrete Structures; Fédération Internationale du Béton (fib): Lausanne, Switzerland, 2016; ISBN 978-2-88394-120-5.

44. fib Bulletin No. 14. Externally Bonded frp Reinforcement for RC Structures; Fédération Internationale du Béton (fib): Lausanne, Switzerland, 2001; ISBN 978-2-88394-054-3.

45. Bai, Y.-L.; Dai, J.-G.; Teng, J.G. Buckling of steel reinforcing bars in FRP-confined RC columns: An experimental study. Constr. Build. Mater. 2017, 140, 403-415. [CrossRef]

46. Lee, J.-Y.; Oh, Y.-J.; Park, J.-S.; Mansour, M.Y. Behavior of Concrete Columns Confined with Steel Spirals and FRP Composites. In Proceedings of the 13th World Conference on Earthquake Engineering, Vancouver, Canada, 1-6 August 2004.

47. Matthys, S.; Toutanji, H.; Audenaert, K.; Taerwe, L. Axial Load Behavior of Large-Scale Columns Confined with Fiber-Reinforced Polymer Composites. ACI Struct. J. 2005, 102, 258-267.

48. Lam, L.; Teng, J.G. Ultimate Condition of Fiber Reinforced Polymer-Confined Concrete. J. Compos. Constr. 2004, 8, 539-548. [CrossRef]

49. Lam, L.; Teng, J.G.; Cheung, C.H.; Xiao, Y. FRP-confined concrete under axial cyclic compression. Concr. Compos. 2006, 28, 949-958. [CrossRef]

50. Ilki, A.; Peker, O.; Karamuk, E.; Demir, C.; Kumbasar, N. FRP Retrofit of Low and Medium Strength Circular and Rectangular Reinforced Concrete Columns. J. Mat. Civil Eng. 2008, 20, 169-188. [CrossRef]

51. Taha, M.R. FRP for Infrastructure Applications: Research Advances. Fibers 2018, 6, 1. [CrossRef]

52. Naser, M.Z.; Hawileh, R.A.; Abdalla, J.A. Fiber-reinforced polymer composites in strengthening reinforced concrete structures: A critical review. Eng. Struct. 2019, 198. [CrossRef]

(C) 2020 by the authors. Licensee MDPI, Basel, Switzerland. This article is an open access article distributed under the terms and conditions of the Creative Commons Attribution (CC BY) license (http://creativecommons.org/licenses/by/4.0/). 